Nevada DOE EPSCoR

October 1, 2010

Award Number: DE-FG02-06ER46295

Recipient: $\quad$ Nevada System of Higher Education

William Schulze, Director Nevada EPSCoR

Phone: 702.522 .7070

E-mail: William schulze@nshe.nevada.edu

Lori Brazfield, Assistant Director for Operations

Phone: 702.522 .7080

E-mail: Lori brazfield@nshe.nevada.edu

Title: Investigations on the fundamental surface reactions involved in the sorption and desorption of radionuclides

Project Director: David Shafer

Phone: 702.862 .5564

E-mail: david.shafer@dri.edu

PI: $\quad$ Ken Czerwinski

Phone: 702.895.0501

E-mail: czerwin2@unlv.nevada.edu

Report period: 15 May 2008 to 30 June 2010

PI/Co-PI: $\quad$ Prof. Ken Czerwinski (PI), Department of Chemistry and Harry

Reid Center, University of Nevada, Las Vegas

Prof. Clemens Heske, Department of Chemistry, University of Nevada, Las Vegas

Dr. Duane Moser, Desert Research Institute, Las Vegas, NV

Prof. Manoranjan Misra, Metallurgical and Materials Science Engineering, University of Nevada, Reno

Prof. L. Glen McMillion, Metallurgical and Materials Science Engineering, University of Nevada, Reno 


\title{
Investigations of the Fundamental Surface Reactions Involved in the Sorption and Desorption of Radionuclides
}

\begin{abstract}
Surface complexation models describing solu tion and surface-phase reactions have been used for 30 years. Data for these $\mathrm{m}$ odels are derived from experimental techniques with recent advances enabling in vestigation of com plex surfaces. Efforts are directed at un derstanding sorption an $d$ desorption behavior o $\mathrm{f}$ contam inates from mineral surfaces, as effected by $\mathrm{m}$ icrobial modifications, em ploying isolates obtained from Nevada Test Site deep alluvium as a $m$ odel system. The contam inants will be rad ionuclides with em phasis on actinide elem ents. Characterization of sedim ents will include bulk an alysis by surface are a measurements, partic le size distribution, X-ray diffracti on, microprobe analysis, chemical extractions, and molecular and cultivation-based $m$ icrobial comm unity structu re asses sments. Studies on surface interactio $n$ includes: XPS; XAFS; X-ray em ission spectroscopy; TEM analysis ; and SEM charact erization. Non-radioactive isotopes of cont aminants will be used when ne cessary. Collaborators include UNR, UNLV, and DRI. Outcom es will enh ance ba sic sc ientific und erstanding of contam inant behavior on surfaces with significant implications to management of DOE sites.
\end{abstract}




\section{Investigations on the fundamental surface reactions involved in the sorption and}

desorption of radionuclides: Final report

Prof. Ken Czerwinski*, Department of Chemistry and Harry Reid Center, University of Nevada, Las Vegas

Prof. Clemens Heske, Department of Chemistry, University of Nevada, Las Vegas

Dr. Duane Moser, Desert Research Institute, Las Vegas, NV, 89119

Prof. Manoranjan Misra, Prof. L. Glen McMillion, Ph.D., Metallurgical and Materials Science Engineering, University of Nevada, Reno

PI: *4505 Maryland Parkway, Box 454003, Las Vegas, Nevada 89154-4003, Phone: 702-8950501, Fax: 702-895-3094, E-mail: czerwin2@unlv.nevada.edu

Report period: 16 May 2008 to 30 June 20092008 (Project months 24-36) (total project 1 July 2006 to 30 June 2009-extended to July 31,2010 )

\section{Contents}

1. Project Task for Reporting Period ........................................................................... 1

1.1. Task 1: Development of Methods for Examination of Radionuclide (months 0-9) .......... 2

1.2. Task 2: Characterization of Solid Phase, including Bacterial Augmentation (months 0-24) 2

1.3. Task 3: Batch and Column Sorption and Desorption Experiments (months 3-30) ........... 2

1.4. Task 4: Inclusion of Data Into Geochemical Codes and Transport Modeling (months 20-

36) 3

2. Expected Milestones ............................................................................................... 3

3. Results from $1^{\text {st }}$ progress report (months $\left.0-9\right)$............................................................ 4

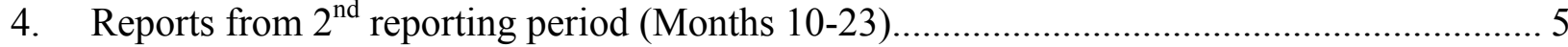

5. Reports from current reporting period (Months 24-36) ................................................ 6

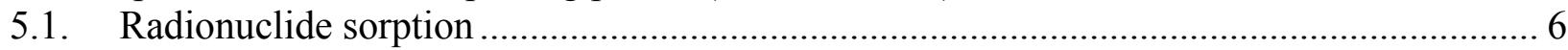

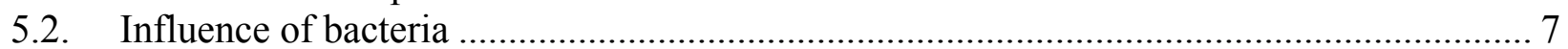

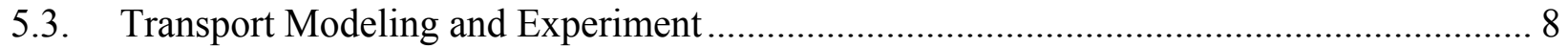

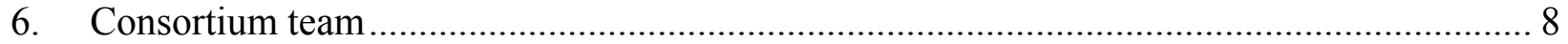

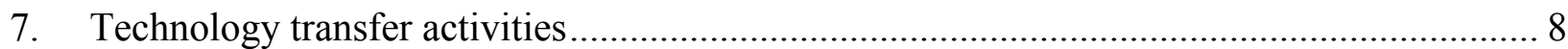

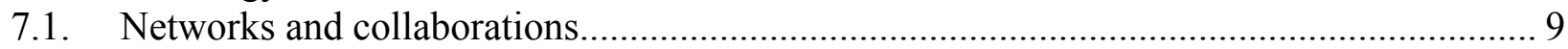

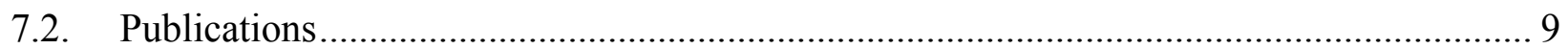

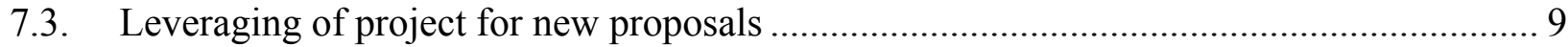

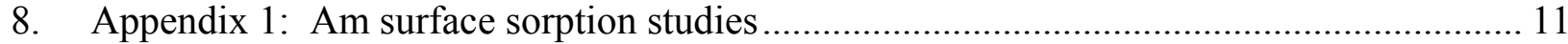

9. Appendix 2: Effect of Bacteria on Radionuclide Sorption ............................................... 22

10. Appendix 3: Transport Modeling and Experiment ..................................................... 34

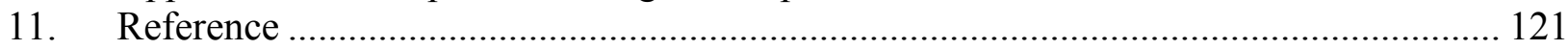

\section{Project Task for Reporting Period}

The project is divided into four separate tasks listed below. For this reporting period efforts in Tasks 2 to 3 are the project focal points. The project tasks are provided below. 


\subsection{Task 1: Development of Methods for Examination of Radionuclide (months 0-9)}

In this task, the necessary equipment, support, and protocols for performing experiments with radionuclides in microscopy and spectroscopy equipment will be developed. The X-ray equipment of Prof. Heske will utilize homologs and non-active fission elements. Within this task we expect to develop suitable protocols for using radionuclides in X-ray diffraction (XRD), scanning electron microscopy (SEM), transmission electron microscopy (TEM), the associated X-ray spectroscopy in TEM, electron energy loss spectroscopy (EELS), laser spectroscopy, and infrared spectroscopy. Funds for equipment will be used to support this task. Examples are chambers and holders for isolating and transporting radioactive samples.

\subsection{Task 2: Characterization of Solid Phase, including Bacterial Augmentation (months 0-24)}

In this task, the surfaces use in experiments will be examined by the microscopic and spectroscopy techniquesprior to and after the introduction of radionuclides. In addition to the techniques listed in Task 1, synchrotron X-ray techniques will be used. The team has experience with synchrotron techniques, including evaluation of radionuclide containing samples.

This task will also include surfaces altered by bacteria. The alterations can include adhesion of bacteria to the surface, changes in surface redox characteristics due to bacterial activity, formation of biofilms on the surface. Furthermore, organics secreted by the bacteria into solution will be employed in batch studies. Shewanella spp. (e.g. S. oneidensis) will be used as a model biological system, since these organisms have become a major "lab rat" of bacterial radionuclide modification, a complete genome sequence is available, and the DRI partner cowrote the generic description of this group [1]. In addition, relevant strains from the collections of our national lab collaborators or obtained from contaminated and uncontaminated sites in Nevada and elsewhere (e.g. Arthrobacter and Deinococcus spp. from beneath the leaking tank farms of Hanford, [2]) are available and will be utilized.

Materials to be tested for sorption/desorption studies will be incubated in the presence and absence of bacteria, under a variety of relevant growth conditions. For example, since many of these bacteria can employ U, Fe, and Mn oxides as solid respiratory electron acceptors, materials containing these radionuclides will be exposed to microbes and conditions favorable for anaerobic growth prior to the addition of actinides. In addition, materials not expected to be directly useful to the bacteria (e.g. concrete) will be incubated in the presence of microbes growing by other mechanisms (e.g. Fe reduction, U reduction) to determine how actinide binding characteristics are influenced by microbial biomass and biomolecules.

\subsection{Task 3: Batch and Column Sorption and Desorption Experiments (months 3-30)}

In Task 3 characterized solid phases from Task 2 will be placed batch or columns under controlled atmospheric conditions with suitable temperature conditions for sorption and desortpion studies. The atmospheric conditions will range from $100 \%$ Ar to $90 \% \mathrm{Ar} / 10 \% \mathrm{CO}_{2}$ for a detailed examination of carbonate influence on sorption based on the relationship [3]:

$$
\log \left[\mathrm{CO}_{3}^{-2}\right]=-17.56+\log \left(\mathrm{P}_{\mathrm{CO} 2}\right)+2 \mathrm{pH} \quad \text { Eq. } 1
$$

The use of differing $\mathrm{CO}_{2}$ partial pressure and $\mathrm{pH}$ conditions will enable us to study the influence of carbonate influence on sorption. Inclusion of other important ligands, such as those from bacteria, will also be examined under this task. 
In the experiments, aliquots are periodically removed or the column effluent, isolated, and the solution radionuclide concentration evaluated by alpha scintillation, gamma spectroscopy, ICPAES, or ICP-MS. UV-Visible spectroscopic measurements of the solution phase will also be taken if the solution phase concentration is sufficiently for spectroscopy. In our previous study on $\mathrm{Np}$ sorption by the PI the results revealed a kinetic component in the $\mathrm{Np}$ solution concentration described by

$$
[\mathrm{Np}]_{\mathrm{sol}}=[\mathrm{Np}]_{\mathrm{eq}}+[\mathrm{Np}]_{\text {sorbed }} * \mathrm{e}^{-\mathrm{kt}} \quad \text { Eq. } 2
$$

where $[\mathrm{Np}]_{\text {sol }}$ is the $\mathrm{Np}$ solution concentration at the measured time, $[\mathrm{Np}]_{\mathrm{eq}}$ the $\mathrm{Np}$ solution concentration at equilibrium and $[\mathrm{Np}]_{\text {sorbed }}$ is the $\mathrm{Np}$ concentration sorbed to the mineral phases. The data from above can be used to input into existing geochemical codes or develop thermodynamic data to describe complexation and speciation for inclusion into models. Once equilibrium has been reached the samples can be evaluated by the techniques used in Task 2 , identifying the chemical components of the solid phase engaged in sorption. Furthermore, subsets of the samples at equilibrium can be used for desorption studies, essentially employing the same experimental technique. The increase in radionuclide solution concentration can be measured over time. Again, samples of the solid phases can be removed and evaluated with the techniques from Task 2 . In the desorption studies the relative strengths of the surface sorption sites and mechanisms can be found.

\subsection{Task 4: Inclusion of Data Into Geochemical Codes and Transport Modeling (months 20-36)}

Data acquired in the project will be introduced into a thermodynamic database for evaluating the speciation and sorption of radionuclides under a variety of conditions. While the speciation model CHESS will be primarily used, EQ3/6 or Geochemist Workbench can also be employed in addition to simple calculations. CHESS is a robust model for examining speciation of radionuclides and auxiliary species in complex, multi-phase solutions [4] using literature data $[5,6]$. The PI has previously used this modeling to examined actinide dissolution, sorption, and speciation in the environment, developing diagrams relating actinide concentration to assessed conditions [7] as well as incorporating speciation modeling in assessing environmental remediation [8]. The transport model will be directed by the UNR partners and incorporates five transport and adsorption processes:

o Bulk transport- transfer of material from liquid bulk solution to the liquid film surrounding the particle.

o Film transport- transfer of the material through the surface film between the bulk solution and the adsorbent particle surface.

o Surface adsorption- adsorption of material onto the surface of the adsorbent particle.

o Pore diffusion- transport of adsorbate between the particle surface and the interior of the particle through the intra-particle pore spaces.

o Pore adsorption- adsorption of diffused material on to the walls of the pores.

\section{Expected Milestones}

This reporting period covers months 24-36. The relevant milestones are highlighted.

Task 1: Protocols and methods for measuring samples containing radioactivity on selected microscopy and spectroscopy equipments (Month 9) 
Task 2: Characterization of $1^{\text {st }}$ surface in the absence of activity (Month 5)

Characterization of surface augmented by bacteria (Month 9)

Characterization of surface with sorbed radionuclides (Month 12)

Characterization of surface augmented by bacteria in the presence of radionculides

(Month 14)

Characterization of surface during radionuclide desorption (Month 16)

Characterization of bacteria influence surface and radionuclide desorption (Month 18)

Start of $2^{\text {nd }}$ set of surface characterization based on interaction and comments from the DOE (Month 20)

Completion of $2^{\text {nd }}$ surface analysis following radionuclide sorption and desorption (Month 33)

Task 3: Sorption and desorption studies with uranium (Month 7), Np (Month 10), and Pu and fission elements (Month 16)

Sorption and desorption studies in the presence of bacteria with uranium (Month 10), $\mathrm{Np}$ (Month 13), and Pu and fission elements (Month 18)

Initiation of sorption and desorption studies with $2^{\text {nd }}$ set of surfaces (Month 20)

Completion of sorption and desorption studies with $2^{\text {nd }}$ set of surfaces (Month 33)

Task 4: Incorporation of surface sorption studies into geochemical models (Month 35)

\section{Results from $1^{\text {st }}$ progress report (months 0-9)}

o Task 1: Protocols and methods for measuring samples containing radioactivity on selected microscopy and spectroscopy equipments (Month 9)

o Task 2: Characterization of $1^{\text {st }}$ surface in the absence of activity (Month 5)

Characterization of surface augmented by bacteria (Month 9)

o Task 3: Sorption and desorption studies with uranium (Month 7)

Methods for utilizing a number of different microscopic and spectroscopic techniques for the evaluation of radionuclide containing samples have been developed at UNLV. The commonality of these techniques is the use of secondary containment for the samples. The samples are prepared in the experimental laboratories at UNLV and transferred to the appropriate analysis laboratories. The methods have been developed with the radionuclides Tc, $\mathrm{U}, \mathrm{Np}$, and $\mathrm{Pu}$ and are listed below:

o Infrared Spectroscopy

o UV-Visible Spectroscopy

o Time Resolved Laser Induced Fluorescence Spectroscopy

$0 \quad$ X-ray diffraction

o Nuclear Magnetic Resonance Spectroscopy

o Optical Microscopy

o Scanning Electron Microscopy

o Tunneling Electron Microscopy (TEM)

- Electron Energy Loss Spectroscopy (within TEM)

- Small Angle Diffraction (within TEM)

o X-ray Absorption Fine Structure Spectroscopy

- performed at the Advanced Photon Source at Argonne National Laboratory

Two surfaces have been examined and characterized by surface area analysis, optical spectroscopy, scanning electron microscopy, x-ray diffraction, and photoelectron spectroscopy. The surfaces are silica carbide, Columbia River Sediment (obtained from PNNL) and sediment 
from the BOMARC site, a site contaminated with $\mathrm{Pu}$. The results will be used for comparison of surfaces and evaluation of sorption data. Radiochemical analyses were performed on the Columbia River sediment and BOMARC sediment. The Columbia River sediment has no anthropogenic radionuclides while the BOMARC sediment contained $\mathrm{Pu}$ and $\mathrm{Am}$.

Initial sorption studies of $U$ on silica carbide were performed. The necessary micromolar concentration level based on surface area analysis results required the use of ${ }^{233} \mathrm{U}$ as an added tracer. Studies at $\mathrm{pH} 3$ showed sorption that was independent of hydroxide species formation. Data was obtained to permit kinetic evaluation of $U$ sorption to silica carbide under different uranium concentrations under a range of acid concentrations.

\section{Reports from $2^{\text {nd }}$ reporting period (Months 10-23)}

An X-ray diffraction single crystal spectrometer was obtained by the UNLV team. Protocols and methods for measuring radionuclide containing samples were prepared. Laboratory equipment was obtained to facilitate sample preparation. The single crystal XRD has been successfully used to measure samples containing $U$ and Tc. A containment box (Error!

Reference source not found.) for X-ray absorption spectroscopy (XAFS) was obtained, tested, and used in experiments containing U, Np, and Tc as the Advanced Photon Source at Argonne National Laboratory. The use of the containment boxes greatly facilitated sample transport and data collection.

Sequential extraction had been designed as a tool to identify the distribution of radioactive materials into operationally defined fractions; water soluble, carbonate, iron and manganese oxides, organic and acid soluble phases of the soil matrix [9]. Samples are treated with different solutions and the radionuclide concentration in the dissolved phase is determined by radiation detection. The technique can be applied to hot particle and surrounding sediment to evaluate change in isotope activity ratios with speciation.

Optical and scanning electron microsocpy is a useful tool for studying the morphological characteristics and variations such as the relative size and structure distribution of particles as demonstrated in the composite of images taken for three of the initial hot particles received from the BOMARC site. Regional density variances or material phases can be identified through high magnification and elemental composition, namely plutonium and uranium, are determined by electron diffraction data. It is of particular interest that these particles have a detectable gallium phase within the particle. Gallium is used as a dopant or stabilizer for the $\delta$-plutonium phase of the metal [10]. Additionally, these techniques have shown that these particles are not natural aggregates where activity has sorbed to the surface.

XAFS spectroscopy uses the photoelectric effect and the wave nature of the electron to determine local structures around selected atomic species and structures in materials. A fundamental advantage of this type of spectroscopy is that the material under investigation does not have to be ordered, meaning amorphous solids, crystalline structures, liquids and gases can evaluated. The UNLV Radiochemistry Group has had the opportunity to conduct XAFS imaging studies at the Advanced Photon Facility at Argonne National Laboratory. In October 2007, one of the BOMARC particles was analyzed using this technique, providing intensity maps of the uranium, plutonium, americium and gallium phases. From the images, it can be observed that the distribution of the plutonium, americium and uranium is fairly uniform throughout the particle. The gallium atoms are dispersed in discrete pockets of the particle, a product of $\delta$-phase stabilization for plutonium. The americium signal intensity drops off more rapidly at the edges of the particle. This may be an indication that americium is more easily removed from the matrix 
than uranium and plutonium or this could be an artifact of the imaging process. EXAFS of an actinide hot particle reveals $\mathrm{U}, \mathrm{Pu}$, and $\mathrm{Am}$ are tetravalent dioxides. This result can be used to develop a rapid chemical or physical sampling technique based on the similar behavior of the tetravalent actinide oxides.

Preliminary batch sorption experiments were conducted at room temperature using lead ions as adsorbate and bentonite clay. Lead was selected for the initial experiments to allow us to determine if the same experimental procedures could be used for actinide ions, and to determine the accuracy of our analytical techniques. Eh-pH diagrams of lead and Uranium has similarities. Adsorption kinetics and adsorption equilibrium at various initial lead concentrations were studied. Distribution coefficients for the lead soil system at $\mathrm{pH}=4.5$ at equilibrium were determined.

Stock solutions of $6.5 \mathrm{ppm}$ lead were prepared by dissolving lead nitrate in deionized water. The $\mathrm{pH}$ of the solution was adjusted to $4.5 \mathrm{using} 1 \mathrm{M}$ nitric acid. An aliquot of $50 \mathrm{ml}$ of the lead solution was transferred into 4 different conical flasks. To each flask, 1 gm of Bentonite clay was added, and placed on a mechanical shaker. One of the conical flasks was removed after 50min, $230 \mathrm{~min}$, 470min, and 1500min. As the flasks were taken, the clay and solution were separated using centrifugation. The supernatant liquid was collected and the resident $\mathrm{Pb}$ concentration was analyzed using ICP. The experimental results of the first kinetic experiment, showed equilibrium lead concentration was achieved in approximately 500 minutes ( $~ 8$ hours).

"Comsol Multiphysics” CFD (Computational Fluid Dynamics Package is used to simulate the concentration distribution in the column. Unsteady one dimensional "Advective Reactive Dispersion equation is employed to explain the solute transport and adsorption behavior in the soil medium Initial and Boundary conditions are applied to get the Concentration distribution in the considered geometry. Inside the column Bed thickness of $5 \mathrm{~cm}$ is considered and Diameter of $7.5 \mathrm{~cm}$ to get the preliminary results. Finite Element Numerical method is used to solve the model equation for discrete time of 0.1 second and the system is simulated for $20 \mathrm{hr}$. The concentration changes from 1 to 0.2 along the length of the column after $3 \mathrm{hr}$ of simulation.

\section{Reports from current reporting period (Months 24-36)}

\subsection{Radionuclide sorption}

The sorption and behavior of Am and Pu using environmental samples was examined (Appendix 1, Section 7.3). To determine how particles containing high fired oxides of 241-Am and $\mathrm{Pu}$ are releasing $\mathrm{Am}$ and $\mathrm{Pu}$ to the soils that contain them under environmental conditions, the 241-Am distribution as a function of soil depth was determined for five soil cores known to contain particles consisting of high fired oxides of $\mathrm{Am}, \mathrm{U}$ and $\mathrm{Pu}$. Based on the Pu isotopic composition of the material used in the BOMARC weapon provided by LANL (Los Alamos National Laboratory), the Bateman equations can be applied to the system to estimate relative isotopic composition of the hot particle matrix as a function of time. The cores studied were $13-26 \mathrm{~cm}$ in length and $5 \mathrm{~cm}$ in diameter. The location of the hot particle in each core had been established by CT mapping experiments, and the hot particles were extracted from the soil prior to starting these experiments. The extracted particles consisted of a mixture of weapons grade plutonium $(\mathrm{WGPu}), 241-\mathrm{Am}$ and $235-\mathrm{U}$ and ranged in activity from $5-66 \mathrm{kBq} 241-\mathrm{Am}$.

These samples sets exhibit five trends:

1. 241-Am is found above the hot particles in the soil column

2. 241-Am concentrations taper off in the soil immediately below the hot particles 
3. There are regions where the 241-Am concentration appears to remain constant with depth

4. There are discrete 241-Am concentration spikes

5. The presence of 239-Pu has been confirmed in most of the 241-Am concentration spikes

The first three characteristics are indicative of surface area driven processes such as sorption and desorption of material to the soil from the particle. The continuous tapering of 241-Am concentrations to a fixed minimum concentration below the hot particle indicates that 241-Am is being shed from the particle at a rate greater than the surrounding soil can sorb it, and the continuous concentrations are indicative of areas where all of the potential binding sites for 241Am have been filled, forcing the 241-Am to move further down the soil column. Of greater interest are the discrete 241-Am concentration spikes found in the core samples. Sorption and desorption processes are expected to occur producing 241-Am concentration gradients. What is unexpected is the particle like behavior indicated by the 241-Am concentration spikes and the presence of 239-Pu and 241-Am in the samples. Experiments demonstrated that hot particles have contributed 241-Am and Pu to their near field environment by mechanisms producing both heterogeneous or particle like distribution patterns and by homogenous distribution patterns that may be caused by dissolution followed by sorption of the 241-Am and Pu to the near field soils.

\subsection{Influence of bacteria}

The effects of bacteria on radionuclide sorption to tuff from the Nevada Test Site (NTS) was examined (Appendix 2, section 9). Towards this end, we have developed of a collection of microorganisms with metal-, nitrate- and sulfur-reducing phenotypes from NTS detonation cavities and the Hanford site (Hanford, WA); and samples of tuff from the vicinity of nuclear tests have been obtained from the NTS core library. For the purpose of methods development, however, the well-characterized metal- and radionuclide-interactive bacterial strain Shewanella oneidensis MR-1 and a generic tuff (Ward Scientific) have been utilized in our experiments to date. The experimental and NTS tuff samples were characterized by scanning electron microscopy (SEM), electron dispersive spectroscopy (EDS), and x-ray diffraction (XRD) to determine the surface structure and composition, and to assess potential surface modifications from bacterial growth. Both tuffs were used in batch experiments to determine the sorption kinetics and equilibrium constants $\left(K_{d}\right)$ for uranium-233 and americium-241. Variables included tuff (type, amount, size fraction), reaction buffer (bicarbonate, $\mathrm{NaOH}$, synthetic NTS groundwater, or NTS U12n.10 groundwater), $\mathrm{pH}$, radionuclide concentration $(2.5-100 \mathrm{~Bq} / \mathrm{mL})$, and bacteria (presence/absence or cell density). Sorption kinetics for both ${ }^{233} \mathrm{U}$ and ${ }^{241} \mathrm{Am}$ were generally rapid, with the majority of sorption occurring within 2 hours (equilibrium by 24 hours). Bacterial treatments reached equilibrium after 24-48 hours, followed by decreased sorption after 96-168 hours, likely due to cell death. In controls with bacteria only, both radioelements sorbed much more strongly to cells than tuff on a weight vs. weight basis $\left(K_{d} \approx 10^{4}\right.$ vs. $\left.K_{d} \approx 10^{1}-10^{2}\right)$.

Conversely, the $K_{d}$ s for uranium sorption was similar to values previously determined for NTS tuff. In these experiments, the radionuclides tightly bound to tuff and/or bacteria, with the presence of bacteria generally increasing sorption by a maximum of $10 \%$ over tuff-only treatments. Thus, assuming that MR-1 is representative of environmental microbiota, indications are that bacteria are not a major factor in the sorption of ${ }^{233} \mathrm{U}$ and ${ }^{241} \mathrm{Am}$ to tuff. However, the strong affinity of ${ }^{233} \mathrm{U}$ and ${ }^{241} \mathrm{Am}$ to cells may indicate that they can act as ligands or colloids to facilitate transport. Column experiments, beginning with MR-1 and the experimental tuff and 
graduating to environmental isolates and NTS tuff are planned for the final phase of this research.

\subsection{Transport Modeling and Experiment}

The examination of radionuclide transport and adsorption on loamy desert soil through modeling the system by the Finite Elem ent Method (FE M) and verification using experimentation is presented in Appendix 3 (see se ction ). The Advectiv e dispersion reaction (ADR) m echanism and pore diffusion model were employed to describe the contaminant transport and adsorption in soil medium. Partial Dif ferential Equations (PDE) obtained from unsteady state $\mathrm{m}$ ass balance consisted of convective diffusion, solute adsorp tion, and dispersion term s for the ADR equation (ADRE). In pore diffusion m odels, the shape of the soil particles were assumed to be spheric al and mass balances were performed on the soil phase as well as on the liquid phase. Equilib rium and kinetic experim ents were conducted using lead, which doe $\mathrm{s}$ not have sim ilar chemical properties to the actinides exam ined by the DR I and UNLV group. Initial batch equilibrium adsorption experiments revealed that the system follows Langmuir adsorption isotherm. The diffusion coefficient was evaluated by nonlinear regression analysis on kinetic experimental data, which was used as a pa rameter in the ADRE. The other required parameters for the model such as Langmuir constant and m aximum adsorption capacity of the adsorbent were evaluated from batch experiments. Darcy's law was coupled w ith the continuity equation to calculate the pressure drop along the length of the column and the velocity. Adsorption isotherm equation and Darcy's law was intern ally coupled with “Advective Dispersion Reaction” Equation and the resulting set of unsteady non linear Partial Difference Equation (P DE) were solved using "COMSOL MULTIPHYSICS - 3.2". The report also includes extensive background information, some of which was covered in the original proposal.

\section{Consortium team}

Dr. Thomas Hartmann will rejoin the UNLV team in July 2008. Dr. Tyler Sullens of UNLV was an unperforming member of the team and dismissed from the project during its first year. Three researchers from DRI (Jen Fisher, Jim Bruckner, and Duane Moser) have been trained and are performing experiments in the UNLV radiochemistry laboratories. Weekly meetings are held to monitor progress. The UNR team is composed of Nagendra Basavaraju and John Shiny (Graduate Students), and Piyush Kar (Post-Doctoral researcher). The UNLV team includes Sherry Stock, Rich Gostic, and Julie Gostic (Graduates students).

\section{Technology transfer activities}

A number of presentations bases on project results and tasks have been made during the past reporting period. Collaborative project data between DRI and UNLVwas presented as a talk at the MARC VIII conference, accepted as a poster presentation at the Migration 2009 conference at PNNL, contributed to a poster presented at the 2009 American Society for Microbiology conference in Philadelphia, and form the basis for a manuscript in preparation. As numerous presentation were made as a result of project research activities, only publication based on project efforts, mainly task 1 , will be presented (see section 7.2) 


\subsection{Networks and collaborations}

Collaborations with PNNL have increased due to the work performed on this project. The ability to perform XAFS experiments at Argonne National Laboratory has been facilitated by the project.

\subsection{Publications}

The bulk of the publications resulted from the ability to develop techniques for studies with radionuclides from task 1 . The publications from during the project lifetime are below. Other publications are in development and are expected to be submitted within the next 6 months.

1. Poineau, F., Hartmann, T., Jarvinen, G., and Czerwinski, K.R.: Preparation of technetium metal by thermal treatment under Argon $/ \mathrm{H}_{2} \mathrm{O}$, J. Radioanal. Nucl. Chem., Journal of Radioanalytical, 279(1), 43-48 (2009).

2. Poineau, F., Rodriguez, E.E., Forster, P.M. Sattelberger, A.P., Cheetham, A.K., Czerwinski, K.R.: Preparation of the Binary Technetium Bromides: $\mathrm{TcBr}_{3}$ and $\mathrm{TcBr}_{4}$. Journal of the American Chemical Society, 131(3), 910-911, (2009).

3. Silva, G. W. Chinthaka; Poineau, Frederic; Ma, Longzhou; Czerwinski, Kenneth R.:

Application of Electron Microscopy in the Observation of Technetium and Technetium Dioxide Nanostructures. Inorganic Chemistry, 47(24), 11738-11744, (2008).

4. Poineau, F.; Du Mazaubrun, J.; Ford, D.; Fortner, J.; Kropf, J.; Silva, G. W. C.; Smith, N.; Long,

5. Rodriguez, Efrain E.; Poineau, Frederic; Llobet, Anna; Czerwinski, Ken; Seshadri, Ram; Cheetham, Anthony K.: Preparation and Crystal Structures of Bismuth Technetates: A New Metal Oxide System, Inorg. Chem. 47(14), 6281-6288, (2008).

6. Silva, G. W. Chinthaka; Yeamans, Charles B.; Ma, Longzhou; Cerefice, Gary S.; Czerwinski, Kenneth R.; Sattelberger, Alfred P.: Microscopic Characterization of Uranium Nitrides Synthesized by Oxidative Ammonolysis of Uranium Tetrafluoride, Chem. Mater., 20(9), 30763084, (2008).

7. Poineau, Frederic; Sattelberger, Alfred P.; Czerwinski, Kenneth R.: XAFS spectroscopic study of $\mathrm{Tc}_{2}\left(\mathrm{O}_{2} \mathrm{CCH}_{3}\right)_{4} \mathrm{X}_{2}(\mathrm{X}=\mathrm{Cl}, \mathrm{Br})$, J. Coord. Chem., 61(15), 2356-2370, (2008).

8. Poineau, Frederic; Sattelberger, Alfred P.; Conradson, Steven D.; Czerwinski, Kenneth R: Octachloro- and Octabromoditechnetate(III) and Their Rhenium(III) Congeners. Inorganic Chemistry, 47(6), 1991-1999 (2008).

9. Charles B. Yeamans, G. W. Chinthaka Silva, Gary S. Cerefice, Kenneth R. Czerwinski, Thomas Hartmann, Anthony K. Burrell, and Alfred P. Sattelberger: Oxidative Ammonolysis of Uranium(IV) Fluorides to Uranium(VI) Nitride, J. Nucl. Mat. 347, 75-78 (2008).

10. L. Mullen, L., Gong, C., and Czerwinski, K.: Complexation of Uranium(VI) with the Siderophore Desferrioxamine B, J. Radioanalytical Nucl. Chem., 273(3), 683-688 (2007).

11. Gong, C-M. S, Poineau, F., and Czerwinski, K.R.: Synthesis and characterization of the solid uranium(VI)dioxo-diacetohydroxamate complex, Radiochim. Acta, 95, 1-12 (2007).

\subsection{Leveraging of project for new proposals}

The development of radiochemical capabilities in Task 1 assisted in securing new projects from the DOE-NE program. Starting September 2009 the UNLV radiochemistry program will obtain over \$2 M in competitive funding. The environmental studies were also useful in supporting nuclear forensic capabilities. The UNLV program is currently active in this area largely based on the efforts within this program. 


\section{Appendix 1: Am surface sorption studies}

To determine how particles containing high fired oxides of 241-Am and $\mathrm{Pu}$ are releasing Am and $\mathrm{Pu}$ to the soils that contain them under environmental conditions, the 241-Am distribution as a function of soil depth was determined for five soil cores known to contain particles consisting of high fired oxides of $\mathrm{Am}, \mathrm{U}$ and $\mathrm{Pu}$.

241-Am may be used as a surrogate for the distribution of $\mathrm{Pu}$, because 241-Am is being directly incorporated into the $\mathrm{Pu}$ matrix through the decay of 241-Pu. This assumption must be made with caution, it will hold true if large pieces of the $\mathrm{Pu}$ matrix (surface area is small relative to the volume) are being transported through the soil, but under conditions where the matrix surface area is large relative the total volume of the sample, $\mathrm{Pu}$ and Am may separate due to differences

in their chemical behavior

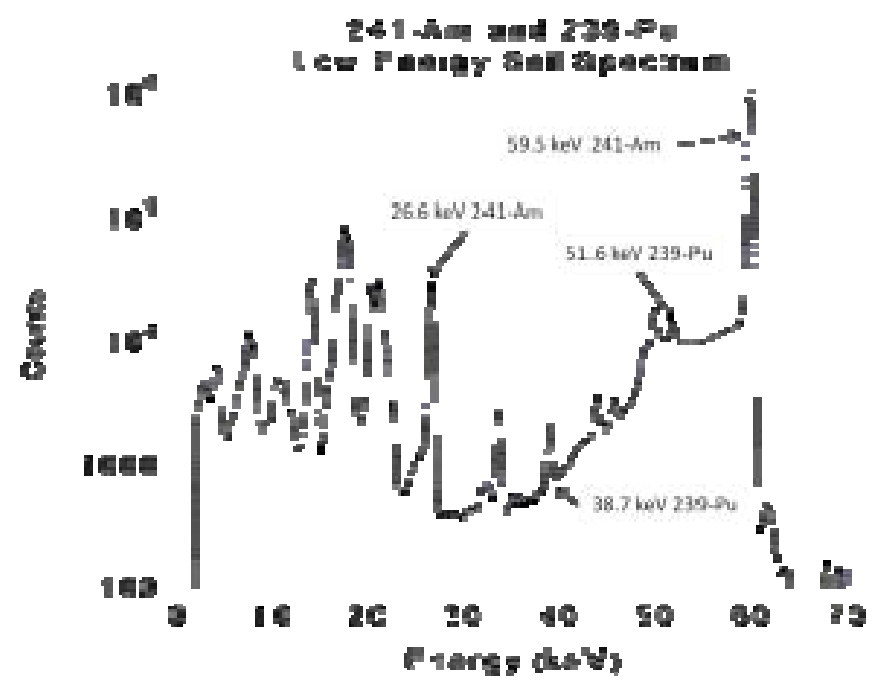

Figure 1: Low Energy Spectrum of 241-Am and 239-Pu in soil resulting in different transport properties. Understanding that $\mathrm{Pu}$ and Am may behave differently in the environment requires that any measurements of 241-Am also verify the presence of $\mathrm{Pu}$ with the 241-Am when describing the behavior of the total hot particle matrix. Based on the $\mathrm{Pu}$ isotopic composition of the material used in the BOMARC weapon provided by LANL (Los Alamos National Laboratory), the Bateman equations can be applied to the system to estimate relative isotopic composition of the hot particle matrix as a function of time. Assuming a 50

year decay period the 241-Am:239-Pu activity ratio is estimated to be 0.24 , meaning that for each 241-Am decay there will be on average four 239-Pu decays. Though this system is dominated by 239-Pu in both mass and activity, 239-Pu yields few unique photons when it decays making direct detection of low concentrations of 239-Pu difficult by gamma spectroscopy.

To illustrate this point, if we observe 100,000 photons (counts) of 241 -Am at $59.5 \mathrm{keV}$ in a 24 hour period with a detector that is $25 \%$ efficient at $59.5 \mathrm{keV}$ there would be approximately $13 \mathrm{~Bq}$ of 241-Am in the sample. If the activity ratio of 0.24 241-Am:239-Pu is applied, then approximately $52 \mathrm{~Bq}$ of $239-\mathrm{Pu}$ would also be present in the sample. The two most intense, unique 239-Pu photons occur at $38.7 \mathrm{keV}$, yield $=0.01044 \%$ and $51.6 \mathrm{keV}$, yield $=0.02722 \%$. Given a detector efficiency of $20 \%$ at $38.7 \mathrm{keV}$, a detector efficiency of $25 \%$ at $51.6 \mathrm{keV}$ and a 24 hour counting period the observed 239-Pu signal at $38.7 \mathrm{keV}$ would be 93 counts and 303 counts at $51.6 \mathrm{keV}$, a signal three orders of magnitude smaller than the 241-Am signal observed at $59.5 \mathrm{keV}$. To complicate matters the $51.6 \mathrm{keV} 239-\mathrm{Pu}$ photon also sits on the Compton continuum generated by the $59.5 \mathrm{keV} 241-\mathrm{Am}$ photon (see Figure 1) making quantification of the 239-Pu signal a difficult procedure. 
Even though quantification of the 239-Pu concentration in the soil may not be possible, the presence of the $\mathrm{Pu}$ in the soil can be verified by the presence of the 38.7 and $51.6 \mathrm{keV} 239-\mathrm{Pu}$ photon peaks, and would indicate that both 241-Am and $\mathrm{Pu}$ are moving in the sample. For these experiments the lack of peaks at 38.7 and $51.6 \mathrm{keV}$ cannot be used to exclude the presence or $239-\mathrm{Pu}$, because the 239-Pu may be below detection limit of gamma spectroscopy for a 24 hour counting period. To confirm the presence of $239-\mathrm{Pu}$ in the low activity samples and determine the 241-Am:239-Pu activity ratio in the soil, and establish if these isotopes are moving in a similar manner or are subject to different transport processes, a series of experiments consisting of total dissolution of the soil followed by chemical separation of $\mathrm{Am}, \mathrm{U}$ and $\mathrm{Pu}, \mathrm{CeF}_{3}$ precipitation and alpha spectroscopy have been planned.

The cores studied were $13-26 \mathrm{~cm}$ in length and $5 \mathrm{~cm}$ in diameter. The location of the hot particle in each core had been established by CT mapping experiments, and the hot particles were extracted from the soil prior to starting these experiments. The extracted particles consisted of a

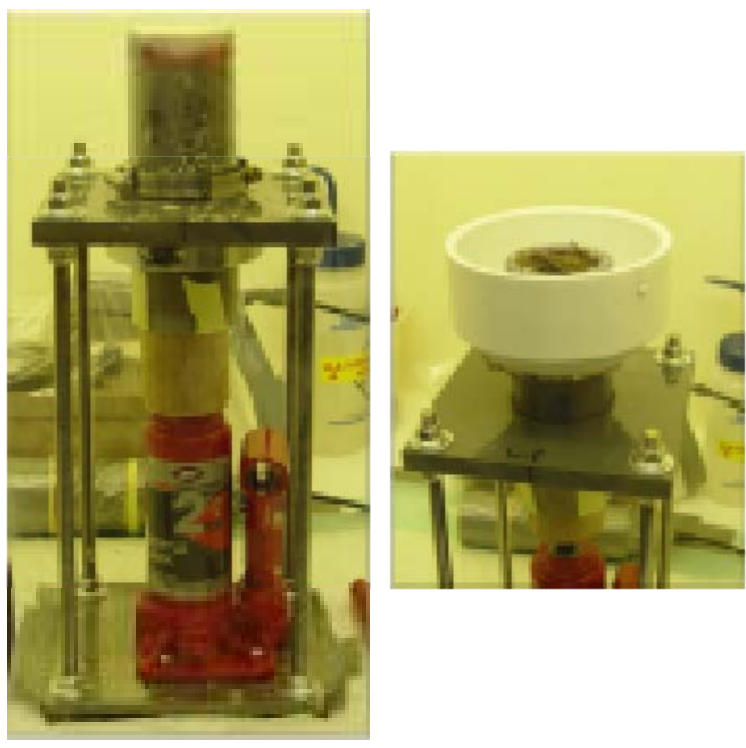

\section{Figure 2 Left: Bottle jack jig, Right: Soil retaining jig} mixture of weapons grade plutonium (WGPu), 241-Am and 235-U and ranged in activity from 5-66 kBq 241-Am. By gamma spectroscopy, four of the five particles consisted of $75 \pm 5 \%$ $239-\mathrm{Pu}, 25 \pm 5 \% 235-\mathrm{U}$ and $0.22 \pm 0.025 \% 241-$ Am by weight. The fifth particle was $97 \pm 13 \%$ $235-\mathrm{U}, 3.5 \pm 0.5 \% 239-\mathrm{Pu}$ and $0.010 \pm 0.001 \%$ 241-Am by weight. The measured 241-Am to $239-\mathrm{Pu}$ activity ratio values ranged from $0.28 \pm 0.04$ to $0.30 \pm 0.04$, indicating slightly higher 241-Am concentrations then modeled from the LANL numbers.

To produce the 241-Am depth profiles each core was disassembled along its vertical axis, into a set of 'slices' by placing each core in a bottle jack jig (see Figure 2) that lifted the soil 3.5 \pm 0.1 mm each time the bottle jack was pumped. After the soil was raised with the bottle jack, the material extending past the lip of the PVC pipe was scraped into a second jig that fits over the PVC pipe and then placed in a sample cup. The sample volumes were kept relatively constant using this technique but sample masses did vary depending on the soil type. The few large rocks and twigs did transect multiple slices and were kept with the last slice that contained them.

Four ounce $(120 \mathrm{cc})$ sample containers were used to hold all of the samples. They are tapered containers that are $74 \mathrm{~mm}$ high, with a top diameter of $58 \mathrm{~mm}$ and a bottom diameter of $50 \mathrm{~mm}$. Soil samples occupied the bottom $3.5 \mathrm{~mm}$ of each container. An illustration of the sample container geometry is presented in Figure 3. 


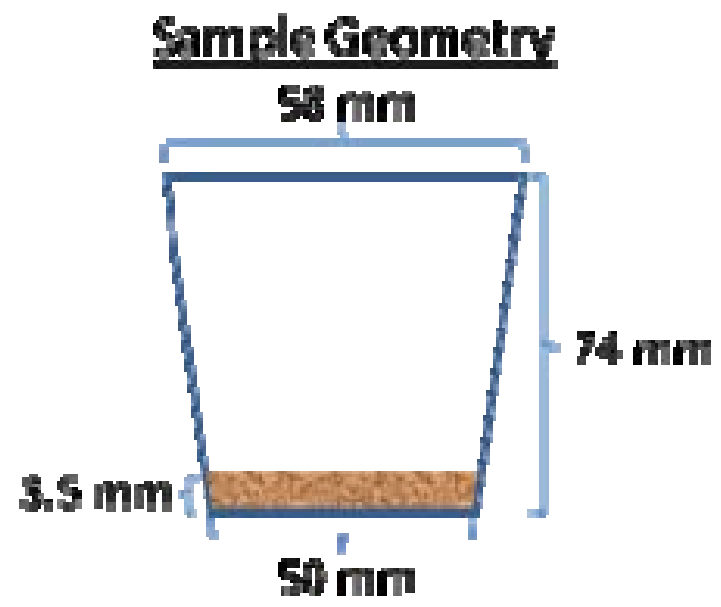

Figure 3: Sample geometry for gamma spectroscopy

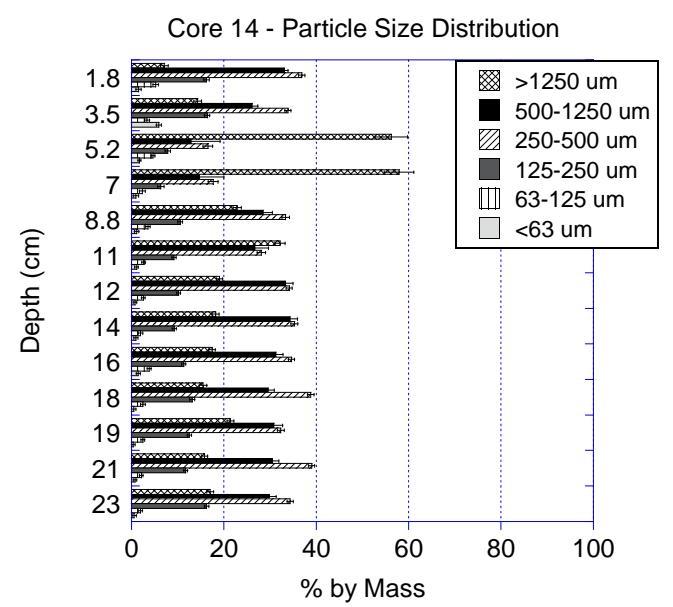

Figure 4: Particle size distribution of soil as a function of depth

experimental conditions.

A Canberra BE3830 BEGE detector, a $63.5 \mathrm{~mm}$ diameter by $30 \mathrm{~mm}$ thick planar detector with a carbon composite window was used for all gamma measurements. All samples were counted for 24 hours with the corresponding dead time correction. The 241-Am concentration in the soil was determined from the $59.5 \mathrm{keV}$ photon, $35.9 \%$ yield with a total detection efficiency of $25.3 \% \pm 1.3 \%$. The presence of 239 -Pu was confirmed, when possible, by peaks at either 38.7 $\mathrm{keV}$ or $51.6 \mathrm{keV}$.

Because a planar type detector was used to determine the 241-Am concentration in each soil sample, the efficiency of the detector had to be determined for the condition where a particle 
containing 241-Am is located at the edge of the sample container. Using a 241-Am point source standard, the efficiency of the detector was found to drop by $27 \%$ at the edge of the sample container (see Figure 5). All counting results are subject to this $27 \%$ relative uncertainty because the distribution of 241-Am within each sample is not known.
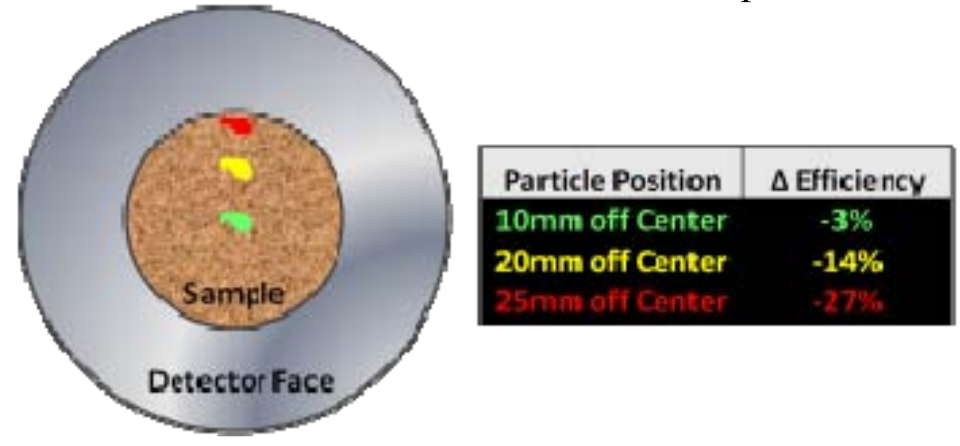

Figure 5: Influence of sample position on detector efficiency
Activity distributions of 241-Am as a function of depth are presented in the horizontal bar graphs below. The $\mathrm{x}$ axis represents the activity concentration in $\mathrm{Bq} / \mathrm{g}$ of 241-Am for soil particles smaller than 1250 um on a $\log$ scale, the y axis represents the depth in cm below the surface of the soil of each sample on a linear scale.

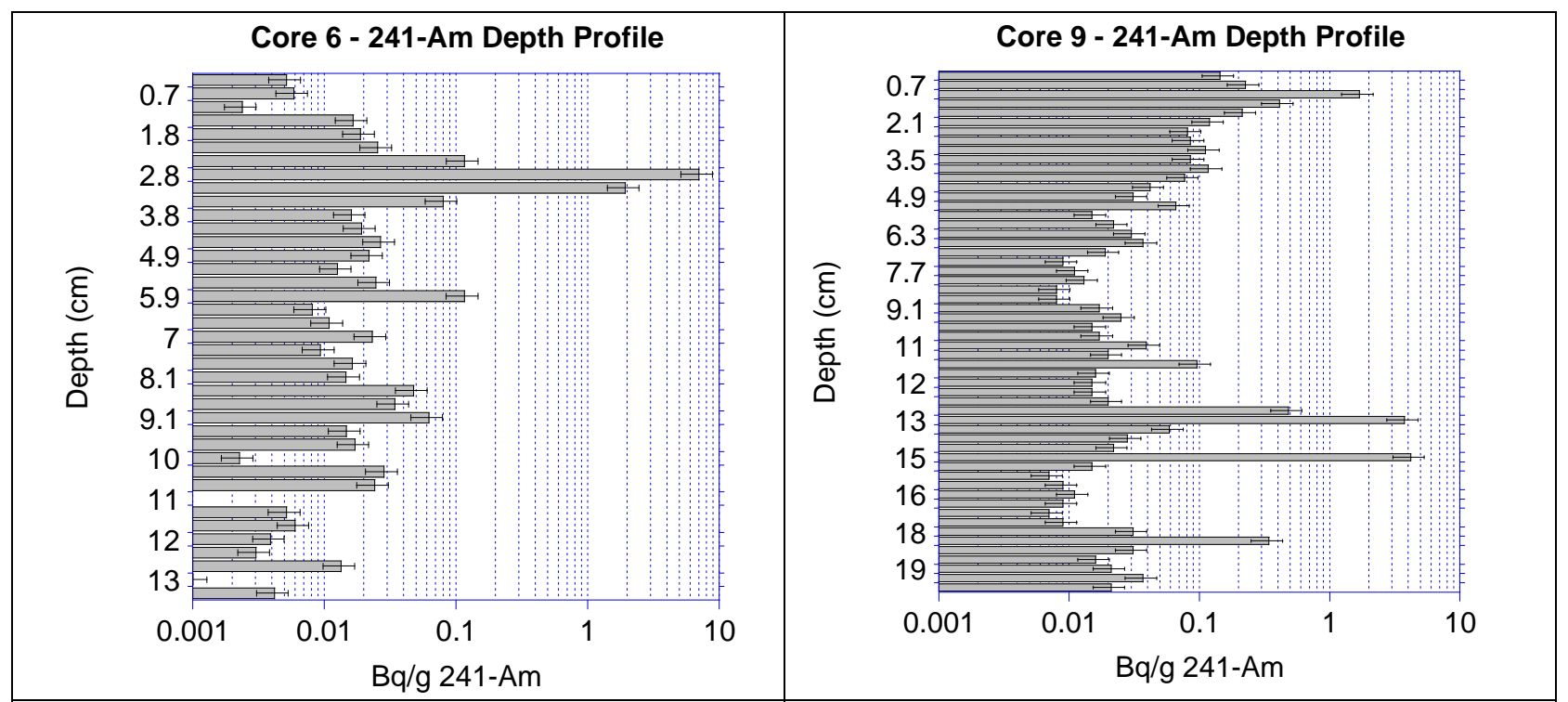

Core 6 (see above) was a $15 \mathrm{~cm}$ long core that contained a $5.1 \mathrm{kBq} 241-$ Am particle that was removed from $2.8 \mathrm{~cm}$ below the surface. The depth profile indicates that the bulk of the residual 241-Am was left in the soil layer that had contained the hot particle and the layers of soil immediately below the hot particle. The presence of 239-Pu was confirmed with gamma peaks at $38.7 \mathrm{keV}$ and $51.6 \mathrm{keV}$ for these same samples. As soil depth increases the 241-Am concentration stabilizes until $11 \mathrm{~cm}$ below the surface when the 241-Am concentration begins to decrease.

Core 9 (see above) was a $20 \mathrm{~cm}$ long core contained a $7.0 \mathrm{kBq} 241-\mathrm{Am}$ hot particle that was removed from $1 \mathrm{~cm}$ below the surface. The depth profile for this core indicates an area of high residual 241-Am activity associated with the layer of soil that contained the particle, and a tapering off of residual 241-Am concentrations as the soil depth increases. The residual activity 
appears to hit a minimum at $9 \mathrm{~cm}$ below the surface and then remains relatively constant except for activity spikes at 13,15 and $18 \mathrm{~cm}$. 239-Pu gamma peaks at 38.7 and $51.6 \mathrm{keV}$ were found with the 241-An activity spikes at $13 \mathrm{~cm}$ and $15 \mathrm{~cm}$ as well as in the layer $(1 \mathrm{~cm})$ from which the hot particle was removed.

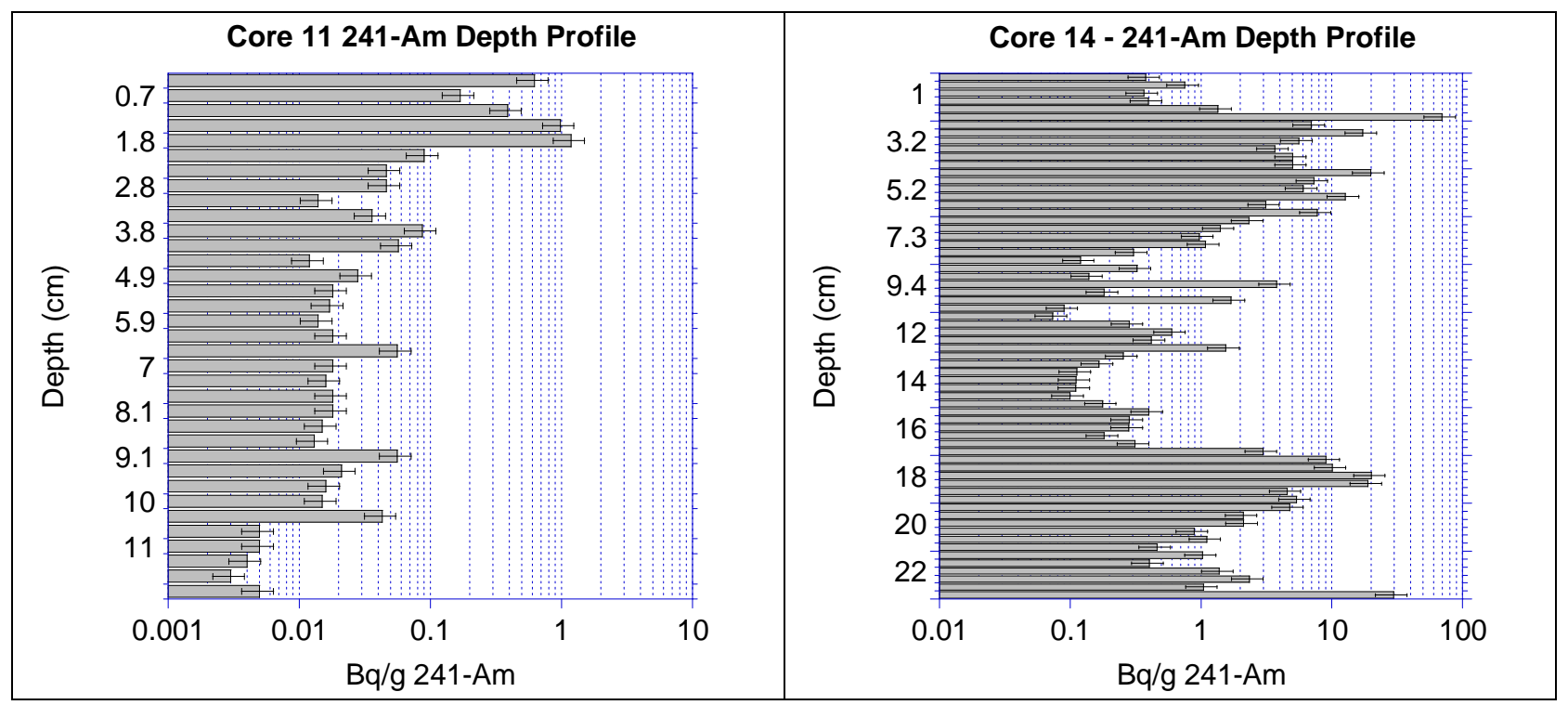

Core 11 (see above) was an $18 \mathrm{~cm}$ long core that contained a $10 \mathrm{kBq} 241-\mathrm{Am}$ hot particle that was removed from $1.4 \mathrm{~cm}$ below the surface. The depth profile for this core shows that areas of high residual 241-Am concentrations can be found in the soil layer that contained the hot particle as well as in the soil layers found above the hot particle. Below the layer that contained the hot particle the residual 241-Am concentration tapers off with increasing depth and then stabilizes until two small activity spikes are observed at 9.1 and $10.1 \mathrm{~cm}$. Below $11 \mathrm{~cm}$ the 241-Am concentration begins to taper off again. 239-Pu was observed by photon peaks at 38.7 and $51.6 \mathrm{keV}$ only at $1.4 \mathrm{~cm}$.

Core 14 (see above) was a $26 \mathrm{~cm}$ long core that contained a $66 \mathrm{kBq} 241-\mathrm{Am}$ particle that was removed from $17.2 \mathrm{~cm}$ below the surface of the soil. Considerable 241-Am was found in the soil layers above the hot particle with the highest activity at $2.1 \mathrm{~cm}$ below the surface. The region of elevated 241-Am concentration extends down to $5.6 \mathrm{~cm}$ below the surface of the soil and 239-Pu has been found in these samples. At $6 \mathrm{~cm}$ below the surface the 241-Am concentration begins to taper off with increasing depth, until several 241-Am concentration spikes are observed between 9 and $13 \mathrm{~cm}$. 239-Pu was observed for all of the activity spikes. At $17 \mathrm{~cm}$ below the surface the soil layer that contained the hot particle as well as several underlying soil layers contained high residual 241-Am concentrations as well as peaks indicating the presence of 239-Pu. Below these layers the 241-Am concentration begins to taper off with increasing depth until another activity spike is detected at $23 \mathrm{~cm}$ below the surface that contains both 241-Am and 239-Pu. 


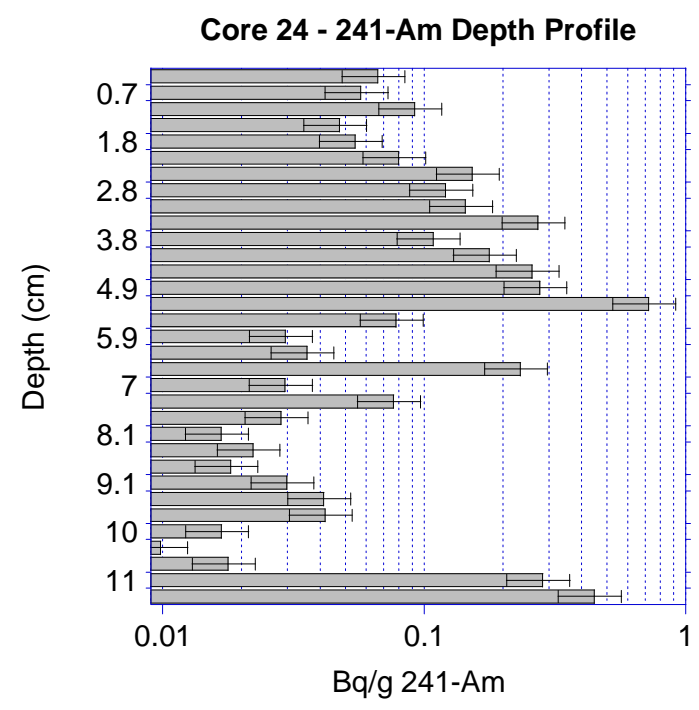

Core 24 (see left figure) was a $12 \mathrm{~cm}$ long core that had a $7.6 \mathrm{kBq}$ hot particle removed from $4.3 \mathrm{~cm}$ below the surface of the soil. Like core 6 , we can see an increase in 241-Am concentrations as we move down the core and approach the layer that contained the hot particle. The soil layers below the hot particle contain elevated 241-Am concentrations as well as 239-Pu. At $5.5 \mathrm{~cm}$ below the surface the 241-Am concentrations begin to taper off with increasing depth until several activity spikes are observed at $6.7,7.4$ and $11.6 \mathrm{~cm}$. The presence of 239-Pu could be verified at 6.7 and $11.6 \mathrm{~cm}$.

These data sets exhibit five trends:

1. 241-Am is found above the hot particles in the soil column

2. 241-Am concentrations taper off in the soil immediately below the hot particles

3. There are regions where the 241-Am concentration appears to remain constant with depth

4. There are discrete 241-Am concentration spikes

5. The presence of 239-Pu has been confirmed in most of the 241-Am concentration spikes

The first three characteristics are indicative of surface area driven processes such as sorption and desorption of material to the soil from the particle. If the assumption is made that the hot particle was initially deposited on the surface of the soil, 241-Am found above the particle would indicate that as the particle has moved down into the soil column it has been shedding 241-Am that has sorbed to the soil and is now fixed in place or moving very slowly under the site conditions. The continuous tapering of 241-Am concentrations to a fixed minimum concentration below the hot particle indicates that 241-Am is being shed from the particle at a rate greater than the surrounding soil can sorb it, and the continuous concentrations are indicative of areas where all of the potential binding sites for 241-Am have been filled, forcing the 241-Am to move further down the soil column.

Of greater interest are the discrete 241-Am concentration spikes found in the core samples. Sorption and desorption processes are expected to occur producing 241-Am concentration gradients. What is unexpected is the particle like behavior indicated by the 241-Am concentration spikes and the presence of 239-Pu and 241-Am in the samples.

To determine if 'micro' hot particles were present in these samples a second set of experiments was devised. A soil sample was parsed into 8-10 sub samples of equal volume, placed on a 1.5" planchet and then counted on a Berthold $\alpha / \beta$ gas proportional counter for 1000 minutes. The sub samples were then stirred and returned to the same chamber and counted again for 1000 minutes. This process was repeated for multiple trials, effectively changing the surface of each sub sample for each trial. If a diffuse activity distribution was present a continuous level of activity would be observed for each sub sample across all the trials. If particles or point sources were present then the count rate would change between trials, as the surface area of each sub sample was exchanged, covering or uncovering the particles. 
This experiment was performed on four samples from two cores ranging in activity from 6.05 to $0.008 \mathrm{~Bq} / \mathrm{g} 241-\mathrm{Am}$ by gamma spectroscopy. The data from the gas proportional counter is reported as a gross alpha count rate in counts per minute (cpm) and cannot be directly reconciled with the activity concentrations determined by gamma spectroscopy. In this case the data from the gas proportional counter will be exclusively used for a trend analysis. The background signal was $0.07 \pm 0.12 \mathrm{cpm}$ alpha and was not subtracted from the reported results. The results of the 4 experiments are show below. If error bars are not visible then the error is smaller than area covered by the data point marker.
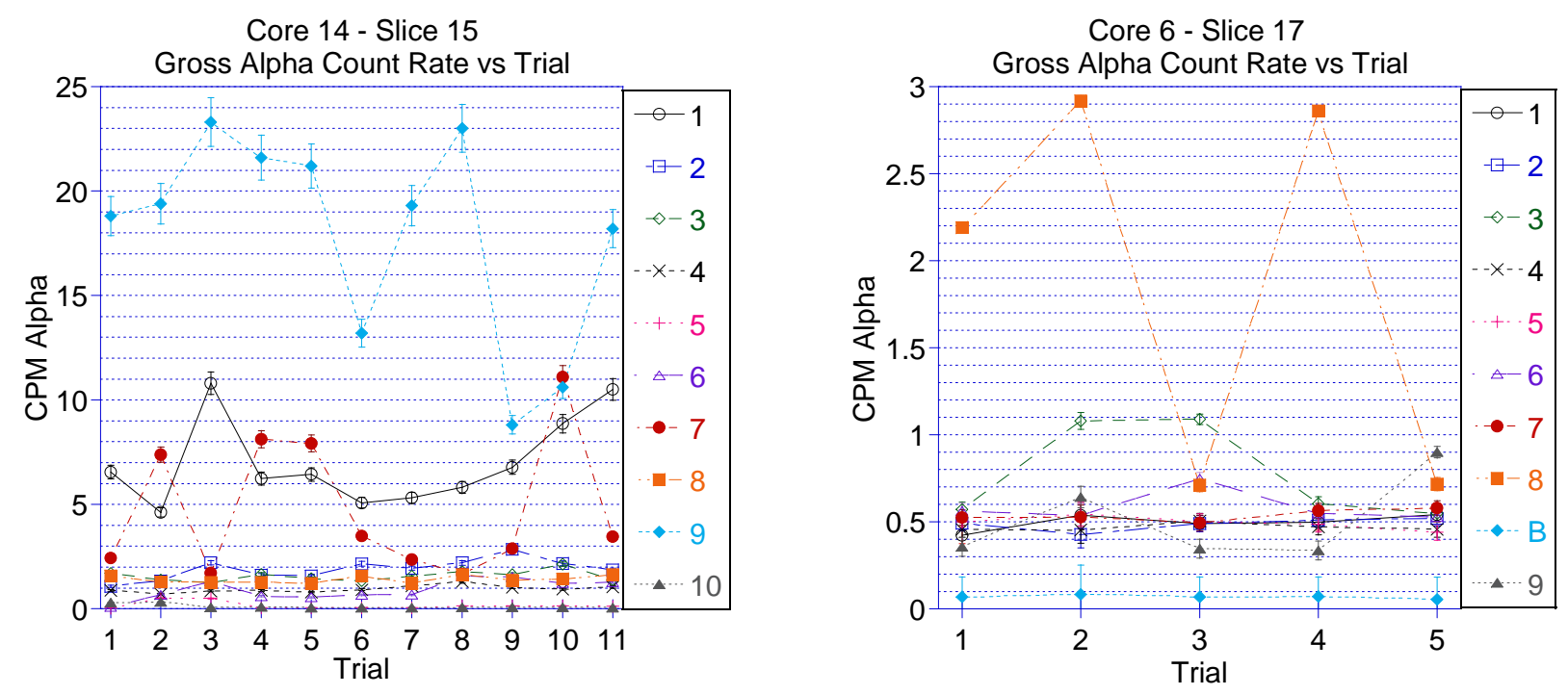

Core 6- Slice 16
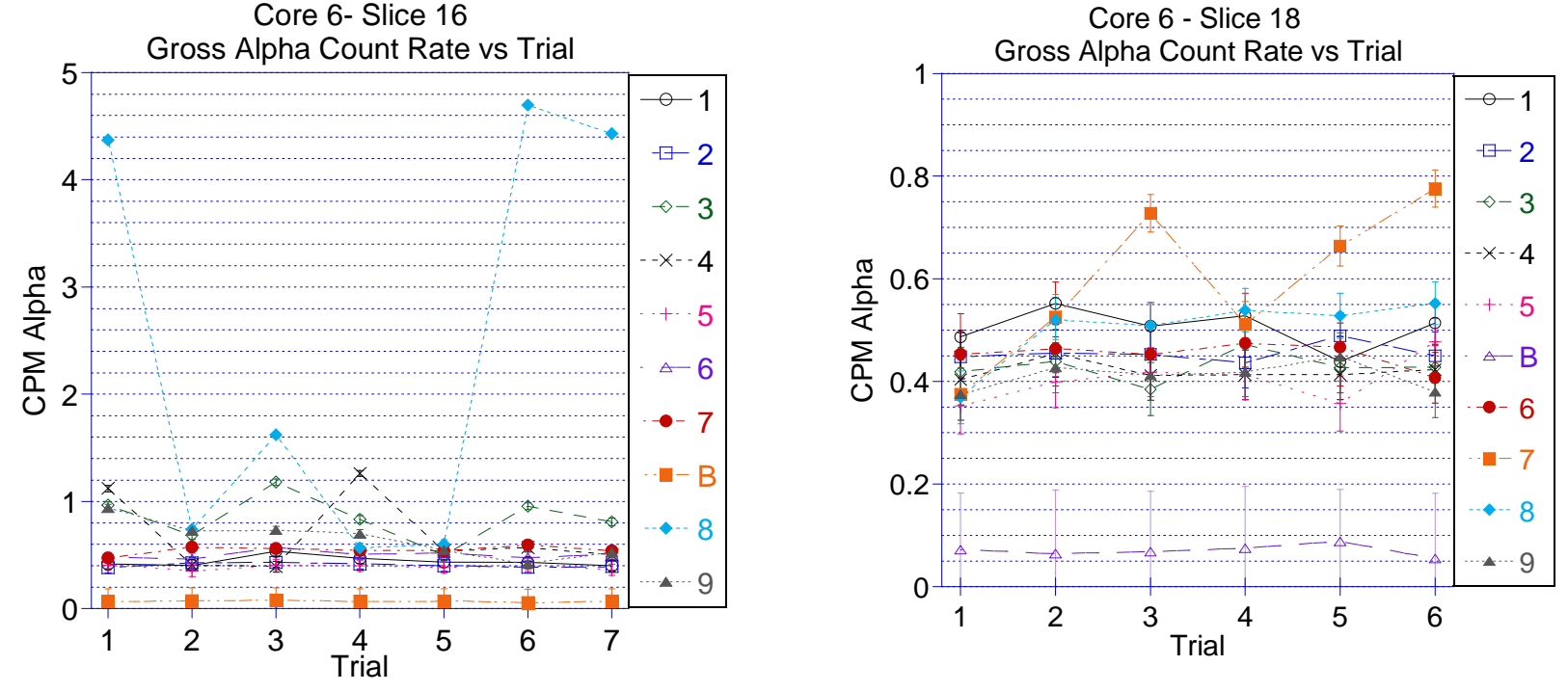
The Core 14 - Slice 15 sample contained the $6.05 \mathrm{~Bq} / \mathrm{g}$ activity spike at $5.25 \mathrm{~cm}$ below the soil surface of Core 14. This sample was split into 10 sub samples and counted 11 times. The Core 6 - Slice 16 sample contained $0.025 \mathrm{~Bq} / \mathrm{g} 241-\mathrm{Am}$ at $5.6 \mathrm{~cm}$, which is representative of the average 241-Am concentration in the middle region of Core 6. This sample was split into 9 sub samples and counted 7 times. Sample Core 6 - Slice 17 is from $5.9 \mathrm{~cm}$ below the surface of Core- 6 and contained an activity spike of $0.116 \mathrm{~Bq} / \mathrm{g} 241-\mathrm{Am}$. This sample was split into 9 sub samples and counted5 times. Although the activity concentration of this sample is greater than the activity concentration of of Core 6 - Slice 16, the maximum count rate observed in the sub samples is lower than that observed in the Core 6 - Slice 16 sub samples. Sample Core 6 - Slice 18 is from $6.3 \mathrm{~cm}$ below the surface of Core 6 and contained $0.008 \mathrm{~Bq} / \mathrm{g} 241-\mathrm{Am}$, a low activity concentration for a sample from the middle of Core 6 . This sample was split into 9 sub samples and counted 6 times.

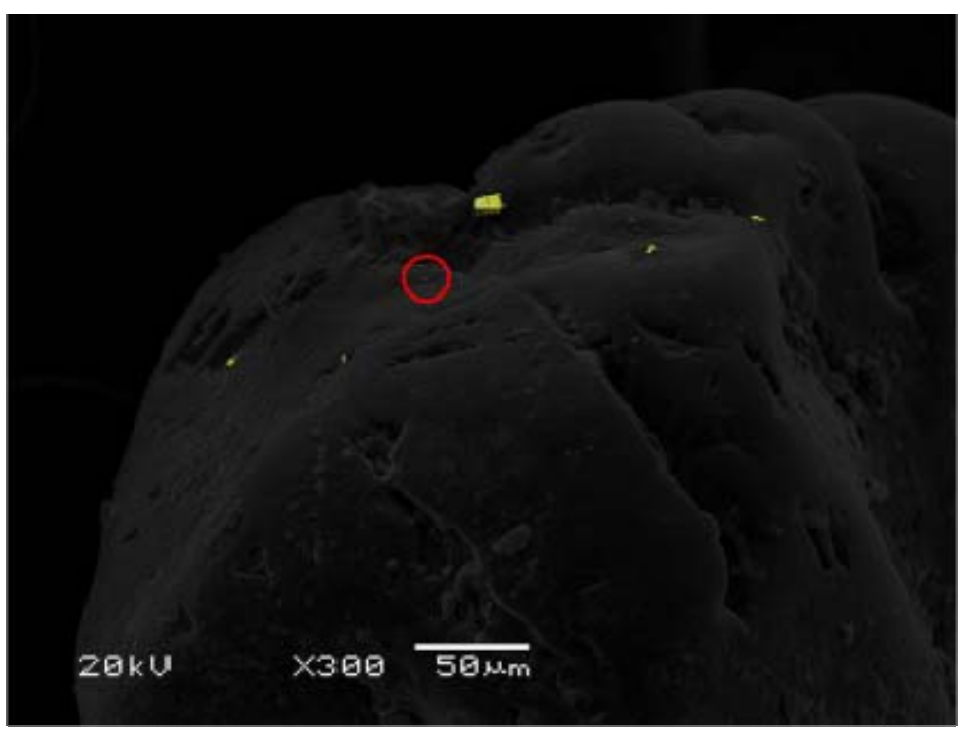

Figure 6: Combined backscatter (BSC) and secondary electron image (SEI) of particles on soil substrate. The suspect particles are highlighted in yellow. The particle under the red circle was imaged at high magnification, Figure 7 , and surveyed by energy dispersive spectroscopy (EDS), Figure 8.
All four experiments exhibit the same two trends, sub samples with count rates independent of experimental trials indicating a homogenous or diffuse activity distribution, and samples with count rates that are affected by the trials, indicating surface area specific areas of high activity (particles) or heterogeneous activity distributions.

To verify that micro particles are present in the core samples scanning electron microscopy (SEM) and

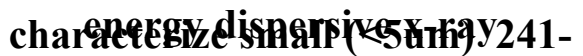

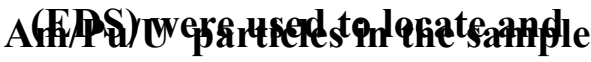
matrix. The image below, (see

6) shows a combined backscatter (BSC) and secondary electron image

\section{density materials are located. High magnification SEI(GEd)BSheineslgesbofght spldowispots}

the red circle in Figure 6 are sindianta areas where high $\mathrm{Z}$, high

Figure 7. An EDS spectra (Figure 8) of the particle under the red circle indicates the presence of $\mathrm{U}$ and $\mathrm{Pu}$ particle by the X-ray triplet at $3164,3340,3534 \mathrm{eV}$ from the combined $\mathrm{Pu}$ and $\mathrm{U} \mathrm{M}_{\alpha}$ and $\mathrm{M}_{\beta}$ signals confirming that it is indeed a 'micro' hot particle. 


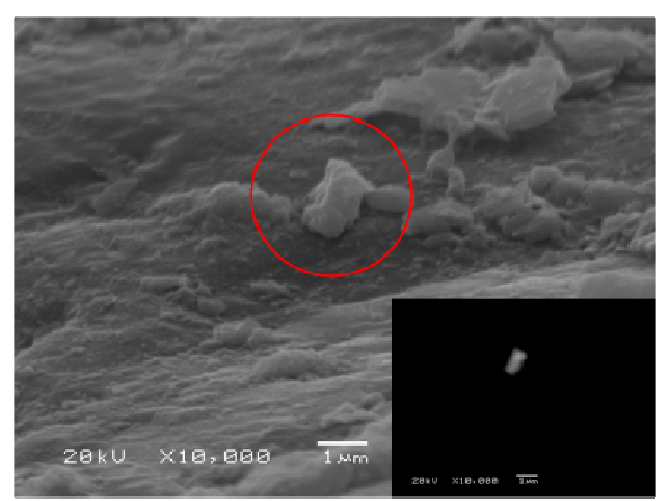

Figure 7: High magnification image of a 'micro' hot particle

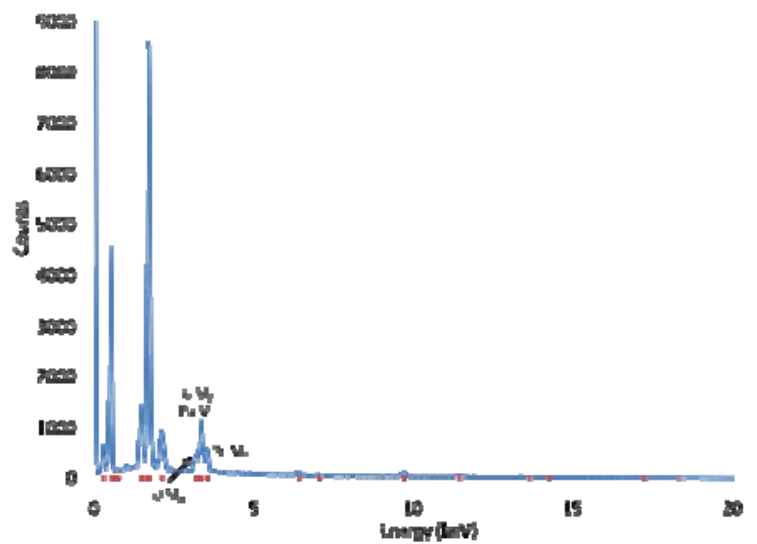

Figure 8: Energy dispersive x-ray spectroscopy (EDS) spectra of the particle from Figure 7. Notice the triplet of $U$ and Pu M shell peaks.

These experiments have shown that hot particles have contributed 241-Am and Pu to their near field environment by mechanisms producing both heterogeneous or particle like distribution patterns and by homogenous distribution patterns that may be caused by dissolution followed by sorption of the 241-Am and $\mathrm{Pu}$ to the near field soils.

The presence of micro particles in the soil presents both opportunity and problems. The opportunity arises in the area of forensics. These particles contain a great deal of information about their source term, but can only be detected through the use of 'high resolution' screening techniques such as gamma spectroscopy and SEM. Because they are difficult to detect, and their dispersion in the soil column appears to be random it is unlikely that they could be completely removed from an area where this type of material may have been dispersed.

The problem occurs with long term modeling of the transport of $\mathrm{Am}$ and $\mathrm{Pu}$ in the environment when particles are present. Chemically driven processes like sorption/desorption driven transport can be modeled using statistical methods because of the large number of small, continuous interactions that occur over time. Particles do not behave this way. They have discrete distributions that make large, localized impacts on distribution of $\mathrm{Pu}$ and $\mathrm{Am}$. To complicate matters the particles may also be mobile, subject to transport by mechanical rather than chemical processes. 


\section{Particle Size Distributions}
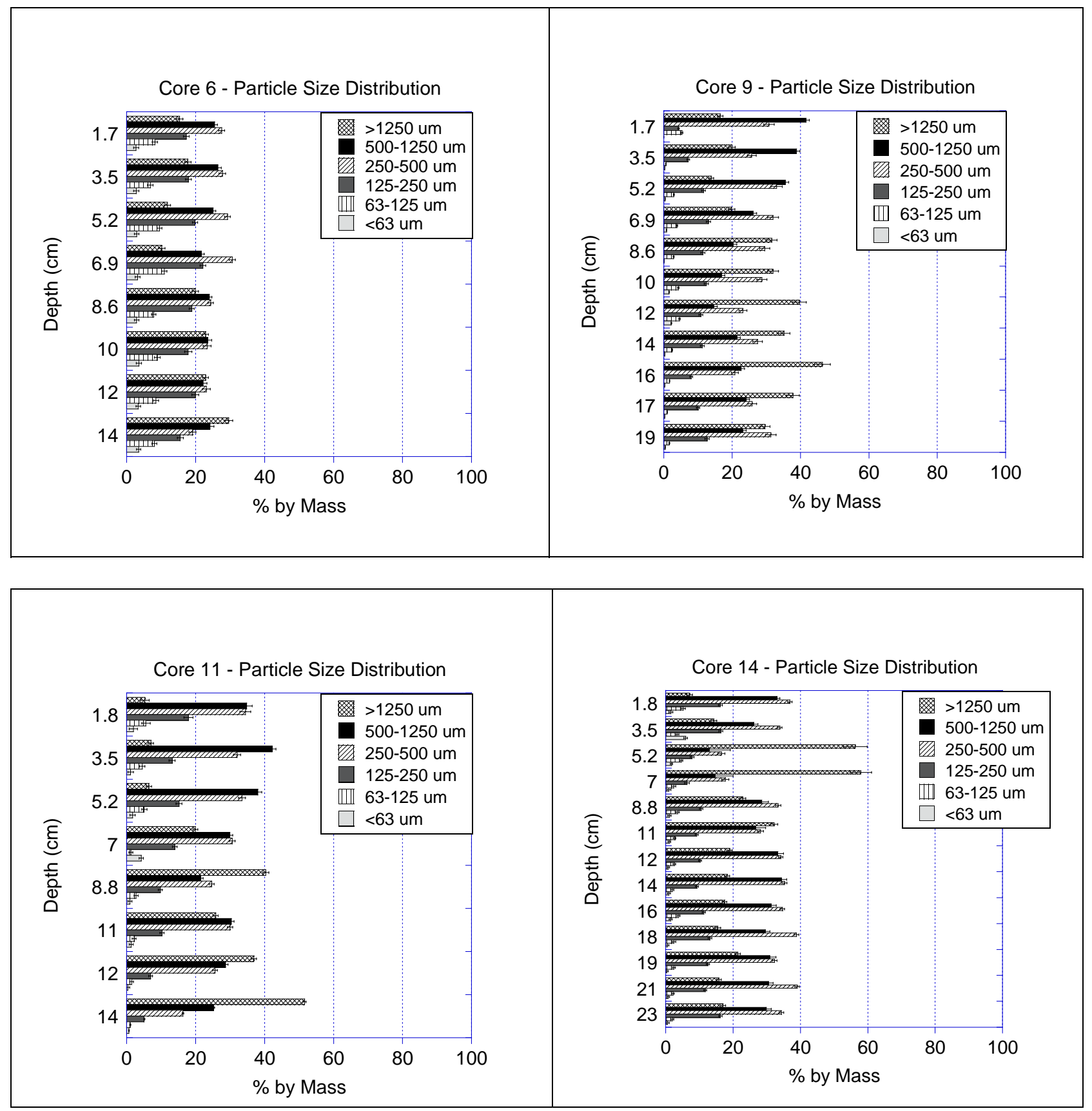


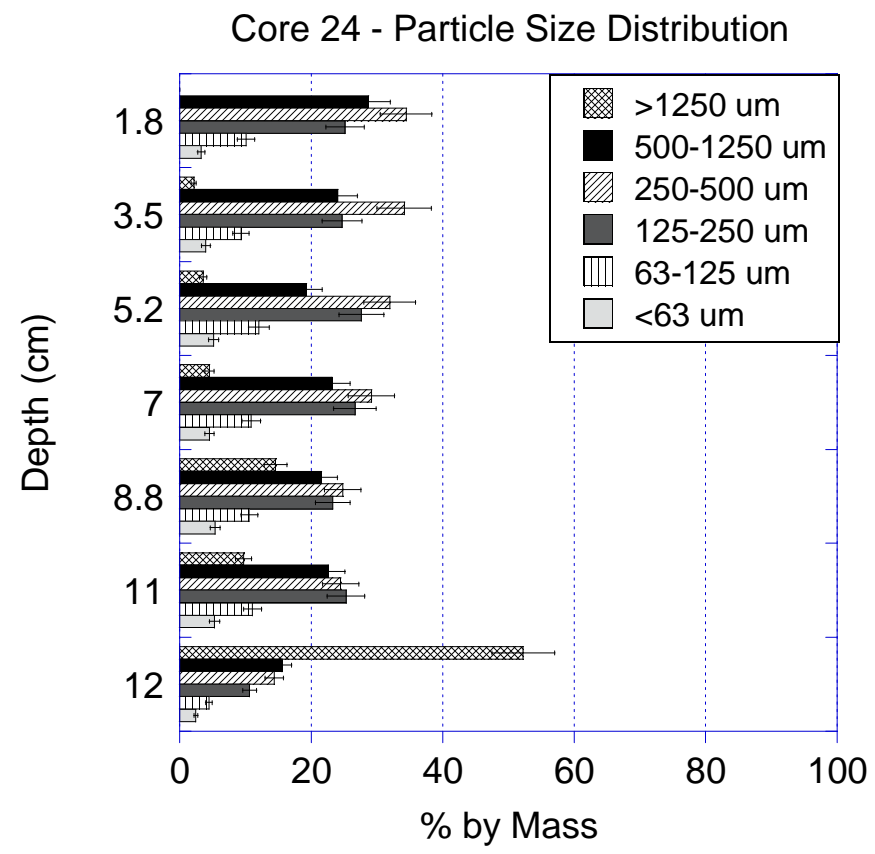




\section{Appendix 2: Effect of Bacteria on Radionuclide Sorption DOE-EPSCoR Report - Microbiology}

\section{Introduction}

Detonation cavities and tunnels at the Nevada Test Site (NTS) contain a variety of radionuclides $\left({ }^{3} \mathrm{H},{ }^{14} \mathrm{C},{ }^{228} \mathrm{Pu},{ }^{239+240} \mathrm{Pu},{ }^{90} \mathrm{Sr},{ }^{99} \mathrm{Tc}\right.$, and $\left.{ }^{234,235,238} \mathrm{U}\right)$ as a result of atomic testing operations that occurred from the 1950s-1990s. Groundwater contamination and migration of these long-lived radioelements, as well as heavy metals used for instrumentation and shielding, is of concern due to the proximity of the NTS to a major population center (Las Vegas, NV). Attempts to model the sorptive behavior of radionuclides at the NTS is difficult because each cavity is a unique environment with a distinct chemical composition and microbial community (Moser, 2008; Smith. D.K. et al., 1998), which may affect sorption of radionuclides to the surrounding substrate in very different ways (Renshaw et al., 2007). Water samples collected from NTS wells vary widely in $\mathrm{pH}$, temperature, dissolved oxygen concentration, alkalinity, and radioactivity ((Moser, 2008; Smith. D.K. et al., 1998), R. Lindvall, pers. comm.); and bacteria may be present in fairly high numbers (up to $10^{6}$ cells $\mathrm{mL}^{-1}$ ) and with highly diverse metabolic capabilities or may not be present at all (Bruckner, 2009; Moser, 2009). While generalizations are often made and environmental samples are considered as a bulk material, a deeper consideration of the role of bacteria is warranted to assess their effects in these diverse environments at the NTS.

The interaction of radionuclides with a variety of natural and industrial materials has been well examined (Chardon et al., 2008; Davis et al., 2006; Gajowiak et al., 2009; Humelnicu et al., 2006), including recent studies on the biosorption and precipitation of transuranic elements by microbes (Gorman-Lewis et al., 2005; Kazy et al., 2008; Luo et al., 2007; Nancharaiah et al., 2006; Renshaw et al., 2007). Extensive modeling of radionuclide sorption to tuff and other minerals from the NTS has been conducted (DOE, 2003), but the role of bacteria was not included in these models.

The NTS evaluation, like many previous studies, addressed one substrate at a time. Many studies have also used a generalized composite approach in which a mix of substrates is approximated as a whole (Curtis et al., 2004). Thus, little is known about the role of natural microbial communities on the sorption of radionuclides to environmental substrates. The only published study to consider a component additivity approach to bacterial sorption (Ohnuki et al., 2005) examined the effects of a single species of Gram positive bacteria on kaolinite clays. Whereas, their results indicated that bacteria had a major effect on uranium sorption, the concentration of bacteria used in most experiments was at least an order of magnitude greater than one would find anywhere in nature and may therefore significantly overestimate the contribution of bacteria to sorption.

In the present study, we compare the sorption kinetics and distribution ratios $\left(\mathrm{K}_{\mathrm{d}} \mathrm{s}\right)$ of uranium and americium to both a generic tuff and tuff collected from the NTS in the presence and absence of a Gram-negative bacterial isolate (Shewanella sp.) as well as endemic bacteria present in NTS water samples. The major objective of this task is to determine if, and to what extent, the local microbial communities affect the sorption and desorption of these radioelements and to determine how the biological component can effectively be incorporated into future models. 
Experiments were performed in a variety of matrices designed to mimic the variety of environmental conditions found at various sites at the NTS.

\section{Methods / Experimental Design}

\section{Characterization of substrate material}

A sample of uncharacterized rhyolitic tuff was obtained from Ward's Natural Science (Rochester, NY). The tuff was ground and sieved into $<125,125-180,180-250,250-400,400$ $500,500-600$, and $>600 \mu \mathrm{m}$ fractions at the UNLV Geosciences Department. Fractions of the tuff were characterized by scanning electron microscopy (SEM) and Energy Dispersive X-ray Spectroscopy (EDS) to determine the surface morphology and elemental composition. X-ray Diffraction (XRD) was used to determine mineral phases of the tuff. Tuff samples with attached bacteria were also analyzed by SEM and EDS to observe any surface modifications caused by the organisms. Both free-living and biofilm forming organisms were used in these surface modification experiments. Tuff samples from the Nevada Test Site (NTS UE12n15A $<75 \mu \mathrm{m}$ and UE12n15A 75-500 $\mu \mathrm{m}$ ) used in experiments were previously characterized at Lawrence Livermore National Lab (M. Zavarin, pers. comm.).

\section{Microbial cultures}

A collection of sulfur-reducing (a proxy for metal/radionuclide reduction) bacteria from Hanford Reach sediments of the DOE Hanford Site (Hanford, WA) was established (Marshall, 2008). Isolates were grown on Luria Bertani (LB) or M1 minimal solid medium containing polysulfide (Moser and Nealson, 1996). Organisms capable of sulfur reduction (as evidenced by clearing zones in the $\mathrm{S}^{0}$ medium) were archived and stored in triplicate as glycerol stocks at $-80{ }^{\circ} \mathrm{C}$. Colonies of pure isolates were picked; cells were lysed; and ribosomal rRNA genes from the cells amplified using the polymerase chain reaction (PCR) and bacteria-specfic primer sets (Giovannoni, 1991). The isolates were phylogentically identified by sequencing of the $16 \mathrm{~S}$ rRNA gene and comparing sequences to known organisms in GenBank. An additional collection of microorganisms with iron-, nitrate- and sulfur-reducing phenotypes was also obtained by cultivation of samples from NTS detonation cavities. Microbial cultures used in experiments included an uncharacterized mixed culture (biofilm-forming) enriched from NTS tuff and a strain of Shewanella by $16 \mathrm{~S}$ rRNA sequence identical to S. oneidensis MR-1 (Myers and Nealson, 1988) isolated from the Hanford Site. Bacterial cultures used in sorption experiments were grown overnight in LB medium to stationary phase at a density of $\sim 10^{9}$ cells $/ \mathrm{mL}$. Cells were centrifuged for 10 minutes at $4000 \mathrm{rpm}$ and the spent medium was decanted. Cells were washed twice and resuspended to a final density of $10^{9}$ cells $\mathrm{mL}^{-1}$ in NTS minimal medium, which contained no organic carbon, phosphorus, nitrogen, or carbonates.

\section{Sorption experiments}

Batch experiments were conducted to determine sorption kinetics and equilibrium constants. Experiments were performed in $50 \mathrm{~mL}$ fluorinated ethylene propylene (FEP) tubes (Nalgene ${ }^{\circledR}$ ) with screw tops. Experimental variables included reaction buffer ( $\mathrm{pH} 7$ deionized water, $30 \mathrm{mM}$ bicarbonate, NTS salts medium (in g L-1): magnesium chloride $\mathrm{MgCl}_{2}$ (0.01), sodium chloride $\mathrm{NaCl}$ (0.013), and sodium sulfate $\mathrm{Na}_{2} \mathrm{SO}_{4}(0.04)$ ), or NTS water from site U12n.10), tuff (Ward's or NTS, size fraction, amount), radionuclide $\left({ }^{233} \mathrm{U}\right.$ or $\left.{ }^{241} \mathrm{Am}\right)$ and bacteria (presence/absence or cell density). Radionuclides were diluted from acidic stock solutions to a final activity of 50- 
$2000 \mathrm{~Bq} \mathrm{~g}^{-1}$ tuff in $20 \mathrm{~mL}$ of reaction buffer. The $\mathrm{pH}$ was adjusted to the desired experimental level with $\mathrm{NaOH}$ or $\mathrm{HCl}$ as necessary. The majority of experiments were conducted at $\mathrm{pH} 7$. Bacteria were added to the appropriate concentration, and the time-zero samples were taken before tuff was added to determine the total concentration of radionuclide prior to sorption. Tuff was added and samples were vortexed at $2000 \mathrm{rpm}$ for $\sim 5$ seconds to ensure mixing of the two phases while protecting cells from lysis. After mixing, the samples were centrifuged at 4000 rpm for four minutes to separate the solid phase from the solution phase. Aliquots of $100 \mu \mathrm{L}$ were then taken from the supernatant of each sample and added to $10 \mathrm{~mL}$ of Ultima Gold liquid scintillation cocktail. Samples were taken every 8-20 minutes for the first $1-2 \mathrm{~h}$, with additional time points taken at approximately 2, 4, 24, 48, 72, and $168 \mathrm{~h}$ for most experiments. Samples were analyzed by liquid scintillation counting (perkin elmer Tri-Carb 3100TR) for 60 minutes or until 10,000 counts were reached.

\section{$\underline{\text { Results }}$}

\section{Characterization of tuff samples}

Scanning electron microscopy (SEM) of samples of Ward's tuff ( $600 \mu \mathrm{m}$ fraction) revealed particles with highly variable surface areas and textures. EDS analysis determined that tuff particles were composed mainly of $\mathrm{Si}, \mathrm{O}, \mathrm{Al}, \mathrm{K}$, and $\mathrm{Na}$ (Figure 1). X-ray diffraction (XRD) analysis confirmed that the majority minerals present in the tuff were silicate-based. Figure 2 shows the identification of three phases: sanidine $\left(\mathrm{KAlSi}_{3} \mathrm{O}_{8}\right)$, Cristobalite $\left(\mathrm{SiO}_{2}\right)$, and $\alpha$-Quartz $\left(\mathrm{SiO}_{2}\right)$. Tuff collected from the NTS was also analyzed by SEM and EDS and compared in

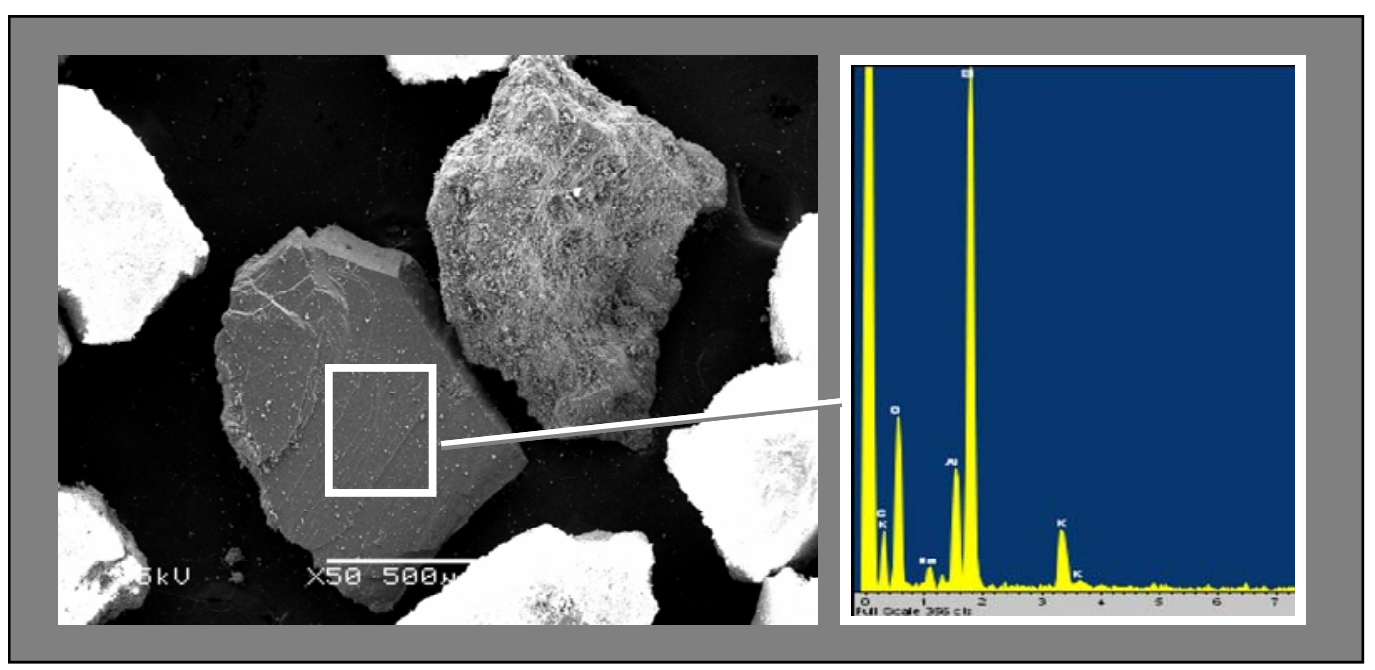

structure

and

Fig. 1. Scanning electron microscope image (left) and EDS analysis (right) of rhyolitic tuff (600 $\mu \mathrm{m}$ fraction).

composition to the Ward's tuff. Additionally, NTS tuff was examined after incubation overnight in LB medium with a mixed NTS culture (Figure 3a) or strain MR-1 (Figure 3b). Figure 3 shows the very different effects on surface site availability of the tuff in the presence of a biofilm versus free-living bacteria. The biofilm covers much of the tuff surface (Figure 3a), eliminating potential sorption sites for radionuclides but also produces an exopolysaccharide (EPS) that may 
trap these elements. The free-living bacteria fill in spaced around the tuff, creating additional surface area for radionuclide binding. Cells of Shewanella MR-1 may be free-living or form a biofilm depending on growth conditions.

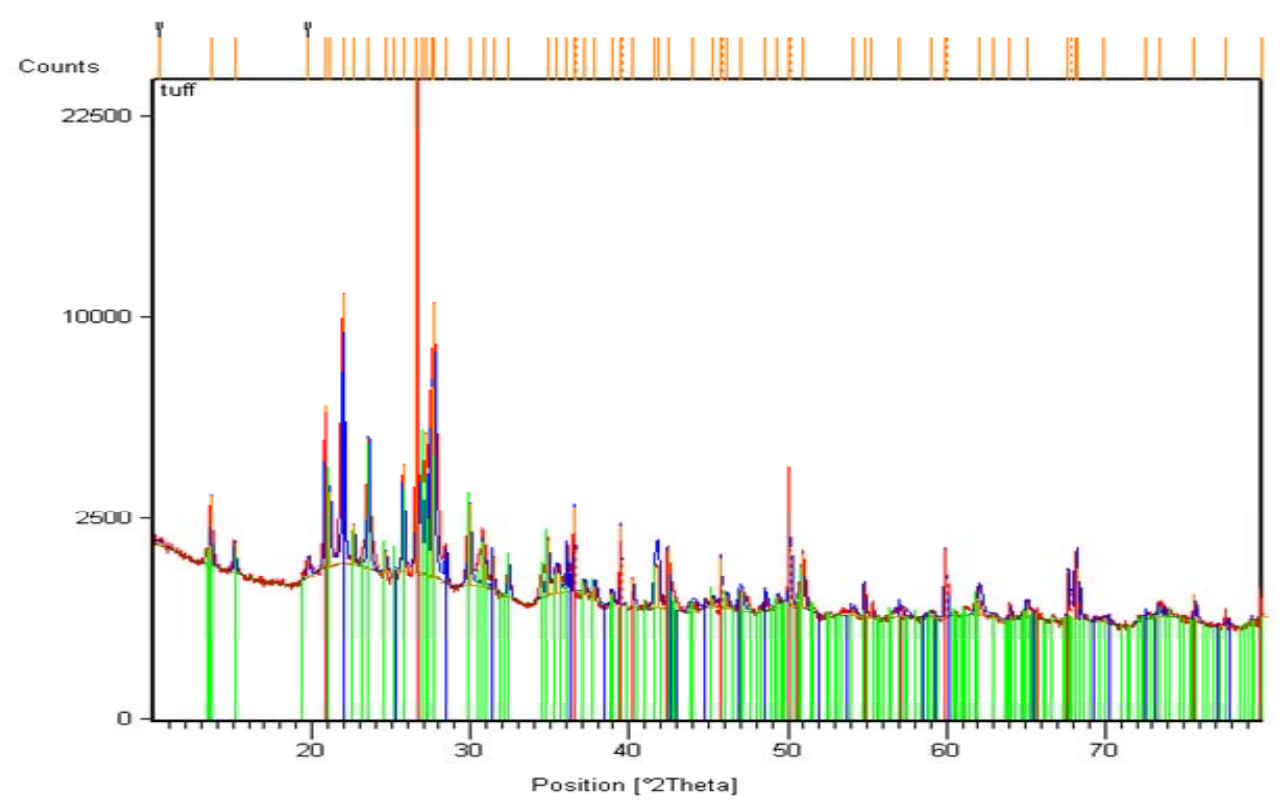

Hanford

Site

Isolates

Forty

isolates

were

obtained

from the

DOE

Hanford

Site

(Table 1).

Most of

these

were

capable of

sulfur

reduction,

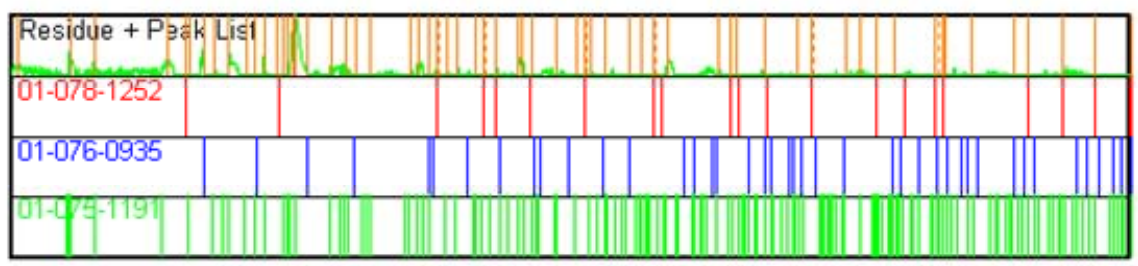

and many

were

closely

related to

well-

characteri

zed

strains of

Shewanell

Fig. 2. X-ray diffraction (XRD) spectra for uncharacterized Ward's tuff.

a. We selected isolate PNNL 3-20B, which was $100 \%$ similar to Shewanella oneidensis MR-1 based on a nearly full-length sequence of the $16 \mathrm{~S}$ rRNA gene, as the organism to be used in sorption batch experiments.

Table 1. Microbial isolates from the DOE Hanford Site

\begin{tabular}{|c|c|c|c|c|c|c|c|}
\hline $\begin{array}{l}\text { PNNL } \\
\text { ID }\end{array}$ & SITE & $\begin{array}{l}\text { DRI } \\
\text { ID }\end{array}$ & MEDIUM & $\begin{array}{c}\mathbf{S}^{0} \\
\text { clearing }\end{array}$ & $\begin{array}{l}\text { Closest } \\
\text { match }\end{array}$ & $\begin{array}{c}\% \\
\text { similarity }\end{array}$ & $\begin{array}{c}\text { Accession } \\
\#\end{array}$ \\
\hline $\begin{array}{c}\text { HRCR- } \\
35\end{array}$ & 2 & $\begin{array}{c}\text { PNNL- } \\
2-1\end{array}$ & LBS & $\mathrm{Y}$ & $\begin{array}{l}\text { Citrobacter } \\
\text { freundii }\end{array}$ & 99 & DQ481465 \\
\hline $\begin{array}{l}\text { HRCR- } \\
36\end{array}$ & 2 & $\begin{array}{l}\text { PNNL- } \\
2-2\end{array}$ & LBS & Y & $\begin{array}{l}\text { Aeromonas } \\
\text { sobria }\end{array}$ & 99 & X74683 \\
\hline HRCR- & 2 & PNNL- & M1S & Y & Shewanella & 99 & $\mathrm{CP} 000503$ \\
\hline
\end{tabular}




\begin{tabular}{|c|c|c|c|c|c|c|c|}
\hline 47 & & $2-12 B$ & & & W3-18-1 & & \\
\hline $\begin{array}{l}\text { HRCR- } \\
\quad 48\end{array}$ & 2 & $\begin{array}{l}\text { PNNL- } \\
2-13\end{array}$ & M1S & $\mathrm{Y}$ & $\begin{array}{c}\text { Stenotropho } \\
\text {-monas } \\
\text { maltophilia }\end{array}$ & 100 & DQ223428 \\
\hline $\begin{array}{l}\text { HRCR- } \\
\quad 58\end{array}$ & 3 & $\begin{array}{c}\text { PNNL- } \\
3-2\end{array}$ & M1S & $\mathrm{Y}$ & $\begin{array}{l}\text { Aeromonas } \\
\text { salmonicida }\end{array}$ & 99 & AY786178 \\
\hline $\begin{array}{l}\text { HRCR- } \\
59\end{array}$ & 3 & $\begin{array}{c}\text { PNNL- } \\
3-3\end{array}$ & M1S & $\mathrm{N}$ & $\begin{array}{l}\text { Aeromonas } \\
\text { hydrophila }\end{array}$ & 99 & DQ207728 \\
\hline $\begin{array}{l}\text { HRCR- } \\
\quad 68\end{array}$ & 3 & $\begin{array}{l}\text { PNNL- } \\
3-12 B\end{array}$ & M1S & $\mathrm{Y}$ & $\begin{array}{c}\text { Shewanella } \\
\text { W-3-18-1 }\end{array}$ & 99 & $\underline{\mathrm{CP} 000503}$ \\
\hline $\begin{array}{l}\text { HRCR- } \\
75\end{array}$ & 3 & $\begin{array}{l}\text { PNNL- } \\
3-19\end{array}$ & M1S & $\mathrm{Y}$ & $\begin{array}{l}\text { Aeromonas } \\
\text { salmonicida }\end{array}$ & 100 & AM931169 \\
\hline $\begin{array}{l}\text { HRCR- } \\
76\end{array}$ & 3 & $\begin{array}{l}\text { PNNL- } \\
3-20 B\end{array}$ & M1S & $\mathrm{Y}$ & $\begin{array}{c}\text { Shewanella } \\
\text { oneidensis } \\
\text { MR-1 }\end{array}$ & 100 & AE014299 \\
\hline $\begin{array}{c}\text { HRCR- } \\
80\end{array}$ & 3 & $\begin{array}{l}\text { PNNL- } \\
3-25\end{array}$ & M1S & $\mathrm{Y}$ & $\begin{array}{l}\text { Uncultured } \\
\text { Aeromonas }\end{array}$ & 94 & $\underline{\text { EF679180 }}$ \\
\hline $\begin{array}{l}\text { HRCR- } \\
\quad 96\end{array}$ & 4 & $\begin{array}{c}\text { PNNL- } \\
4-1\end{array}$ & M1S & $\mathrm{Y}$ & $\begin{array}{c}\text { Shewanella } \\
\text { W3-18-1 }\end{array}$ & 99 & $\underline{\mathrm{CP} 000503}$ \\
\hline $\begin{array}{l}\text { HRCR- } \\
97\end{array}$ & 4 & $\begin{array}{c}\text { PNNL- } \\
4-2\end{array}$ & LBS & $\mathrm{Y}$ & $\begin{array}{c}\text { Shewanella } \\
\text { W3-18-1 }\end{array}$ & 100 & $\underline{\mathrm{CP} 000503}$ \\
\hline $\begin{array}{l}\text { HRCR- } \\
\quad 98\end{array}$ & 4 & $\begin{array}{c}\text { PNNL- } \\
4-3\end{array}$ & LBS & $\mathrm{Y}$ & $\begin{array}{c}\text { Shewanella } \\
\text { W3-18-1 }\end{array}$ & 100 & $\underline{\mathrm{CP} 000503}$ \\
\hline $\begin{array}{l}\text { HRCR- } \\
\quad 99\end{array}$ & 4 & $\begin{array}{c}\text { PNNL- } \\
4-4\end{array}$ & LBS & $\mathrm{Y}$ & $\begin{array}{c}\text { Shewanella } \\
\text { W3-18-1 }\end{array}$ & 100 & $\underline{\mathrm{CP} 000503}$ \\
\hline $\begin{array}{c}\text { HRCR- } \\
100\end{array}$ & 4 & $\begin{array}{c}\text { PNNL- } \\
4-5\end{array}$ & LBS & $\mathrm{Y}$ & $\begin{array}{c}\text { Shewanella } \\
\text { W3-18-1 }\end{array}$ & 100 & $\underline{\mathrm{CP} 000503}$ \\
\hline $\begin{array}{c}\text { HRCR- } \\
101\end{array}$ & 4 & $\begin{array}{c}\text { PNNL- } \\
4-6\end{array}$ & LBS & $\mathrm{Y}$ & $\begin{array}{c}\text { Shewanella } \\
\text { W3-18-1 }\end{array}$ & 100 & $\underline{\mathrm{CP} 000503}$ \\
\hline $\begin{array}{c}\text { HRCR- } \\
110\end{array}$ & 4 & $\begin{array}{l}\text { PNNL- } \\
4-15 B\end{array}$ & LBS & $\mathrm{Y}$ & $\begin{array}{c}\text { Shewanella } \\
\text { W3-18-1 }\end{array}$ & 100 & $\underline{\mathrm{CP} 000503}$ \\
\hline $\begin{array}{c}\text { HRCR- } \\
111\end{array}$ & 4 & $\begin{array}{l}\text { PNNL- } \\
4-16\end{array}$ & LBS & $\mathrm{Y}$ & $\begin{array}{l}\text { Aeromonas } \\
\text { hydrophila }\end{array}$ & 99 & DQ207728 \\
\hline $\begin{array}{c}\text { HRCR- } \\
112\end{array}$ & 4 & $\begin{array}{l}\text { PNNL- } \\
4-17\end{array}$ & LBS & $\mathrm{Y}$ & $\begin{array}{c}\text { Shewanella } \\
\text { W3-18-1 }\end{array}$ & 100 & $\underline{\mathrm{CP} 000503}$ \\
\hline $\begin{array}{c}\text { HRCR- } \\
114\end{array}$ & 4 & $\begin{array}{l}\text { PNNL- } \\
4-20\end{array}$ & LBS & $\mathrm{Y}$ & $\begin{array}{c}\text { Shewanella } \\
\text { W3-18-1 }\end{array}$ & 100 & $\underline{\mathrm{CP} 000503}$ \\
\hline $\begin{array}{c}\text { HRCR- } \\
115\end{array}$ & 4 & $\begin{array}{c}\text { PNNL- } \\
4-21\end{array}$ & LBS & $\mathrm{Y}$ & $\begin{array}{c}\text { Shewanella } \\
\text { W3-18-1 }\end{array}$ & 100 & $\underline{\mathrm{CP} 000503}$ \\
\hline $\begin{array}{l}\text { HRCR- } \\
116\end{array}$ & 4 & $\begin{array}{l}\text { PNNL- } \\
4-22\end{array}$ & M1S & $\mathrm{Y}$ & $\begin{array}{c}\text { Shewanella } \\
\text { W3-18-1 }\end{array}$ & 100 & $\underline{\mathrm{CP} 000503}$ \\
\hline $\begin{array}{c}\text { HRCR- } \\
118\end{array}$ & 4 & $\begin{array}{c}\text { PNNL- } \\
4-24\end{array}$ & M1S & $\mathrm{Y}$ & $\begin{array}{c}\text { Shewanella } \\
\text { W3-18-1 }\end{array}$ & 100 & $\underline{\mathrm{CP} 000503}$ \\
\hline $\begin{array}{c}\text { HRCR- } \\
119\end{array}$ & 4 & $\begin{array}{l}\text { PNNL- } \\
4-25\end{array}$ & M1S & $\mathrm{Y}$ & $\begin{array}{c}\text { Shewanella } \\
\text { W3-18-1 }\end{array}$ & 100 & $\underline{\mathrm{CP} 000503}$ \\
\hline HRCR- & 4 & PNNL- & M1S & $\mathrm{Y}$ & Shewanella & 100 & $\underline{\mathrm{CP} 000503}$ \\
\hline
\end{tabular}




\begin{tabular}{|c|c|c|c|c|c|c|c|}
\hline 120 & & $4-26$ & & & W3-18-1 & & \\
\hline $\begin{array}{c}\text { HRCR- } \\
121\end{array}$ & 4 & $\begin{array}{c}\text { PNNL- } \\
4-27\end{array}$ & M1S & $\mathrm{Y}$ & $\begin{array}{c}\text { Acinetobac- } \\
\text { ter sp. Hi9 }\end{array}$ & 99 & AB192395 \\
\hline $\begin{array}{c}\text { HRCR- } \\
122\end{array}$ & 4 & $\begin{array}{c}\text { PNNL- } \\
4-28\end{array}$ & M1S & $\mathrm{Y}$ & $\begin{array}{c}\text { Shewanella } \\
\text { W3-18-1 }\end{array}$ & 100 & $\underline{\mathrm{CP} 000503}$ \\
\hline $\begin{array}{c}\text { HRCR- } \\
123\end{array}$ & 4 & $\begin{array}{c}\text { PNNL- } \\
4-29\end{array}$ & M1S & $\mathrm{Y}$ & $\begin{array}{c}\text { Shewanella } \\
\text { W3-18-1 }\end{array}$ & 100 & $\underline{\mathrm{CP} 000503}$ \\
\hline $\begin{array}{c}\text { HRCR- } \\
135\end{array}$ & 5 & $\begin{array}{c}\text { PNNL- } \\
5-1\end{array}$ & M1S & $\mathrm{N}$ & $\begin{array}{l}\text { Aeromonas } \\
\text { sp. } 54\end{array}$ & 99 & $\underline{\mathrm{AJ} 308468}$ \\
\hline $\begin{array}{c}\text { HRCR- } \\
136\end{array}$ & 5 & $\begin{array}{c}\text { PNNL- } \\
5-2\end{array}$ & M1S & $\mathrm{Y}$ & $\begin{array}{l}\text { Pseudomo- } \\
\text { nas KBR-55 }\end{array}$ & 100 & AM992007 \\
\hline $\begin{array}{c}\text { HRCR- } \\
156\end{array}$ & 6 & $\begin{array}{l}\text { PNNL- } \\
6-2 \mathrm{~A}\end{array}$ & M1S & $\mathrm{Y}$ & $\begin{array}{c}\text { Shewanella } \\
\text { W3-18-1 }\end{array}$ & 99 & $\underline{\mathrm{CP} 000503}$ \\
\hline $\begin{array}{c}\text { HRCR- } \\
156\end{array}$ & 6 & $\begin{array}{c}\text { PNNL- } \\
6-2 B\end{array}$ & M1S & $\mathrm{Y}$ & $\begin{array}{l}\text { Aeromonas } \\
\text { sobria }\end{array}$ & 99 & $\underline{X 74683}$ \\
\hline $\begin{array}{c}\text { HRCR- } \\
157\end{array}$ & 6 & $\begin{array}{c}\text { PNNL- } \\
6-3\end{array}$ & M1S & $\mathrm{Y}$ & $\begin{array}{c}\text { Shewanella } \\
\text { W3-18-1 }\end{array}$ & 100 & $\underline{\mathrm{CP} 000503}$ \\
\hline $\begin{array}{c}\text { HRCR- } \\
158\end{array}$ & 6 & $\begin{array}{c}\text { PNNL- } \\
6-4 A\end{array}$ & M1S & $\mathrm{Y}$ & $\begin{array}{c}\text { Aermonas } \\
\text { salmonicida }\end{array}$ & 100 & $\underline{\mathrm{CP} 000644}$ \\
\hline $\begin{array}{c}\text { HRCR- } \\
158\end{array}$ & 6 & $\begin{array}{c}\text { PNNL- } \\
6-4 B\end{array}$ & M1S & $\mathrm{Y}$ & $\begin{array}{c}\text { Shewanella } \\
\text { W3-18-1 }\end{array}$ & 99 & $\underline{\mathrm{CP} 000503}$ \\
\hline $\begin{array}{c}\text { HRCR- } \\
159\end{array}$ & 6 & $\begin{array}{c}\text { PNNL- } \\
6-5\end{array}$ & M1S & $\mathrm{Y}$ & $\begin{array}{c}\text { Shewanella } \\
\text { W3-18-1 }\end{array}$ & 99 & $\underline{\mathrm{CP} 000503}$ \\
\hline $\begin{array}{c}\text { HRCR- } \\
176\end{array}$ & 7 & $\begin{array}{l}\text { PNNL- } \\
7-7 \mathrm{~A}\end{array}$ & LBS & $\mathrm{Y}$ & $\begin{array}{c}\text { Shewanella } \\
\text { W3-18-1 }\end{array}$ & 99 & $\underline{\mathrm{CP} 000503}$ \\
\hline $\begin{array}{c}\text { HRCR- } \\
177\end{array}$ & 7 & $\begin{array}{c}\text { PNNL- } \\
7-8\end{array}$ & M1S & $\mathrm{Y}$ & $\begin{array}{c}\text { Shewanella } \\
\text { W3-18-1 }\end{array}$ & 99 & $\underline{\mathrm{CP} 000503}$ \\
\hline $\begin{array}{l}\text { HRCR- } \\
196\end{array}$ & 8 & $\begin{array}{c}\text { PNNL- } \\
8-3 B\end{array}$ & M1S & $\mathrm{Y}$ & $\begin{array}{c}\text { Shewanella } \\
\text { ANA-3 }\end{array}$ & 89 & CP000469 \\
\hline $\begin{array}{c}\text { HRCR- } \\
198\end{array}$ & 8 & $\begin{array}{c}\text { PNNL- } \\
8-5 B\end{array}$ & M1S & $\mathrm{Y}$ & $\begin{array}{c}\text { Shewanella } \\
\text { oneidensis } \\
\text { MR-1 }\end{array}$ & 98 & $\underline{\mathrm{AE} 014299}$ \\
\hline
\end{tabular}




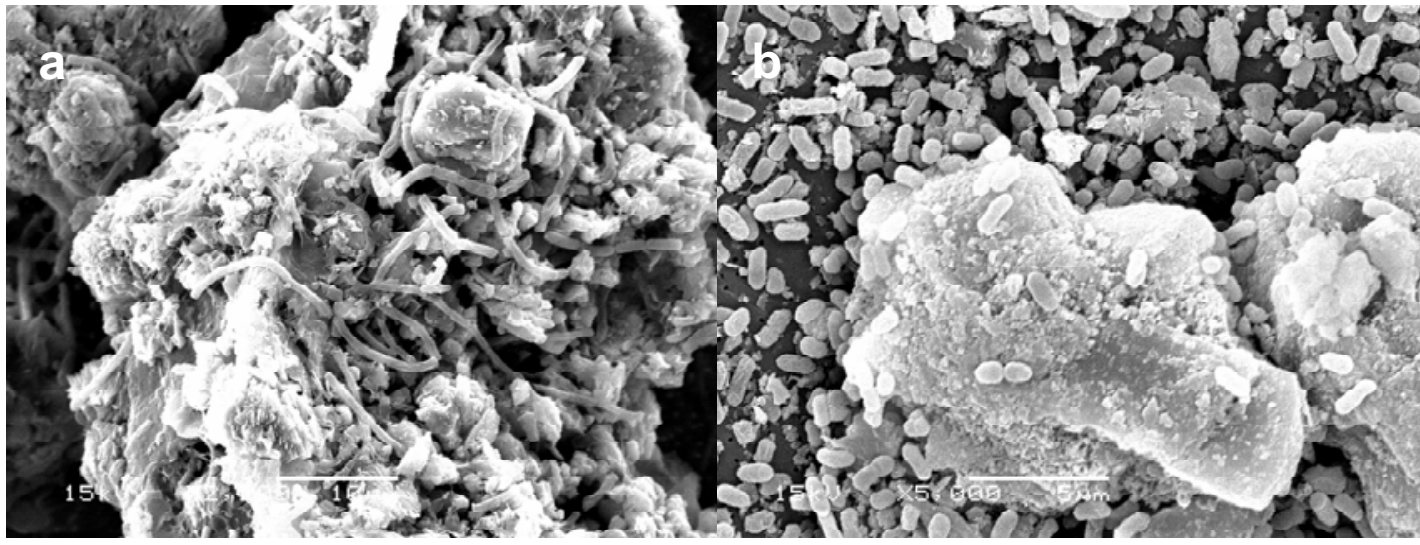

Fig. 3. SEMs of NTS tuff $(12 \mathrm{n} 15 \mathrm{~A}<75 \mu \mathrm{m})$ with a) biofilm of endemic bacteria or b) culture of Shewanella MR-1.
Sorptio

$n$ of

${ }^{233} U$

Ideal

conditi

ons for

the

sorptio

$\mathrm{n}$ batch

experi

ments

were

determined through a ranging experiments which the

in

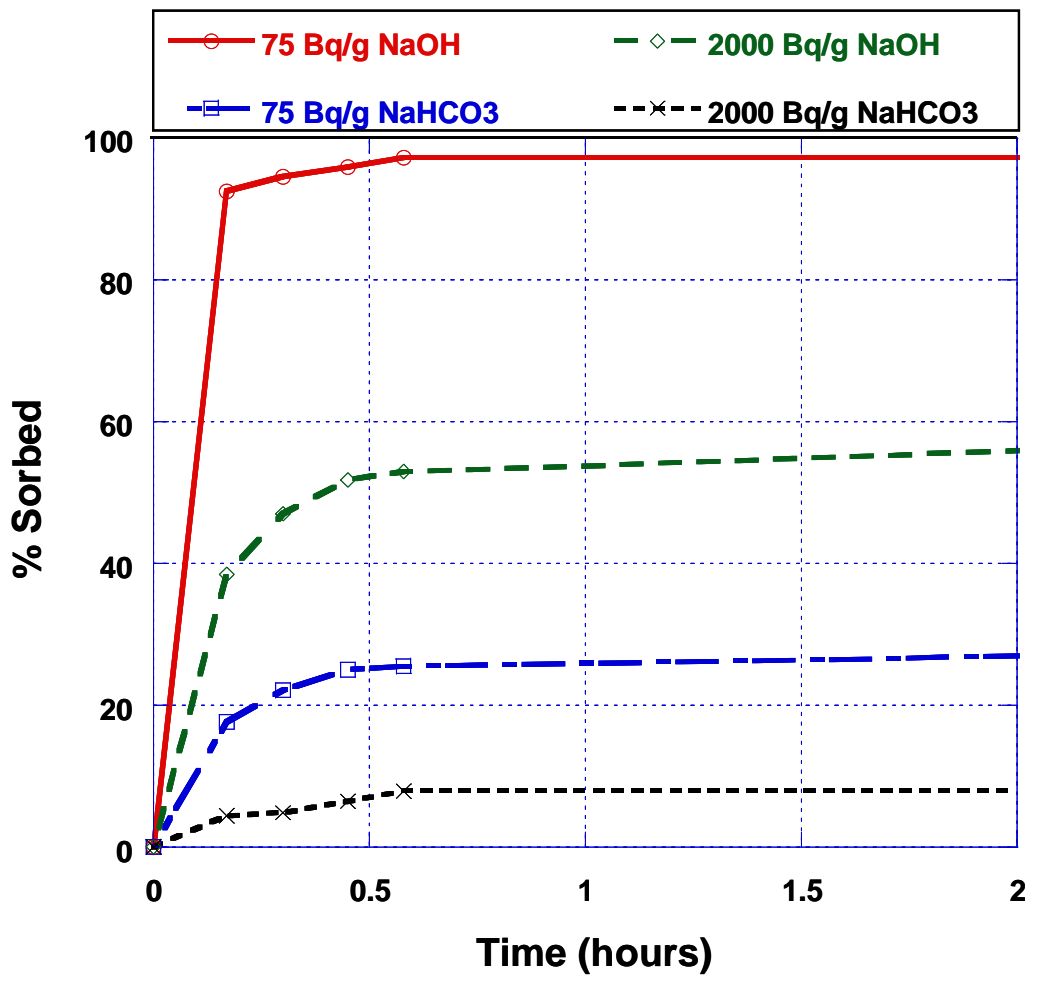

Fig. 4. Sorption of ${ }^{233} \mathrm{U}$ to tuff in deionized water amended with either sodium hydroxide or sodium bicarbonate to achieve a $\mathrm{pH}$ of $\sim 7$.

concentration of radionuclide and the radionuclide:tuff ratios were varied. These experiments used the $600 \mu \mathrm{m}$ fraction of Ward's tuff. Two buffers (sodium hydroxide and sodium bicarbonate) were also compared. The treatments buffered with sodium bicarbonate exhibited very little sorption of ${ }^{233} \mathrm{U}$ (Figure 4), likely due to the formation of uranyl carbonate complexes. Sorption was reduced by approximately fourfold in both the high and low $\mathrm{U}^{233}$ :tuff treatments. 
Sorption of $1500 \mathrm{~Bq}^{233} \mathrm{U}$ to $10 \mathrm{~g}$ of tuff in $\mathrm{NaOH}$ buffer was nearly complete ( $\left.>95 \%\right)$ after less than one hour, while only $\sim 25 \%$ of the ${ }^{233} \mathrm{U}$ sorbed in the presence of bicarbonate buffer in the same time period. The $2000 \mathrm{~Bq} / \mathrm{g}$ tuff treatment showed slightly greater than $50 \%$ sorption in $\mathrm{NaOH}$ solution and $<10 \%$ sorption in bicarbonate. Thus, $\mathrm{NaOH}$ was chosen as the sole addition to deionized water for the subsequent ranging experiments, as it appeared to cause no interference with sorption of ${ }^{233} \mathrm{U}$ at $\mathrm{pH} 7$.

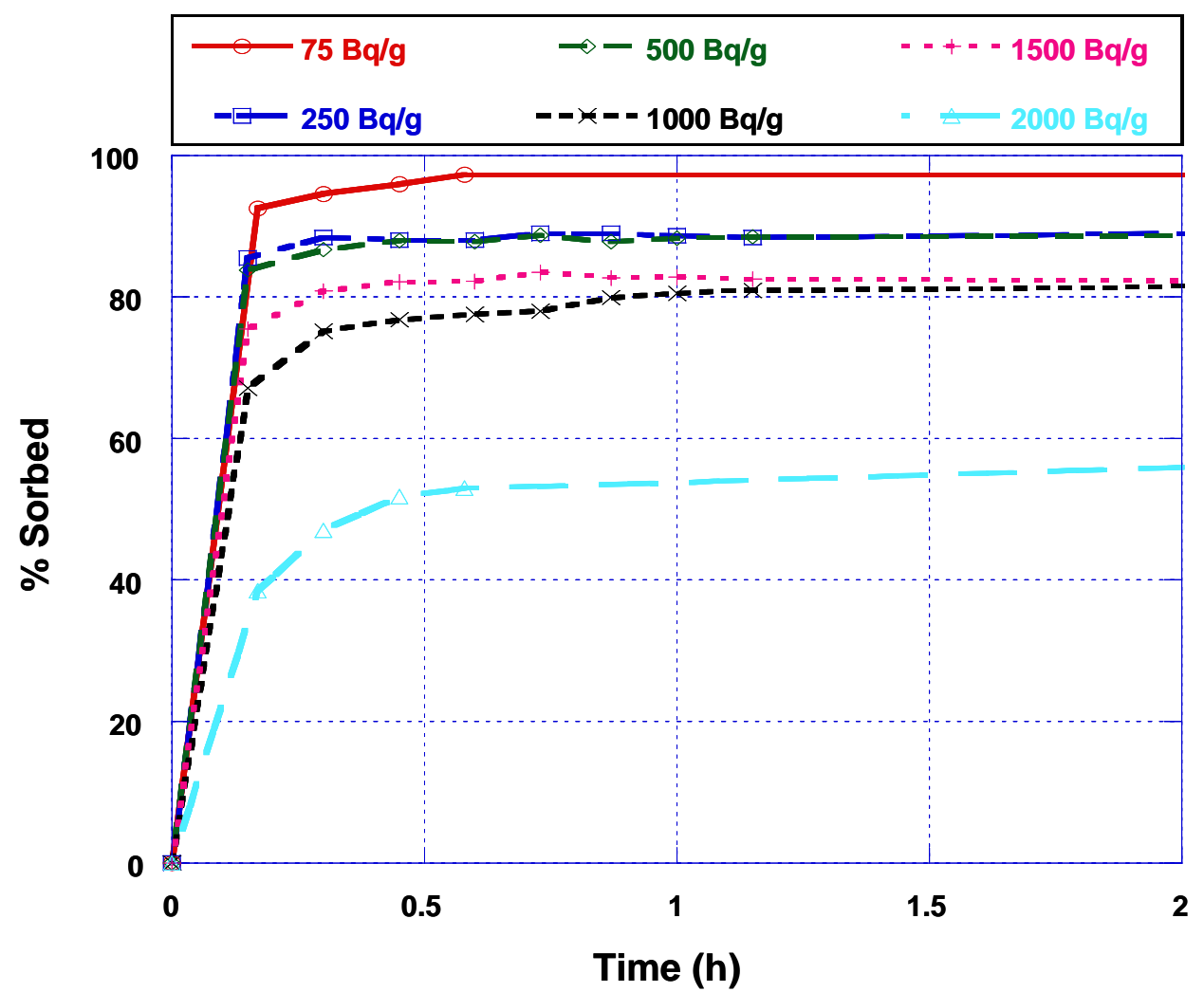

Fig. 5. Ranging experiment with variable ${ }^{233} \mathrm{U}$ to tuff ratios.

A significant difference in sorption kinetics and percent sorption between the two treatments with varying uranium to tuff ratios was observed. The effects of radionuclide:tuff were addressed in a ranging experiment with samples containing between $75 \mathrm{~Bq} \mathrm{~g}^{-1}$ tuff and $2000 \mathrm{~Bq}$ $\mathrm{g}^{-1}$ tuff. Experiments were conducted in deionized water adjusted to $\mathrm{pH} 7$ with $\mathrm{NaOH}$. All treatments reached their maximum sorption value within 2 hours of the addition of tuff (Figure 5). Equilibrium sorption values showed a general trend of decreasing with increasing radionuclide:tuff ratio. However, the amount of tuff present versus the ${ }^{233} \mathrm{U}$ :tuff seemed to be a more important factor. Equilibrium sorption percentages were nearly the same in samples with the same amount of tuff (e.g., 500 and $250 \mathrm{~Bq} / \mathrm{g}$ or 1000 and $1500 \mathrm{~Bq} / \mathrm{g}$ ).

Similar experiments were repeated in triplicate with tuff (UE12n15A) and water (U12n.10) collected from the NTS. Water was filtered with a $0.2 \mu \mathrm{m}$ filter for sterilized controls. Approximately $10 \%$ less sorption occurred in the NTS treatments, possibly due to the presence of carbonates in the natural water (Figure 6, NTS tuff). No significant differences were observed between the filtered and unfiltered samples. To remove the effects of carbonates, NTS samples 
were acidified and shaken to degas $\mathrm{CO}_{2}$. The $\mathrm{pH}$ was then adjusted to 5, 6, or 7 to examine the effects of $\mathrm{pH}$ on sorption. Sorption increased

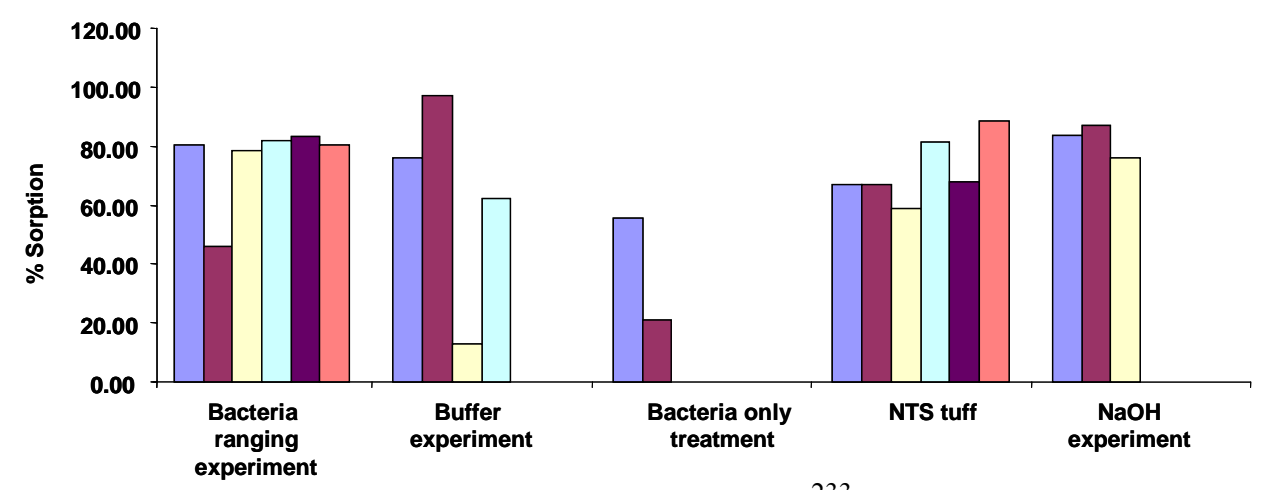

Fig. 6. Comparison of maximum $\%$ sorption of ${ }^{233} \mathrm{U}$ to tuff, bacteria, or both in various experimental treatments.

after removal of carbonates. This experiment also compared the effects of particle size on sorption. As expected, the smaller size fraction $(<75 \mu \mathrm{m})$ sorbed more ${ }^{233} \mathrm{U}$ than the larger fraction $(75-500 \mu \mathrm{m})$ due to greater surface area per weight. One experiment tested the sorption capability of variable cell densities of microbes only (Figure 6, Bacteria Only). The treatment with $10^{10}$ cells $\mathrm{mL}^{-1}$ sorbed approximately three times as much ${ }^{233} \mathrm{U}$ as the treatment with $10^{6}$ cells $\mathrm{mL}^{-1}$. A final experiment was conducted to compare to sorption potential of the generic tuff (Ward's) to the NTS tuff. NTS tuff with bacteria sorbed $\sim 10 \%$ less uranium than the generic tuff with or without bacteria (Figure $6, \mathrm{NaOH}$ experiment).

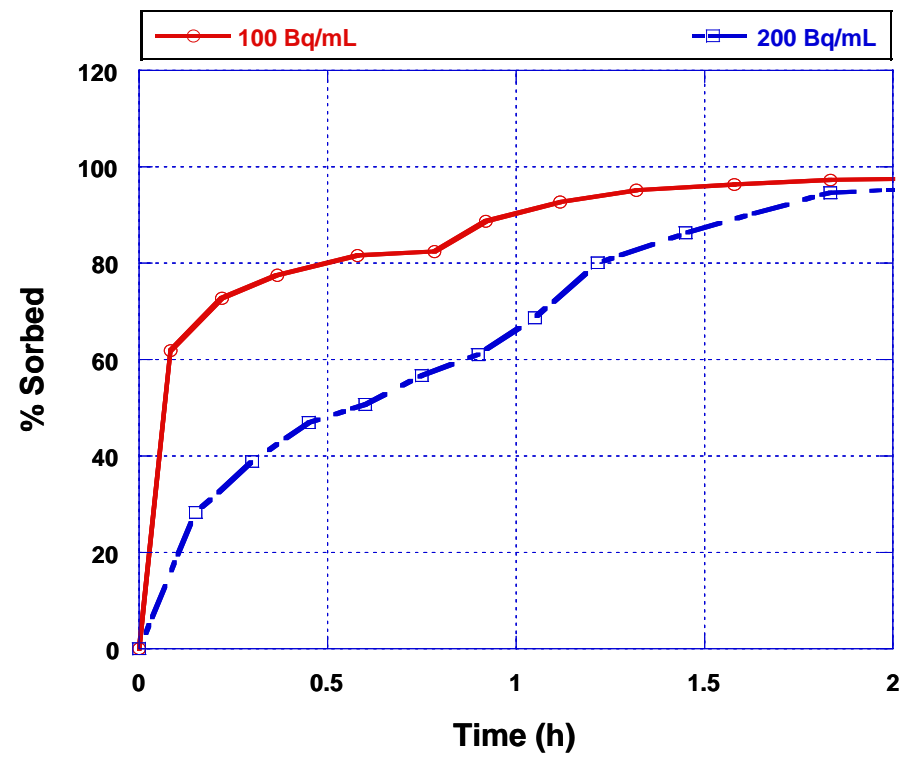

Fig. 7. Sorption of ${ }^{241}$ Am to tuff in bicarbonate buffer.

Figure 6 summarizes the maximum sorption of ${ }^{233} \mathrm{U}$ achieved in the various experiments. Few differences were seen among most treatments, with the most significant differences occurring between samples with or without tuff and samples that contained carbonates.

Sorption of ${ }^{241} \mathrm{Am}$

A similar set of experiments was conducted with americium, including variable buffers, ${ }^{241}$ Am:tuff ratios, and presence or absence of bacteria. The sorption kinetics of ${ }^{241} \mathrm{Am}$ were also rapid, but equilibrium sorption values tended to be higher than for ${ }^{233} \mathrm{U}$

(Figure 7) and were not affected by the presence of carbonates. 

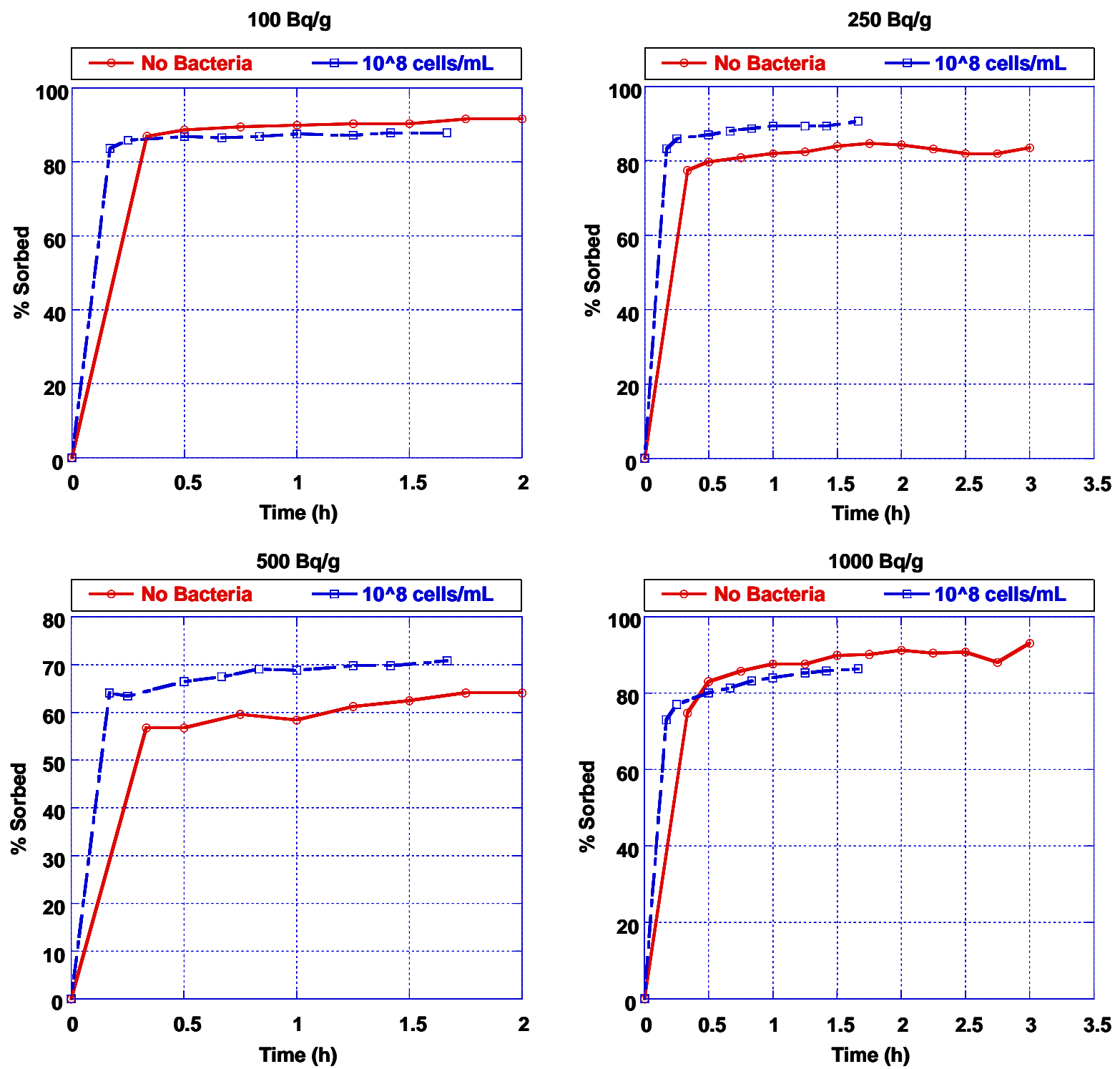

Fig. 8. Sorption of ${ }^{241} \mathrm{Am}$ to Ward Tuff in the presence or absence of bacteria.

The effects of bacteria on americium sorption were more notable for uranium (Figure 8). In the ranging experiment with ${ }^{241} \mathrm{Am}$ :tuff ratios of $100-1000 \mathrm{~Bq} / \mathrm{g}$, little effect was seen in the 100 or $1000 \mathrm{~Bq} / \mathrm{g}$ treatments, but an increase of $\sim 5-10 \%$ occurred in the presence of bacteria in the 250 and $500 \mathrm{~Bq} / \mathrm{g}$ samples (Figure 8). Bacteria sorbed $>60 \%$ of the americium present in samples without tuff (data not shown), which is significantly greater than uranium samples without tuff, indicating possible differences in sorption sites for the two radionuclides.

Distribution coefficients $\left(\mathrm{K}_{\mathrm{d}}\right)$

Distribution coefficients for ${ }^{233} \mathrm{U}$ and ${ }^{241} \mathrm{Am}$ were determined for all treatments. This coefficient is the ratio of the radionuclide concentration in the sorbed phase to the concentration in the aqueous phase. $K_{d}$ 's for ${ }^{233} \mathrm{U}$ ranged between $\sim 5-10$ and ${ }^{241} \mathrm{Am} K_{d}$ 's were similar. Bacteria had 
significantly higher Kds $\sim 10^{3}-10^{4}$ for ${ }^{233} \mathrm{U}$ and $10^{5}$ for ${ }^{241} \mathrm{Am}$. No significant differences were observed for the same treatments with and without bacteria, indicating that bacteria do not significantly affect sorption in batch experiments when present at relevant environmental concentrations.

\section{Conclusions and future directions}

Our experiments indicate that although the bacteria tested have a high affinity for americium and uranium, their effects are outweighed by the amount of tuff present in our samples. The dry weight of bacteria present in experiments with tuff was equal to $<0.1 \%$ of the total solids component, compared to work by Ohnuki et al. (2005) which used bacterial fractions of $0.5-10 \%$ of the total weight. This large disparity in cell density likely explains why we found a significantly smaller contribution from the bacteria than in their study. Experiments with only bacteria present showed that environmentally relevant amounts of cells could sorb $20-60 \%$ of radionuclide present. This indicates that bacteria may have a greater influence on sorption in the role of colloids or ligands that may facilitate radionuclide transport in groundwater systems. We plan to explore this possibility in column experiments containing a mix of radionuclides including $\mathrm{U}, \mathrm{Am}, \mathrm{Pu}$, and $\mathrm{Np}$.

\section{References}

Bruckner, J.C., Fisher, J. C., Lindval, R., Zavarin, M., Czerwinski, K., Russell, C., and D.P. Moser. 2009. Microbial communities of underground nuclear blast cavities. American Society for Microbiology, Philadelphia, PA.

Chardon, E.S., D. Bosbach, N.D. Bryan, I.C. Lyon, C. Marquardt, J. Romer, D. Schild, D.J. Vaughan, P.L. Wincott, R.A. Wogelius, and F.R. Livens. 2008. Reactions of the feldspar surface with metal ions: Sorption of $\mathrm{Pb}(\mathrm{II}), \mathrm{U}(\mathrm{VI})$ and $\mathrm{Np}(\mathrm{V})$, and surface analytical studies of reaction with $\mathrm{Pb}(\mathrm{II})$ and $\mathrm{U}(\mathrm{VI})$. Geochimica Et Cosmochimica Acta 72:288297.

Curtis, G.P., P. Fox, M. Kohler, and J.A. Davis. 2004. Comparison of in situ uranium K-D values with a laboratory determined surface complexation model. Applied Geochemistry 19:1643-1653.

Davis, J.A., G.P. Curtis, M.J. Wilkins, M. Kohler, P. Fox, D.L. Naftz, and J.R. Lloyd. 2006. Processes affecting transport of uranium in a suboxic aquifer. Physics and Chemistry of the Earth 31:548-555.

DOE. 2003. Contaminant Transport Parameters for the Groundwater Flow and Contaminant Transport Model of Corrective Action Units 101 and 102: Central and Western Pahute Mesa, Nye County, Nevada, pp. 464, In N. N. S. A. N. S. Office, (ed.).

Gajowiak, A., M. Majdan, and K. Drozdzal. 2009. Sorption of uranium(VI) on clays and clay minerals. Przemysl Chemiczny 88:190-196.

Giovannoni, S.J. 1991. The polymerase chain reaction, p. 177-203, In E. Stackebrandt, Goodfellow, M., ed. Nucleic Acid Techniques in Bacterial Systematics. John Wiley \& Sons., New York.

Gorman-Lewis, D., P.E. Elias, and J.B. Fein. 2005. Adsorption of aqueous uranyl complexes onto Bacillus subtilis cells. Environmental Science \& Technology 39:4906-4912. 
Humelnicu, D., G. Drochioiu, M.I. Sturza, A. Cecal, and K. Popa. 2006. Kinetic and thermodynamic aspects of U(VI) and Th(IV) sorption on a zeolitic volcanic tuff. Journal of Radioanalytical and Nuclear Chemistry 270:637-640.

Kazy, S.K., P. Sar, and S.F. D'Souza. 2008. Studies on uranium removal by the extracellular polysaccharide of a Pseudomonas aeruginosa strain. Bioremediation Journal 12:47-57.

Luo, J., F.A. Weber, O.A. Cirpka, W.M. Wu, J.L. Nyman, J. Carley, P.M. Jardine, C.S. Criddle, and P.K. Kitanidis. 2007. Modeling in-situ uranium(VI) bioreduction by sulfate-reducing bacteria. Journal of Contaminant Hydrology 92:127-146.

Marshall, M.J., Beliaev, A.S. Zachara, J.M.,Fredrickson, J.K. 2008. Biogeochemical mechanisms controlling reduced radionuclide particle properties and stability. PI Meeting, Environmental Remediation Sciences Program (ERSP), Lansdowne, VA.

Moser, D.P., and K.H. Nealson. 1996. Growth of the facultative anaerobe Shewanella putrefaciens by elemental sulfur reduction. Applied and Environmental Microbiology 62:2100-2105.

Moser, D.P., Russell, Bruckner, J.C., Fisher, J., C., Marshall, M., Czerwinski, C.,Daly, M.J., Zavarin, M. 2009. Characterization of microbial communities in subsurface nuclear blast cavities of the Nevada Test Site. PI Meeting, Environmental Remediation Sciences Program (ERSP), Lansdowne, VA.

Moser, D.P., Russell, C., Marshall, M., Czerwinski, C.,Daly, M.J., Zavarin, M. 2008. Characterization of microbial communities in subsurface nuclear blast cavities of the Nevada Test Site. PI Meeting, Environmental Remediation Sciences Program (ERSP), Lansdowne, VA.

Myers, C.R., and K.H. Nealson. 1988. Bacterial Manganese Reduction and Growth with Manganese Oxide as the Sole Electron Acceptor. Science 240:1319-1321.

Nancharaiah, Y.V., H.M. Joshi, T.V.K. Mohan, V.P. Venugopalan, and S.V. Narasimhan. 2006. Aerobic granular biomass: a novel biomaterial for efficient uranium removal. Current Science 91:503-509.

Ohnuki, T., T. Yoshida, T. Ozaki, M. Samadfam, N. Kozai, K. Yubuta, T. Mitsugashira, T. Kasama, and A.J. Francis. 2005. Interactions of uranium with bacteria and kaolinite clay. Chemical Geology 220:237-243.

Renshaw, J.C., J.R. Lloyd, and F.R. Livens. 2007. Microbial interactions with actinides and long-lived fission products. Comptes Rendus Chimie 10:1067-1077.

Smith. D.K., A.B. Kersting, Rose. T.I., J.M. Kenneally, G.B. Hudson, G.F. Eaton, and M.L. Davisson. 1998. Hydrologic resources management program and Underground Test Area operable unit FY 1997 progress report. Lawrence Livermore National Laboratory, Livermore, CA. 
10. Appendix 3: Transport Modeling and Experiment

DOE/EPSCOR FINAL REPORT

Project Title: Investigation of the Fundamental Surface Reactions Involved in the Sorption and Desorption of Radionuclides

UNR Investigation

Analysis of Adsorption and Migration Behavior of Contaminants in Aqueous Phase through

Desert Soil Porous Medium

Submitted by: Dr. M. Misra

Department of Chemical \& Metallurgical

Engineering

University of Nevada, Reno

Reno, Nevada 89557 


\section{ABSTRACT}

The main focus of this pro ject was to investigate transport an $\mathrm{d}$ adsorption of contaminants (radionuclide) on loamy desert soil through modeling the system by the Finite Element Method (FEM) and verification using experim entation. The Advective dispersion reaction (A DR) mechanism and pore diffusio $\mathrm{n}$ model were em ployed to describe the contam inant transport and adso rption in soil $\mathrm{m}$ edium. Partial Dif ferential Equations (PDE) obtained from unsteady st ate mass balance cons isted of convective diffusion, solute adsorption, and dispersion terms for the ADR equation (ADRE). In pore diffusion models, the shape of the soil partic les were assumed to be spherical and mass balances were performed on the soil phase as well as on the liquid phase. Equilibrium and kinetic experiments were conducted using lead as a surrogate radionuclide. Initial batch equilibrium adsorption experim ents revealed that the system follows Lan gmuir adsorption isotherm. The diffusion coeffici ent was evaluated by nonlinear regression analysis on kinetic experimental data, which was used as a param eter in the ADRE. The other required param eters for the $\mathrm{m}$ odel such as Langmuir constant and $\mathrm{m}$ aximum adsorption capacity of the adsorbent were evaluated from batch experiments. Darcy's law was coupled with the continuity equation to calculate the pressure drop along the length of the colu mn and the velocity. Adsorpti on isotherm equation and Darcy's law was internally coupled with “Advective Dispersion Reaction” Equation and the resulting set of unsteady non linear P artial Difference Equation (PDE) were solved using “ COMSOL MULTIPHYSICS - 3.2". 


\section{$\mathcal{T} \mathcal{A B} \mathcal{L} \mathcal{E} O \mathcal{F} C O \mathcal{N} \mathcal{T} \mathcal{E} \mathcal{N} \mathcal{T S}$}

\begin{tabular}{|c|c|}
\hline SECTION & PAGE \\
\hline Abstract & ii \\
\hline Table of contents & iii \\
\hline List of tables & iv \\
\hline List of figures & $\mathrm{v}$ \\
\hline \multicolumn{2}{|l|}{ 1. Introduction and Background } \\
\hline 1.1. Background & 1 \\
\hline 1.2. Impact on Ground water & 5 \\
\hline 1.3 Radionuclide contaminates in the Nevada Test Site & 5 \\
\hline 1.4 Precipitation in Nevada Test Site & 7 \\
\hline 1.5 Scope and Importance & 8 \\
\hline 1.6 Radionuclide Interaction with the Environment & 10 \\
\hline 1.7 Solution and Oxidation States of Radionuclides & 11 \\
\hline 1.8 Solubility of actinides & 13 \\
\hline 1.9 Sorption at the soil solution Interface & 13 \\
\hline 1.10 Background & 14 \\
\hline 2. Experimentation & 21 \\
\hline $2.1 \quad$ Nevada Test Soil properties & 21 \\
\hline 2.2 Selection of Contaminate for Experiments & 23 \\
\hline 2.3 Batch equilibrium experiments at different temperatures & 26 \\
\hline 2.4 Batch kinetics experiments & 26 \\
\hline 2.5 Batch experiments at different $\mathrm{pH}$ & 27 \\
\hline 2.6 Column Experiments & 27 \\
\hline 2.7 Determination of porosity of the soil medium & 31 \\
\hline 2.8 Determination of soil bed density & 31 \\
\hline 3. Modeling & 32 \\
\hline 3.1 Bulk phase contaminate transport modeling & 32 \\
\hline 3.2 Pore Diffusion Modeling & 32 \\
\hline 3.3 Darcy's Law & 33 \\
\hline 3.4 Advective Dispersion Reaction Equation & 34 \\
\hline 3.4.1 Advective Transport equation & 34 \\
\hline 3.4.2 Dispersive transport & 36 \\
\hline 3.4.3 Sorption term in the Advective dispersion transport equation & 38 \\
\hline 3.4.4 Adsorption dynamic modeling using pore diffusion model & 41 \\
\hline 4. Modeling using Comsol Muiltiphysics -3.2 & 44 \\
\hline 4.1 Comsol Multiphysic and Finite Element Method & 44 \\
\hline 4.2 Solution to Advective Dispersion Reaction Equation & 45 \\
\hline 4.2.1 Geometry of the system: & 46 \\
\hline
\end{tabular}




\begin{tabular}{|l|l|}
\hline 4.2.2 Meshing & 47 \\
\hline 4.2.3 Solver settings & 48 \\
\hline 4.2.4 Post processing & 48 \\
\hline 4.3 Solution to pore diffusion model & 49 \\
\hline 4.3.1 Geometry and meshing & 49 \\
\hline 4.3.2 Solver settings & 51 \\
\hline 4.3.3 Post processing & 51 \\
\hline 5 Results and Discussion & 52 \\
\hline 5.1 Effect of Temperature on adsorption Equilibrium & 52 \\
\hline 5.1.1 Effect of pH on adsorption Equilibrium & 54 \\
\hline 5.1.2 Thermodynamics of adsorption & 56 \\
\hline 5.2 Kinetics of Adsorption process & 58 \\
\hline 5.2.2 Simulation using Comsol Multiphysics - 3.2 & 59 \\
\hline 5.2.3 Initial and boundary conditions & 60 \\
\hline 5.2.4 Simulation results & 62 \\
\hline 5.2.5 Parametric study of Adsorption dynamic & 64 \\
\hline 5.2.6 Effect of initial concentration on adsorption dynamics & 66 \\
\hline 5.3 Experimental and Simulation Results of column experiments & 68 \\
\hline 5.3.1 Initial and boundary conditions & 68 \\
\hline 5.3.2 Quantitative evaluation of migration behavior & 71 \\
\hline 5.3.3 Effect of bed thickness & 72 \\
\hline 5.3.4 Effect of inlet concentration & 73 \\
\hline 5.3.5 Effect of adsorption Coefficient & 75 \\
\hline Conclusion & 77 \\
\hline Reference & 78 \\
\hline & \\
\hline
\end{tabular}




\begin{tabular}{|l|c|}
\hline \multicolumn{1}{|c|}{ Table Name } & $\begin{array}{c}\text { Page } \\
\text { number }\end{array}$ \\
\hline I. $\quad$ Oxidation states of the most common actinides. & 12 \\
\hline II. Physical Properties of the Nevada test soil & 22 \\
\hline III. Chemical Composition and properties of Nevada test soil & 22 \\
\hline IV. Meshing statistics for ADRE model & 48 \\
\hline V. Meshing statistics for Pore diffusion model & 49 \\
\hline VI. Langmuir isotherm parameters evaluated at different temperatures & 54 \\
\hline VII. Langmuir isotherm parameters evaluated at different pH conditions & 55 \\
\hline VIII. Change in Gibbs free energy at different temperature & 57 \\
\hline IX. Parameters and constants for the pore diffusion model & 60 \\
\hline X. Initial and Boundary conditions for ADER model & 61 \\
\hline XI. Values for Parameters and constants & 69 \\
\hline XII. Initial and Boundary conditions for Pore diffusion Model & 70 \\
\hline
\end{tabular}




\section{LIST OF FIGURES}

\begin{tabular}{|c|c|}
\hline Figure name & Page number \\
\hline 1 Area of potential ground water contamination in Nevada Test Site & 4 \\
\hline 2 Graphical representation of contaminate flow through rain water & 6 \\
\hline $\begin{array}{l}3 \text { Schematic overview of reactions of radionuclide in a natural } \\
\text { environment }\end{array}$ & 10 \\
\hline 4 Eh-pH diagram for Lead water system & 24 \\
\hline 5 Eh-pH Diagram for water Uranium system & 25 \\
\hline 6 Photograph of the column experimental setup & 28 \\
\hline 7 Schematic representation of the column experimental set up & 29 \\
\hline 8 Solute mass transport in the porous medium & 34 \\
\hline 9 Dispersion of fluid around solid particles in the porous medium & 36 \\
\hline 10 Representation of the element in the porous medium & 37 \\
\hline 11 Geometry of the column & 46 \\
\hline 12 Triangular meshing of the geometry & 47 \\
\hline 13 Geometry represents the radius of the particle & 50 \\
\hline 14 Meshing the geometry of the pore diffusion model & 50 \\
\hline $\begin{array}{l}15 \text { Equilibrium Isotherms for the batch adsorption experiments solid } \\
\text { lines: Langmuir Curve fit, points: experimental data }\end{array}$ & 53 \\
\hline $\begin{array}{l}16 \text { Langmuir fit to batch adsorpti on data for the different } \mathrm{pH} \\
\text { conditions }\end{array}$ & 55 \\
\hline 17 Van't Hoff plot for lead adsorption on Nevada test soil clay & 56 \\
\hline 18 Kinetic batch experimental results & 58 \\
\hline 19 Representation of particle radius in one dimension & 61 \\
\hline $\begin{array}{l}20 \text { Concentration distribution insi de a particle at different } \\
\text { temperature }\end{array}$ & 62 \\
\hline $\begin{array}{l}21 \text { Adsorption dynamic data fitted to pore diffusion model equations } \\
\text { and modeling results for different } K_{d} \text { values }\end{array}$ & 64 \\
\hline 22 Simulation results after $3 \mathrm{hr}$ for different $K_{d}$ values & 65 \\
\hline 23 Bulk phase concentration profile at different initial conditions & 67 \\
\hline 24 Boundaries of the geometry representing the column & 69 \\
\hline 25 Simulated Lead Concentration Distribution in the column & 71 \\
\hline 26 Break through curve at various bed thicknesses & 72 \\
\hline 27 Effect of inlet adsorbate concentration on break through curve & 74 \\
\hline $\begin{array}{l}28 \text { Break through curves for different values of adsorption } \\
\text { coefficient }\end{array}$ & 75 \\
\hline
\end{tabular}




\section{CHAPTER 1}

\section{INTRODUCTION AND BACKGROUND}

\subsection{Background}

The Nevada Test Site (NTS) was considered a unique national resource; it was a massive outdoor laboratory and national experim ental center for nuclear weapon testing. Thousands of acres surrounding the site are abandoned from public dom ain for use as a protected wildlife range and for a military gunnery range, creating an unpopulated land area comprising some 5,470 square $m$ iles [1]. The Nevada test site is four tim es larger than the State of Rhode Island, approximately 1,375 square miles.

Established as the Atom ic Energy Commission's on-continent proving ground, the Nevada Test Site has seen m ore than four decades of nuclear weapons testing. Sin ce the nuclear weapons testing moratorium in 1992 and under the direction of the Department of Energy (DOE), the test site use has dive rsified into $m$ any other programs such as hazardous chemical spill testing, emergency response training, conventional weapons testing, and waste management and environmental technology studies [1].

Larger than many small countries, the Nevada Test Site offers an enormous a mount of space, including more than a 1,000 $\mathrm{m}$ iles of completely undisturbed land available for new projects. The vast site also offers security, as boundary and security areas are guarded, and the area is far from population centers [1]. 
The first underground nuclear test at the NTS was conducted on Septem ber 19, 1957 (DOE, 1994). Underground nuclear testing conducte $d$ at the Nevada test site included a total of 908 tests in the shaft and tunnels at the depths ranging from 27 to 1452 meters ( 89 to 4764 feet) below ground level. $\mathrm{T}$ he underground nuclear tests we re conducted at 878 locations, some of which contained $\mathrm{m}$ ultiple tests. Of tho se, 717 were conducted in th $\mathrm{e}$ Yucca Flat, ten in Frenchm en Flat, 18 in the Western Pahute Mesa, 64 in Central Pahute Mesa,66 in the Rainier Mesa/Shoshone m ountain area, and three were conducted near or below the water table and have introduced contaminants into the NTS ground water (IT,1996g).

This legacy of nuclear testing has resulted in the contamination of groundwater in som e areas. The Underground Test Area (UGTA) subproject addresses groundwater contamination resulting from historic underground nuclear testing conducted by the U.S. Department of Energy at the Nevada Test Site.

The total mass of radioactive elements that are present following an underground nuclear detonation is called the radi ologic source term. The $\mathrm{m}$ inor portion of the radiologic source term that is no $t$ tightly contained within the melted rock and $m$ etal residue, and which can be dissolved or transported with ground water, is called the hydrologic source term. Only lim ited information based upon actua 1 field data is available regarding the actual composition of the hydrologic source te $\mathrm{rm}$. The three predom inant types of the potential contaminants associated with the source term are in-s itu material or those contained within the device which have not undergone fission or thermonuclear reaction; direct product of the nuclear reaction, su ch as fission produc ts and radionuclides 
produced by activation of the fuel, material used within the test, and those injected into the surrounding geologic layer during the nuclear test. Larger quantities of materials used to support the test were introduced into th e shaft or tunnels (Bryant and Fabrika Martin,1991). These materials include steel used to support th e device, lead and magnetite used as shielding $\mathrm{m}$ aterial, and cement grave 1 to back $\mathrm{f}$ ill the opening. In addition, nuclear devices comm only contained fissionable radioactive elem ents in the critical mass for detonation. These elem ents included uranium, plutonium, tritium, and lithium. Small amounts of radiochemical detectors were also u sed. Incomplete consumption of these radioactive $\mathrm{m}$ aterials during detonation from testing would leave them within the surface for potential leaching to ground.

Currently, there is no technology available th at would allow for the cleanup of deep, extensive groundwater contamination. Knowing that cleanup is not feasible, the Nevada Site Office's strategy is to identify contam inant boundaries and im plement an effective, long-term monitoring system.

The first phase of the strate gy (already com plete) consisted of a regional evaluation, which explored the groundwater pathways over the entire Nevada Test Site. The second phase (currently in progress) will help sc ientists determine contaminant movement and the boundaries that are unique to each of the underground test areas. Both of these phases incorporate various com ponents, such as sampling, contaminant characterization, computer modeling, and process validation. [1] 


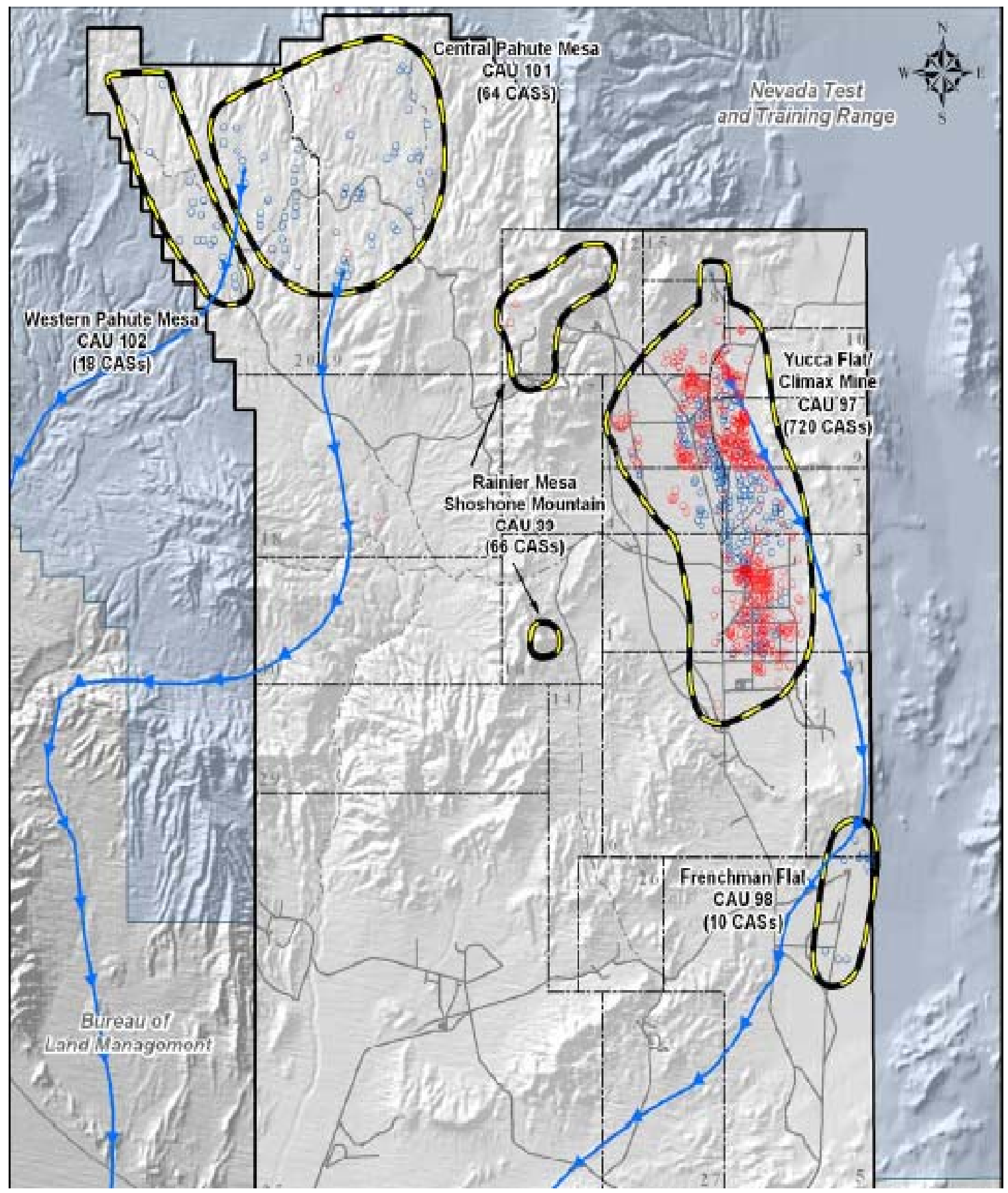

Figure-1: Area of potential ground water contamination in Nevada Test Site [2] 


\subsection{Impact on Ground water:}

During detonation of tests c onducted at or below the wa ter table, groundwater is evacuated from the shot cavity and then seep s back into the cavity after the denotation. As the water seeps back into the cavity and rubber chimney, leaching of radionuclides to the ground water begins. Radionuclides are also introduced into the ground water through the prompt injection that occurs during the detonation. Ground water $\mathrm{m}$ ight also impact from the tests conducted in the vadose $\mathrm{z}$ one through leaching of radionuclides by downward percolating precip itation and surface runoff through the chim ney. Another mode of ground water contam ination is through rain water mobilization of radionuclides which is comm only found in th e rainfall region of the $\mathrm{Ne}$ vada test site. Figure-2 represents the $\mathrm{m}$ igration of radionuclides through rain water. Loosely attached radionuclide to soil can easily be ionized by the rainwater which pe rcolates through the porous structure of the desert so il; as a result, soil lay ers away from the tested lo cation will be contaminated because of the strong retention capacity of the soil. [1]

\subsection{Radionuclide contaminates in the Nevada Test Site:}

The ground water is monitored by DOE for common radioactive nuclides such as tritium $\left[{ }^{3} \mathrm{H}\right]$, gross alpha rad ioactivity ,gross be ta activity gamm a - e mitting radionuclides, plutonium-228 $\left[{ }^{228} \mathrm{Pu}\right]$, plutonium $-239+240\left[{ }^{239+240} \mathrm{Pu}\right]$ Carbon-14 $\left[{ }^{14} \mathrm{C}\right]$, Strontium-90 $\left[{ }^{90} \mathrm{Sr}\right]$, Technetium-99 $\left[{ }^{99} \mathrm{Tc}\right]$. Most of these are genera ted by the subs urface tests and they are short lived, having grea ter potential to sorb onto the soil surface. Some of these species like tritium, plutonium -228 , plut onium-[239+240], isotopes of uranium are created in the greatest quantities found to be highly mobile. These represent the 


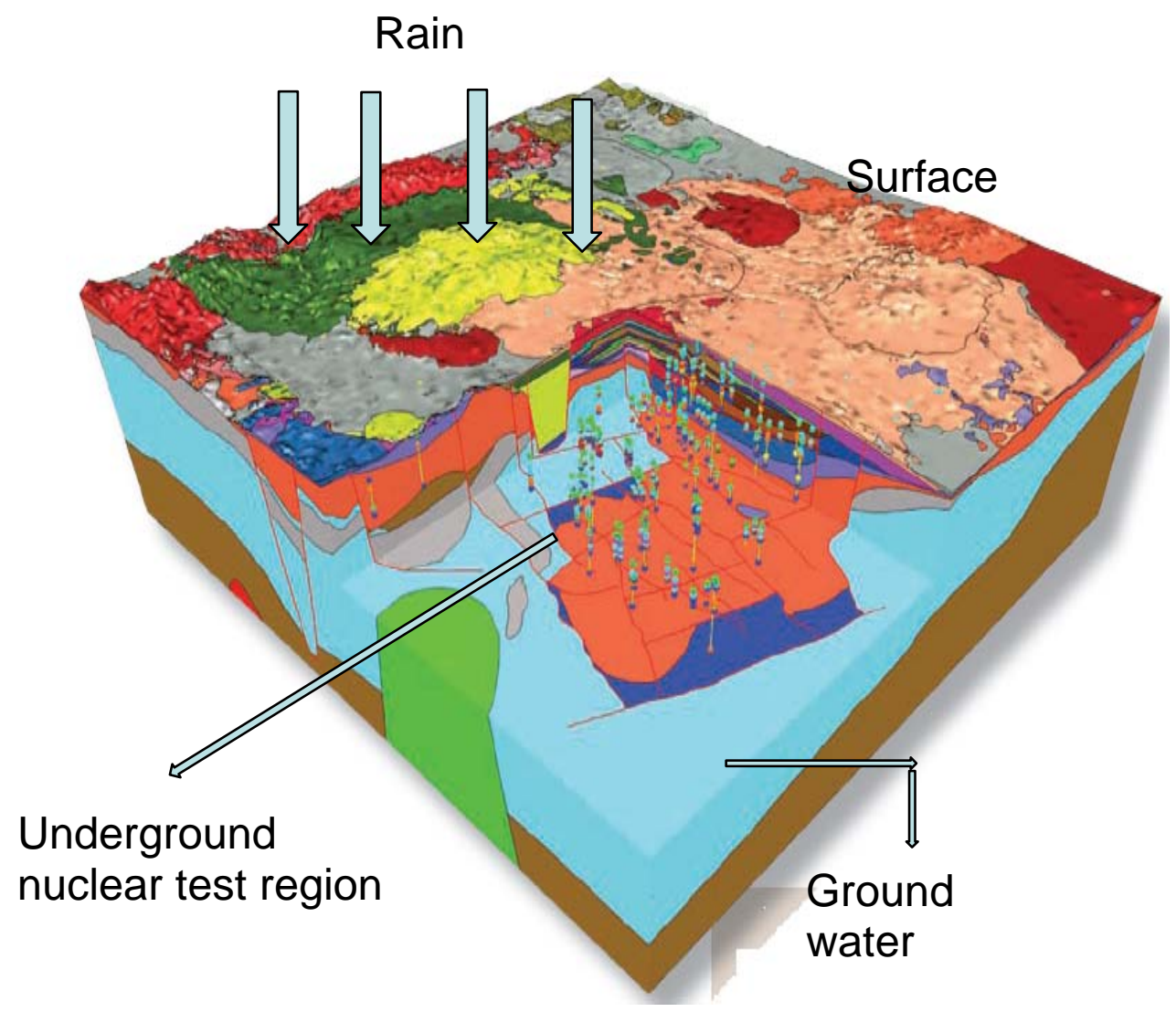

Figure - 2: Graphical Representation of Contaminate flow through rain water

greatest concerns for the ground water users on and around the Nevada test sites for at least the next 100 years due to high mobility and concentration.

Radionuclides are generally classified as $\mathrm{m}$ an-made and natural both contribute to the gross alpha and beta radioactivity in the NT S. The alpha radiati on is basically from isotopes of uranium and radium $-226\left[{ }^{226} \mathrm{Ra}\right]$ and beta radiation is from radium-228 
$\left[{ }^{228} \mathrm{Ra}\right]$ and potassium $-40\left[{ }^{40} \mathrm{~K}\right]$. W ater sample were collec ted and analyze $\mathrm{d}$ for manmade and natural radionuclides from DOE. Man made radionuclides includes americium $-241\left[{ }^{241} \mathrm{Am}\right]$, cesium- $137\left[{ }^{137} \mathrm{Cs}\right]$, cobalt- $60\left[{ }^{60} \mathrm{Co}\right]$, and europium $-152\left[{ }^{152} \mathrm{Eu}\right.$ and $\left.{ }^{154} \mathrm{Eu}\right]$. Species like actin ium-228 $\left[{ }^{228} \mathrm{Ac}\right]$, lead-212[$\left[{ }^{212} \mathrm{~Pb}\right],{ }^{40} \mathrm{~K}$, Uranium-235[ $\left.{ }^{235} \mathrm{U}\right]$, and thorium-234[ $\left[{ }^{234} \mathrm{Th}\right]$ are classified as natural radionuclides. [5]

\subsection{Precipitation in Nevada test site:}

Rain fall in the Nevada Test site is dr iven by two fundam ental physical processes resulting from the cool season, $\mathrm{m}$ id troposphere cyclones and those from summertime convection. Cool season preci pitation consists of rain or snow where as summ er precipitation is associated with of heavy rain fall and, flash flood, intense cloud to ground lightning. Mean annual precipitation totals on the NTS range from nearly 13 inches in Frenchmen flat. However, inter-annual variations can be great. For example, 9.67 inches fell in 1998 only 1.14 fell in 1989. On, average, annually, only 4.8 inches of precipitation are measured at well 5B in area 5, eleva tion 3080ft, while an annual average of 12.82 inches occurs on Rainier Mesa, elevation 7490ft. Annual totals of less than 1.0 inch have occurred over the lower elevation of the Nevada Test Site. Daily pre cipitation totals can also be large and can range from 2.0 to ove $\mathrm{r} 3.5$ inches. The highe st daily precipitation event on the NTS was 3.77 inches which was measured at the Rock Valley on September 21, 2007. A storm-total precipitation amount of 3.5 inches is a 100 years, $24 \mathrm{hr}$, extreme precipitation event. Two to three inch daily totals have been measured at the several sites on the NTS. Figure -2 represents the effect of rainfall on any area in the NTS region. 
Snow can fall on the NTS between October and May. In Yucca Flat, the highes t daily snow depth measured was 10inchs in January 1974. The greatest daily depth m easured at the Desert Rock is 6 inches in the Februa ry 1987. Maximum daily totals of 15 to 20 inches or more can occur on Pahute and Rainier Mesas.

The U.S Departm ent of Energy an d Regulatory agencies are m ore concern about the potential for the contam ination migration from area of past underg round tests due to contaminate leach into the rain water which in turn flow to the ground water. Hence more emphasize is given to understand the adsorp tion and $\mathrm{m}$ igration of radionuclides in Nevada test site soil. [3]

\subsection{Scope and Importance:}

One of the most difficult environmental problems facing scientists in this industrial world is pertaining to the ground water contam ination. A wide variety of contaminates ranging from solvent, heavy metals and radionucli des, can leak from tanks of underground nuclear tests. This kind of problem has a common need to demonstrate the understanding migration behavior in porous $\mathrm{m}$ edium of the NTS soil where th ere are very lim ited opportunity for experimentati on and observation. Hence, solution to the ground water contamination problems relies extensively on numerical models of flow and $\mathrm{m}$ igration. Great advances in both theore tical and applied areas of num erical modeling have been made in rec ent years, driven in large part by advances in com puter resources. This has enabled sophisticated incorporation of equation and variable coupling, complex nonlinear regression analysis in all tim e dependent an alysis of adsorption and diffusion transport models of radionuclides through use of finite element modeling (FEM) technique. [4] 
During the past two decades, hydrologists commonly used adsorption transport models to predict the numerical contaminate migration. These studies made it clear that insufficient data limit the model's estimation of the system's behavior without suitable assum ptions. Usually the m odeling predictions are approxi mate results to the na turally occurring phenomena. Uncertainty is always inherent in the model prediction and is the result of the inability to fully characterize the migration behavior and the processes controlling the system behavior. Complete characterization is restricted by acces s to the sub surface, which requires extensive borehol e drilling that can advers ely affect the integrity of the geologic structure of the site or be prohibitively expensive. [4]

The advances in num erical computational resources made in the past decade $h$ ave elevated the level of complexity of numerical and analy tical solutions to contam inate transport models to such a high level that a gap has been created between $\mathrm{m}$ odel results and confident assessment of the accuracy (or at least relevance) of model simulations by regulators and the pub lic. The acceptance of the model results by the regulators and the public is an essential p rerequisite to clos e subsurface contaminated sites. Hence, new models have to be developed and im provements over pre-existing $\mathrm{m}$ odels need to be done by overcoming the limitations and minimizing the assumptions results in the mimic of the actually physical phenomena. 


\subsection{Radionuclide Interaction with the Environment:}

Most of the radionuclides produced in th e nuclear fuel cycle are short lived. The actinides formed by the neutron capture reaction are long lived, and are of major concern for the long term risk for human health. The light actinides (U, Np, Pu, Am, Cm) exhibit complex chemistry with the hundreds of chem ically active compounds and minerals in the environmental systems. Some of the light actinides under go reduction oxidation reactions and exist in two or $m$ ore oxidation states[6][7]. In each oxidation state, the actinides have a characteris tic chemical reactivity and form complex solids of different stability and solubility. The in teraction of actinides with the environment is a complex phenomenon and various possible reactions are represented in the following Figure-3. [5]

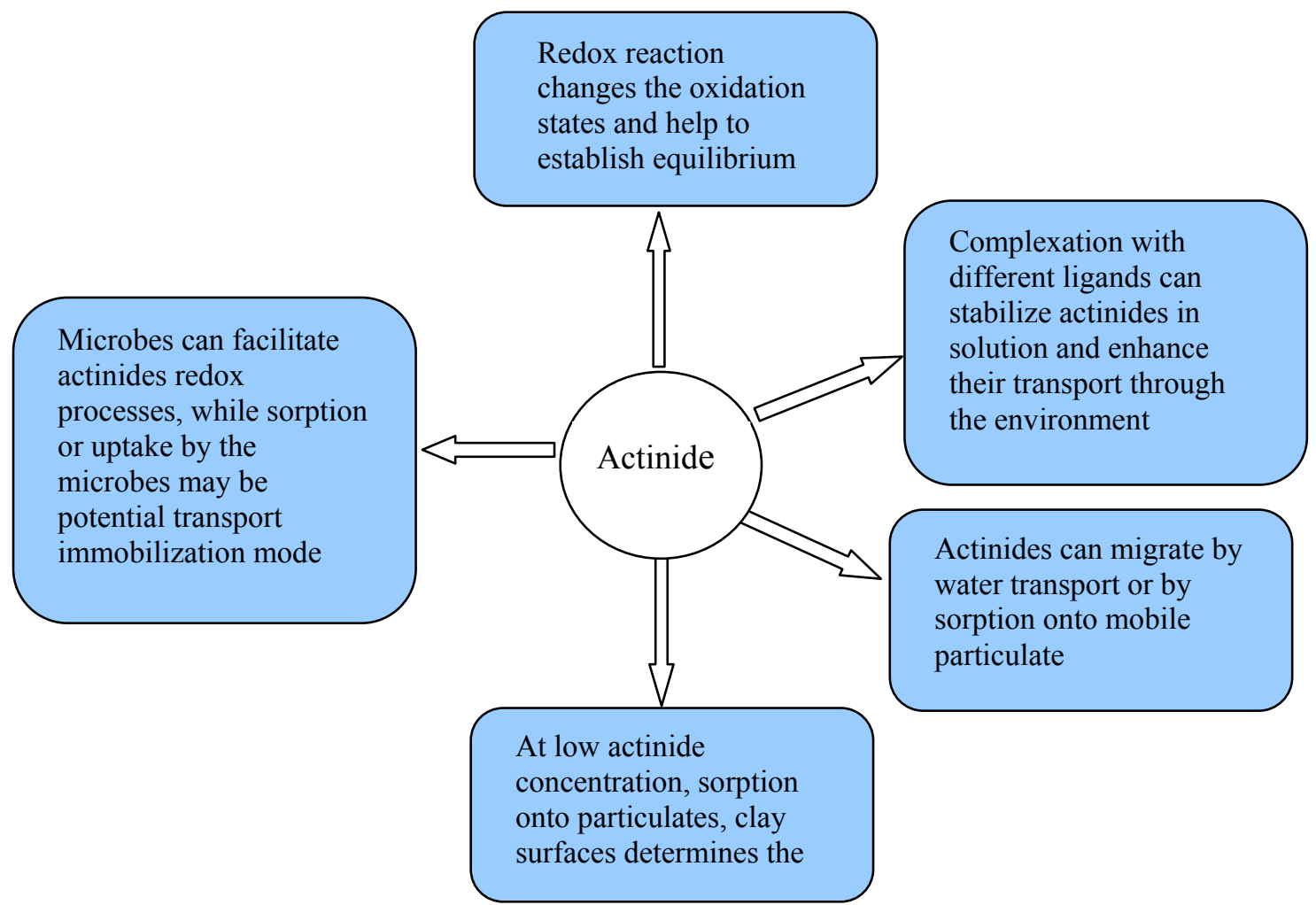

Figure-3: Schematic overview of reactions of radionuclide in a natural environment. [5] 
There are many other $\mathrm{w}$ ays in which the actin ides can in teract with the soil which are much more difficult to understand. It is necessary to pred ict how fast these nuclides might migrate in the specific environm ent and ch aracterize the environmental components, including natural minerals and soil and local conditions like tem perature, pressure profiles, $\mathrm{pH}$, ion con centration for the purpose of cl eaning up and safe disposal of nuclides [7]. The present work is prim arily focused on actinide $m$ igration by water transport and sorption on to an immobile phase (soil phase).

\subsection{Solution and Oxidation States of Radionuclides:}

Water is the major mode of transportation for the actinides in the environment. The $\mathrm{pH}$ of the naturally available water is relatively mild around 6-9 but has wide range of reduction oxidation potential and low salinity (ionic st rength less then $1 \mathrm{M}$ ). Solution containing radionuclides are enriched with chem icals. The natural water is e ither highly acidic or basic depending upon the type of ions exist. When this kind of solution interacts with soil it alters the surface functional group present on the soil that greatly controls the migration characteristics of the actinides. Adso rption of contaminates by ion exch ange mechanism covers the soil and minerals and in turn changes the geochemistry of the environment.

Most of the actin ides, like $\mathrm{U}, \mathrm{Np}$, and Pu readily disso lve in water and can exist in different oxidation states in the same solution. The behavior of multiple appearances is of significant for the transport characteristics of reduction oxidation sensitive actinides. For example plutonium can coexist in four differe nt oxidation states under certain conditions 
of $\mathrm{pH}$ and temperature. The oxidation states of some of the commonly found actinides are given in the Table-I.

\begin{tabular}{|c|c|c|c|c|c|}
\hline Th P: & & $\mathbf{N p}$ & $\mathbf{P u}$ & Am & $\mathbf{C m}$ \\
\hline III & \multicolumn{2}{|c|}{ III III III } & & \multicolumn{2}{|c|}{ III III } \\
\hline \multirow[t]{3}{*}{ IV } & IV & \multicolumn{2}{|c|}{ IV IV } & IV & IV \\
\hline & $\mathbf{V}$ & $\mathrm{V}$ & $\mathbf{V}$ & $\mathrm{V}$ & \\
\hline & & \multicolumn{2}{|c|}{ VI III } & VI & \\
\hline & & & VII & & \\
\hline
\end{tabular}

Table-1. Oxidation states of the most co mmon actinides. The environ mentally most important oxidation states are bolded.

Actinides in each oxidation state have different behavior, as an example the actinides in III and IV oxidation state for $\mathrm{m}$ hydrated ions and in V and VI the actin ides are highly cationic, they hydrolyze in stantly to for $\mathrm{m}$ linear Trans - dioxo (actinly) cations. Temperature and $\mathrm{pH}$ are the two im portant factors which control the speciation of the actinides in the solution phase. Pourbaix (Eh-pH) diagrams explain the oxidation stability of the actinides based on therm odynamic calculations. It acts as a tool to determ ine the existence of the species at different $\mathrm{pH}$. Usually, lower oxidation states are more stable in the lower $\mathrm{pH}$ range and higher oxidations states are more stable in the $\mathrm{pH}$ range. 


\subsection{Solubility of actinides:}

Intensive knowledge on solubility of actinid es in water is required to understand the transport behavior of the radionuclides. The maximum concentration of the actinide ions are limited by the solubility of the actinide com pound. In order to understand the solubility of actinides in water or any solvent the following factors need to be studied. The composition and solubility product of the solid phase, the com plex compounds that are formed in the solution and th eir stability constants, the concentration of the ligands formed and cations that are competing for ligand coordination. Thermodynamic stability of the species is intensively studied through well defined experimental procedures under different relevant conditions. Speciation diag rams which are basically solid liquid phase equilibrium diagrams explain the existence of various species at particular $\mathrm{pH}$ for constant temperature [7].

\subsection{Sorption at the soil solution Interface:}

In the rainfall region of the Nevada Test Site, the infiltration of rain water can d issolve most of the freely available actinid es in the pore space of the soil $\mathrm{m}$ edium. Water is a solvent which has a maxim um solubility for various salts. The actinide com pounds readily ionize in water and exhibit differe nt oxidation states depending upon $\mathrm{pH}$ and Eh. These ions and complex compounds formed move along water transport paths, eventually comes in contact with the various chemical active surfaces and minerals. Sometimes this interaction leads to favorable chemical reactions or physical sorption of the actinides ions on the surface of the solids (so il, minerals) [8] [9]. More often the functional group, properties are reorganized by the complex reactions on the mineral surface in turn greatly affect the transport mechanism of the actinides. 


\subsection{Back ground:}

T. Tanaka, H.Ogawa, and group have studied m igration behavior of Am (III) on sandy soil and reddish soil through column and batc h experiments [10]. Simple thermodynamic linear equilibrium relations were e mployed with the solute migration model to describe the retardation process of the actinides. They concluded that the adsorption of Am (III) on the sandy soil was controlled by irreversible reactions, whereas on reddish so il it was controlled by reversible ion-exchange reactions. L.Bergaoui, J.F Lamert and others have investigated cesium adsorption on soil clay [11]. Macroscopic data from batch adsorption experiments were combined with the microscopic data such as structure of the selectivity sites on which cesium adsorbed. They reported that the clay and cesium solution follows the Freundlich type of isotherm. Another group F. Ginannakopulou , C. Haidouit and team have worked on cesium and sandy loam, clay loam, clay systems and concluded that the linear adsorp tion isotherms governs the equi librium relations between the solution and the solid phases[12] . Again it is very uncerta in to predict the adsorption isotherm without experiments. $\mathrm{Pb}$ (II) adsorption on bentonite was well discussed by R. Naseem and S.S Tahir, batch experim ents were conducted and reported that the systems follows Langmuir adso rption isotherm [13]. Temperatu re effect on adsorptio $\mathrm{n}$ and thermodynamic of adsorption were studied and concluded that the process is spontaneous as the calculated change in Gi bb's free energy is negative. Sim ilar kind of research was perform ed by M. Cruz-GuzMan, R.Ceils and J.Cornejo research group conducted experiments on soil using lead (II) a nd mercury (II) [14] in which test were focused on sorbent characterization, $\mathrm{m}$ ethod of sorption and desorption batch experiments, they also discussed the Langmuir fit to the batch adsorption data. 
Shih-Chin Tsai, Kai-Wei and group have done extensive studies on adsorption isotherms for the cesium soil system [15]. They were focused on the heterogeneity based isother $\mathrm{m}$ models. Regression analysis was perfor med on three different models such as Lang muir, Langmuir-Freudlich (LF) and Generalized - Freundlich. The m odel parameters were evaluated. It was concluded that for cesiu $\mathrm{m}$ soil sys tems all the se models agr eed. Adsorption behavior of heavy m etals such as $\mathrm{Zu}, \mathrm{Cu}$ was studied by another group MinZhang, Wenquing, Yuechao Yang and research team [16].

Most of the research group em ployed "Advective Dispersion Reaction" (ADR) model in associate with adsorp tion isotherm to expla in the migration behavior of actinides and heavy metals and validated with the column experimental results. Quantitative evaluation of migration behavior of Am (III) in porous soil m edium was well discuss ed by $T$. Tanaka, [10]. They incorporated linear adso rption model with the ADR model and resulting equation was solved using finite difference m ethod. Adsorption coefficient $k_{d}$, which was the predom inant model parameter was determ ined by batch experim ents. Dispersion coefficient and velocity are dete rmined using tracer experim ents. Break through curves were reported at constant te mperature and $\mathrm{pH}$. Si milar experiments and modeling were conducted by the L.Krauz, Z. Kilka for the cesium and sand bentonite system [17]. Migration experim ents were performed for different conditions such as mass ratio of bentonite to sand, height of th e column packing, input concentration of the contaminate solution. The one dim ension model was solved using Transport Geochemical code PHREEQC. It is reporte $d$ that the dispersion coefficient was determined by the regression analysis over the 1-D trans port model. An adv ective 
dispersion model was also adopted to $\mathrm{m}$ odel many other applications such as to heavy metal $(\mathrm{Cs}, \mathrm{Pb})$ rem oval from water in a water trea tment process. J. Romero Gonzalez, J.C.Walton and team have m odeled adsorption dynamic behavior of cesium (II) on biomass. The model equation was developed using a mass balance with the ad sorption isotherm [18]. Packed colum $\mathrm{n}$ experiments were conducted $\mathrm{f}$ or different inlet concentrations to validate the model. In this work axial dispersion coefficient, retardation factor and adsorption coefficient were considered as characteristic parameters. Regression analysis was perf ormed on the m odel equation to evaluate the param eters. Analytical solution to the Advective Dispersion Equation (ADE) was critically analyzed and compared with the numerical solutions and experimental results. It is concluded that the adsorption is only on the external surface. Similarly, B.V. Babu and Suresh Gupta has modeled the fixed bed adsorption process [20]. Internal mass transfer resistance due to pore diffusion m echanism was considered in the model. To expla in the intr a-particle transport Ficksion diffusion was employed. The model equations are solved using explicit finite difference method. The effect of velo city along the length of the colum $n$ on the adsorption process was well discussed and concluded that velocity variation has significant effect on the br eakthrough curves. Effect of flow rate, bed height, concentration and part icle radius were discussed a nd reported. Colloi d properties and their effect on the radionuclides transport through the soil and ground water have been studied by the James F.Ranville [21]. The standard retardat ion equation was m odified and coupled with the ADRE and compared with the standard equations. The limitation of advective dispersion model is that it cannot be applicable to unsaturated porous medium. 
Basically, unsaturated $\mathrm{m}$ edium was characterized by the stagnant and $\mathrm{m}$ obile liquid phase.

Suresh A. Kartha and Rajesh Srivastava have documented the concept of m odeling the immobile liquid phase [20] an d effect of immobile water content on the contam inant transport in the unsaturated zone. Contam inant transport in the stagnant liquid phase cannot be explained by this $\mathrm{m}$ odel. A dual porosity $\mathrm{m}$ odel gives the best solution for contaminate transport in the unsaturated medium. The system was represented by the two equations one for $\mathrm{m}$ obile liquid and another for immobile liquid phases. The flow of liquid is given by Darcy's law, with the hydra ulic head (or moisture content) being a function of pressure head in unsaturated conditions. In the pre sent literature one dimensional numerical model was developed to predict the contaminant transport in the unsaturated porous media. The PDE's are solved using implicit finite difference method. According to the num erous research inves tigations, the soil part icles are highly porous and the uptake of contam inant is a diffu sion controlled phenom ena. Many groups have proposed pore diffusion $\mathrm{m}$ odel to describe the intra-particle diffusion followed by adsorption. Most of the diffusion/adsorp tion models have been derived from the advective dispersion adsorption equation. Ian C. Bourg, Alain, C.M Bourg, Garrison Sposito in their rev iew article have critically analyzed th e diffusive transport in the compacted clay [21]. The diffusion coefficient was the adjus table parameter evaluated by fitting to the batch ads orption data. Modified diffusion adsorption $\mathrm{m}$ odel suggests that diffusion through highly com pacted clay ta kes place through the inter-layers was proposed. The model was developed by fusing Fick's law of diffusion with the linear adsorption isotherm. The term effective diffusion coefficient was evalu ated by 
considering the tortuosity. It is documented in the literature that the particles are made up of smectite layers as a result in terlayer space is availab le for porous volum e hence porosity is divided into large pores and very thin interlayer pores. It was concluded in the review article that the diffusion in the inte rlayer is difficult to predict. Neither can it be neglected that it is not fast enough nor too slow that it limits the adsorption kinetics. The shape of the soil is irregular and hence usually for the purpose of modeling the shape of the particle is assum ed as spher ical. Chi-Wai Hui, Buning Chen and Gordon McKay proposed pore surface diffusion model for batch adsorption process which is based on the shrinking core model (SCM) and compared with two other m odels which are based on the lumped effective diffusion coefficient [22]. The advantage of this model over the others is that it can predict the time dependent surface and pore diffusion coefficient. An assumption has been made that the ions di ffuse from the surface to the core of the particle. Langmuir adsorption isotherm was coupled with the diffusion equation to model the batch adsorption process. Diffusion coe fficient was ev aluated by fitting the $b$ atch adsorption data. It is concluded th at the pore - surface $\mathrm{d}$ iffusion model is a univ ersal model applicable for most batch adsorpti on processes. The $\mathrm{m}$ odel overcomes the assumption of constant diffusivity with time. Hrissi K. Karspanagioti, Chris M. Grossard, Keith A. Stervett article demonstrates the modeling of intra-particle, diffusion/sorption coupled nonlinear sorption [23]. Fick's second law of one dim ensional form in spherical coordinates was considered and solved using finite difference method with crank-Nicholson tim e stepping. The model was incorporated with Freundlich isotherm parameters. Unlike others this re search group also considered an apparent diffusion coefficient. It was assum ed that the physical system $\mathrm{c}$ onsists of homoge nous 
mixture of porous spherical particles. To validate the model with experimental results the mass balance equation in the bulk phase wa $\mathrm{s}$ coupled with the $\mathrm{m}$ ass balance on the spherical adsorbate particle at the solid-liquid interface. Bulk phase concentration change obtained from kinetic batch adsorption was compared with the $\mathrm{m}$ odel concentration profiles. The uniqueness of the model is th e incorporation of non linear sorption. It is observed by the researchers that the $49 \%$ deviation was found between linear and nonlinear prediction in the concentration profiles.

The literature clearly illustrates that inte raction between radionuclides and heavy metals and the soil is we 11 explained by adsorption phenomena. As discuss ed in the lite rature survey it is very difficult to generalize the mechanism of adsorption process without experimental measurements for every system . Adsorption behavior of radioactive nuclides on various soils and clays has been st udied by various research groups [14] [12] [10] [16]. Most of the researchers report us ing linear adsorption isotherm models [12] [10] [17] but som e employed nonlinear adsorption isotherm (Langmuir and Freundlich isotherms) [14] [15]. Few have studied the specific radionuclide transport and adsorption on Nevada test soil despite the need for info rmation for the Nevada Test Site regulatory. The aim of this study was to perf orm laboratory experiments using NTS soil and $t \quad o$ incorporate an "Advective Dispersion React ive model" [10] [24] [17] along with Langmuir adsorption isotherm to model the behavior of migration and retention of radionuclide species. Many researchers had inco rporated nonlinear adsorption models to gas solid phase system s [26] [27]. In the pres ent work an attempt had been $\mathrm{m}$ ade to use the same technique to s oil liquid phase system. Instead of uranium, which is hazardous 
and not recomm ended to use in laboratories, lead was u sed as a su rrogate ion for the study. The ionic behavior of the uranium and lead are similar and lead is m uch safer for use in the experim ents to validate the $\mathrm{m}$ odel. In many reports the m odel equations are solved using finite difference num erical method [10] [17]; however in the present study the finite element method was employed and solved using "Com sol multiphysics -3.2 ". The finite element method offers greater flexibility in spatial discretization which is very difficult to achieve in finite difference method. It also helps one to visualize the results in more efficiently. 


\section{CHAPTER 2}

\section{EXPERIMENTATION}

\subsection{Nevada Test Soil properties:}

Soil samples collected from the Nevada Test Site were used to perform batch and column experiments. Soils are com plex mixtures of organic com pounds, minerals and living organisms that interact continuously in resp onse to natural, and im posed biological, chemical, and physical forces. The physical proper ties include soil texture, soil structure, compaction, and organic $m$ atters. Clay, sand, and silt co nstitute the soil tex ture. The relative proposition of these is very im portant to determine the water holding capacity of the soil. Sand consists of larger particle s which are typically in the range $2.0-0.06 \mathrm{~mm}$, silt consists of medium size particles ranging from $0.06-0.02 \mathrm{~mm}$, and fine clay particles less than $0.002 \mathrm{~mm}$. Clay is the important constituent of the soil. Clay particles have very high surface area relativ e to their vo lume, and are highly porous hence they can attract and hold io ns [28]. The physical $\mathrm{p}$ roperties of the so il are given in the Table-II. The physical properties are som ewhat easier to determine. To determine chemical properties, numerous laboratory test and analysis have to be carr ied out. Analysis includes determination of elements such as sodium, calcium, potassium and determ ination of $\mathrm{pH}$, and cation exchange capacity. Cation exchange is the ability of the soil clay to adsorb and exchange the cations with those in the wate $r$ in the pore space. Dynam ic equilibrium is established between ions in water and on the soil phase. The quantity of cation exchange is measured per unit of soil weight and is termed as cation s exchange capacity. Cation exchange capacity is on e of the more im portant phenomena. Exchangeable cations like 
calcium, sodium, magnesium are readily available for the uptake of heavy metal ions such as lead, and cesium. Soil $\mathrm{pH}$ is the $\mathrm{m}$ ost commonly measured chemical property and is also one of the more informative. Soil pH represents certain characteristic associated with a soil. The soil $\mathrm{pH}$ increas es as the acidity increases, $\mathrm{pH}$ decreases as the acidity decreases. The chemical composition of the Nevada test soil is given in the TableIII.

\begin{tabular}{|c|c|}
\hline Sand & $75 \%$ \\
\hline Silt & $14.22 \%$ \\
\hline Clay & $10.78 \%$ \\
\hline
\end{tabular}

Table-II: Physical properties of the Nevada test soil

\begin{tabular}{|c|c|}
\hline Chemical properties & Composition \\
\hline $\mathrm{pH}$ & 6.97 \\
\hline $\mathrm{Na}$ & $14.35 \mathrm{mg} / \mathrm{kg}$ \\
\hline $\mathrm{Ca}$ & $12.69 \mathrm{mg} / \mathrm{kg}$ \\
\hline $\mathrm{Mg}$ & $4.11 \mathrm{mg} / \mathrm{kg}$ \\
\hline $\mathrm{SAR}$ & 0.91 \\
\hline $\mathrm{K}$ & $10 \mathrm{mg} / \mathrm{kg}$ \\
\hline $\mathrm{B}$ & $0.05 \mathrm{mg} / \mathrm{kg}$ \\
\hline $\mathrm{TSS}$ & $185.77 \mathrm{mohms} / \mathrm{cm}$ \\
\hline ESP & $0.18 \%$ \\
\hline EC & $281.47 \mathrm{micro} \mathrm{ohms} / \mathrm{cm}$ \\
\hline
\end{tabular}

Table-III: Chemical properties and composition of the Nevada test soil 
The soil was washed and sized before use in the experim ents. A sample between 2 and 3 kgs of loess soil sam ple was cleaned and sieved to remove course particles larger then $0.5 \mathrm{~mm}$ then it was dried in the oven at $120{ }^{\circ} \mathrm{C}$ for about $24 \mathrm{hr}$ to rem ove the moisture in the soil.

\subsection{Selection of Contaminate for Experiments:}

Preliminary batch sorption experiments were conducted at room temperature using lead ions as ads orbate and treated Nevada tes $\mathrm{t}$ soil. Lead was selec ted for the initial experiments to allow us to dete rmine if the same experimental procedures could be used for actinide ions, and to determ ine the ac curacy of our analyti cal techniques. Eh-pH diagrams of lead and uranium in the Figures -4 and 5 show the sim ilarities. Adsorption kinetics and adsorption equilibr ium at various initial lead concentrations were studied. Distribution coefficients for the lead soil system at $\mathrm{pH}=4.5$ at equilib rium were determined. 


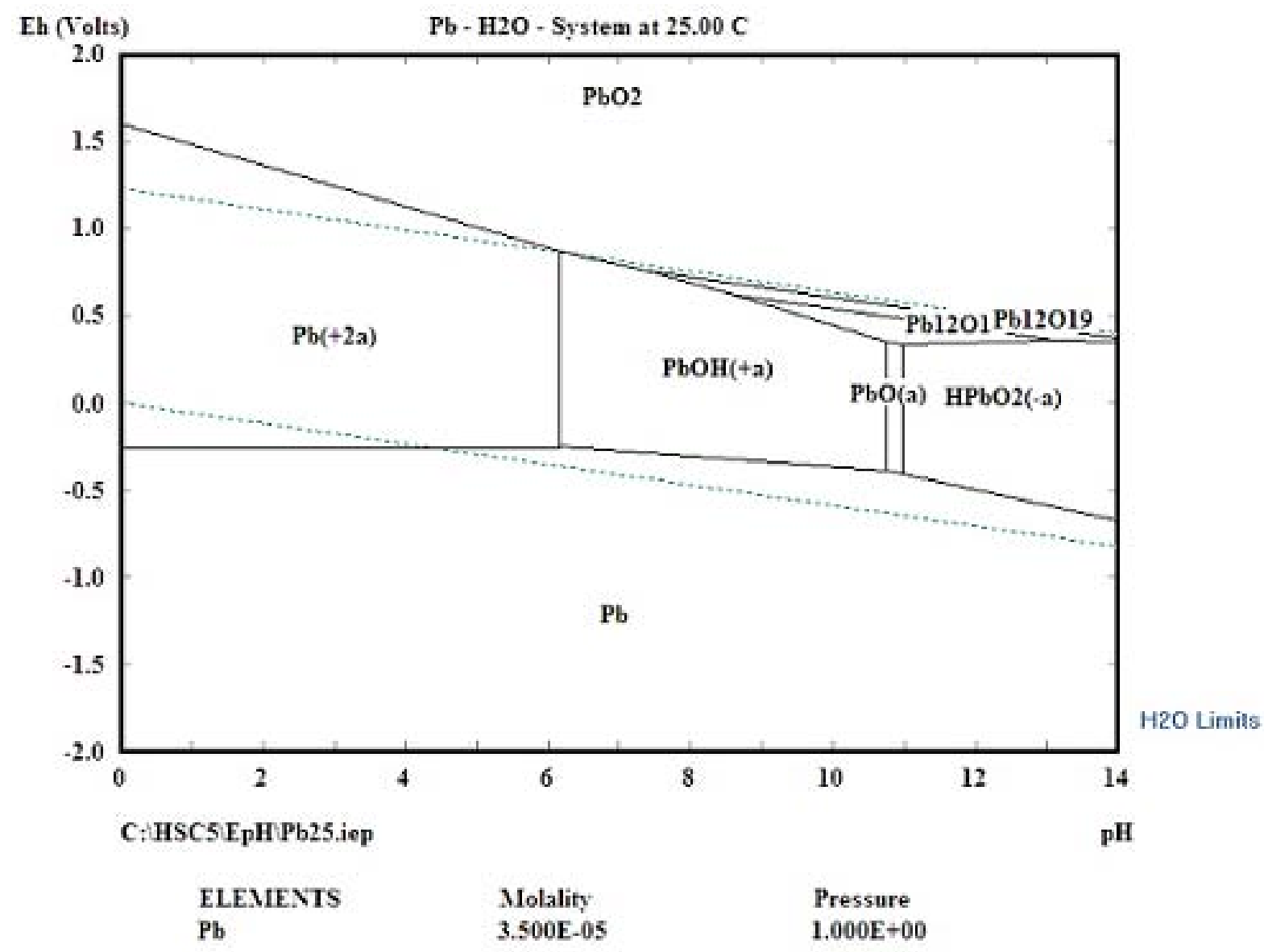

Figure-4: Eh-pH diagram for Lead water system [28] 


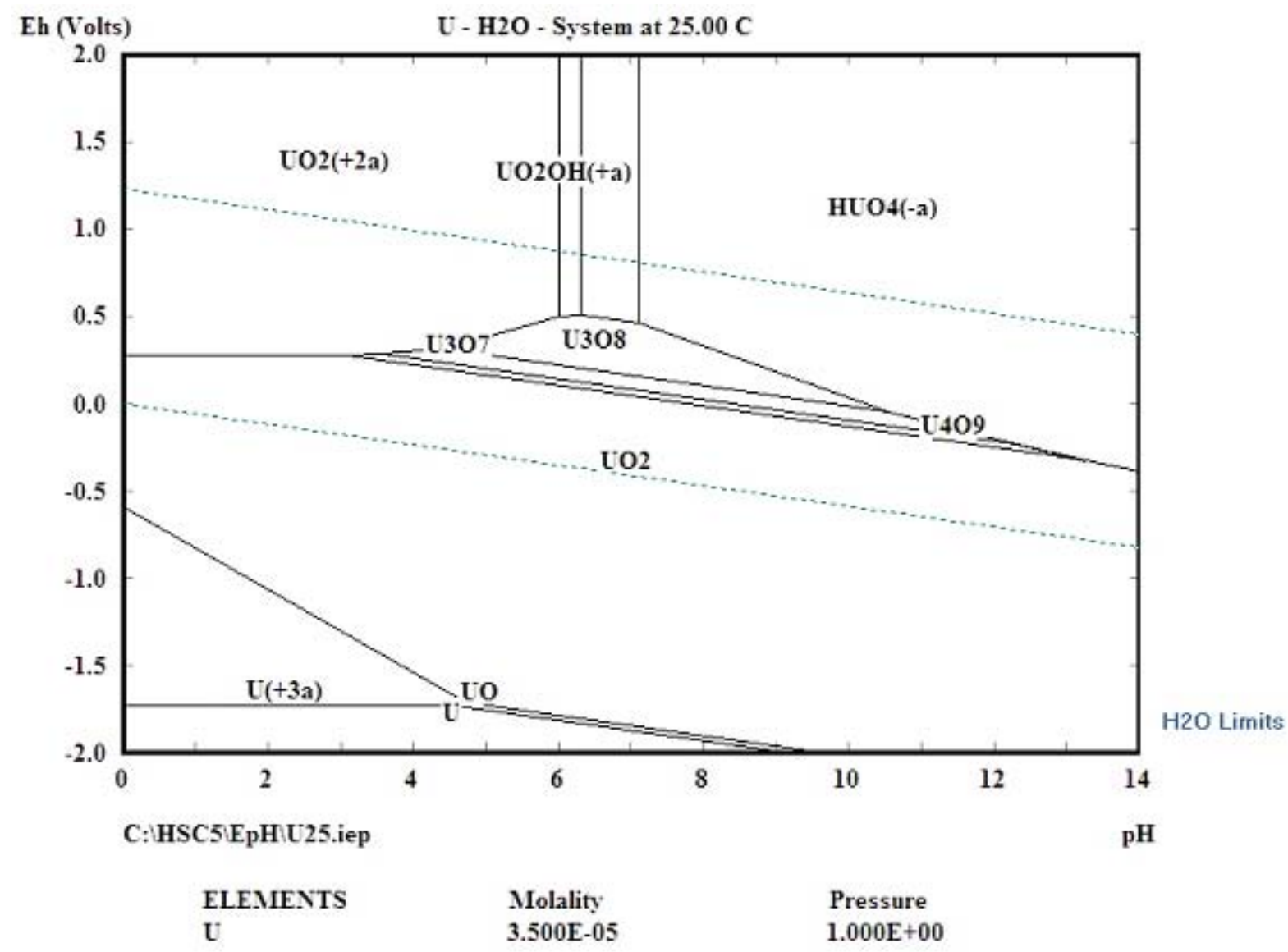

Figure-5: Eh-pH Diagram for water Uranium system [28]

As discussed previous ly temperature and $\mathrm{pH}$ are the $\mathrm{p}$ redominate parameters for the adsorption of heavy metals and actinides, hence three sets of experiments were conducted and listed below.

- Batch equilibrium experiments at different temperatures

- Batch kinetic experiments

- Batch experiments at various $\mathrm{pH}$ 


\subsection{Batch equilibrium experiments at different temperatures:}

Batch experiments were perform ed on prep ared Nevada test soil to observe the equilibrium adsorption behavior of the system. A stock solution of lead ions was prepared by dissolving $320 \mathrm{mg}$ of lead nitrate in $2 \mathrm{~L}$ of de-ionized water producing a solution with approximately $100 \mathrm{ppm} \mathrm{Pb}$. The $\mathrm{pH}$ was adjusted to 4 using $1 \mathrm{~N}$ nitric acid. The stock solution was diluted to prepare $80 \mathrm{ppm}, 60 \mathrm{ppm}, 40 \mathrm{ppm}$, and $20 \mathrm{ppm}$ initial concentration solutions. An aliquot of $50 \mathrm{~m} 1$ of each initial concentration solution was pipetted in to the conical flasks each contain ing $10 \mathrm{mg}$ of drie $\mathrm{d}$ soil sam ple. These conical flasks were placed in a constant tem perature water ba th and $\mathrm{m}$ echanically shaken for $24 \mathrm{hr}$ to equilibrate. The solution and soil slurry was then centrifuged and filtered to obtain a clear supernatant for the analysis of lead ion concentration using IC P-MS. The experiments were performed at $25^{\circ} \mathrm{C}, 35^{\circ} \mathrm{C}, 45^{\circ} \mathrm{C}$ and the experim ents were repeated, and the results were averaged [12] [10] [16].

\subsection{Batch kinetics experiments:}

Stock solutions of 100ppm lead ion concentr ation solution were prepared by dissolving lead nitrate in deionized water. The $\mathrm{pH}$ of the solution was adjusted to 4.5 using $1 \mathrm{M}$ nitric acid. An aliquot of $50 \mathrm{~m} 1$ of the lead solution was transferred into a number of different conical flasks. To each flask, $10 \mathrm{mg}$ of treated Nevada test soil was added, and placed on a mechanical shaker maintained at constant temperature using a water bath. The conical flasks were rem oved sequentially after $1 \mathrm{hr}, 2 \mathrm{hr}, 6 \mathrm{hr}, 8 \mathrm{hr}, 12 \mathrm{hr}, 14 \mathrm{hr}, 18 \mathrm{hr}, 24 \mathrm{hr}$, and 28hr. As the flasks were take $\mathrm{n}$, the soil and solu tion were separated using centrifugation and filtered to recover the superna tant. The supernatant liquid was collec ted and the 
resident $\mathrm{Pb}$ concentration was analyzed using ICP-MS. The experiments were conducted at $25^{\circ} \mathrm{C}$. The experiments were repeated and results were reported.

\subsection{Batch experiments at different $\mathrm{pH}$ :}

In order to determine the $\mathrm{pH}$ at which the adsorption process is $\mathrm{m}$ aximum, batch experiments were conducted at different $\mathrm{pH}$. The stock solution 100ppm lead ions concentration was diluted to $80,60,40,20 \mathrm{ppm}$. The $\mathrm{pH}$ of all the solution was adjusted to 4 using $1 \mathrm{M}$ nitric acid. These solutions were mixed with $10 \mathrm{mg}$ of soil sample for $24 \mathrm{hr}$ in a m echanical shaker $\mathrm{m}$ aintained at cons tant temperature. The s oil solution was centrifuged and filtered to get the supernatant and analyzed for the lead ion concentration using ICP-MS. [12] [13]

\subsection{Column Experiments:}

Column experiments were performed to observe the migration behavior of the lead in the Nevada test soil porous m edium. A column experimental set up was designed. The lead stock solution of know concentration was stored in a tank. The lead solution was pumped to an overhead reservoir using a centrifuga 1 pump and maintained at constant head bypassing the excess solution back to the storage tank. The over head reservoir was connected to the bottom of the colum $\mathrm{n}$ through a $5 \mathrm{~mm}$ diam eter flexible pipe. The column was fed from the bottom to reduce the possibility of channeling. The top of the column was plumbed to the effluent collector through the $5 \mathrm{~mm}$ flexible pipe. By trial and error the pressure head was adjusted so the liquid easily flowed through the column against the pressure drop. Effluent solution was collected from the top of the column. 


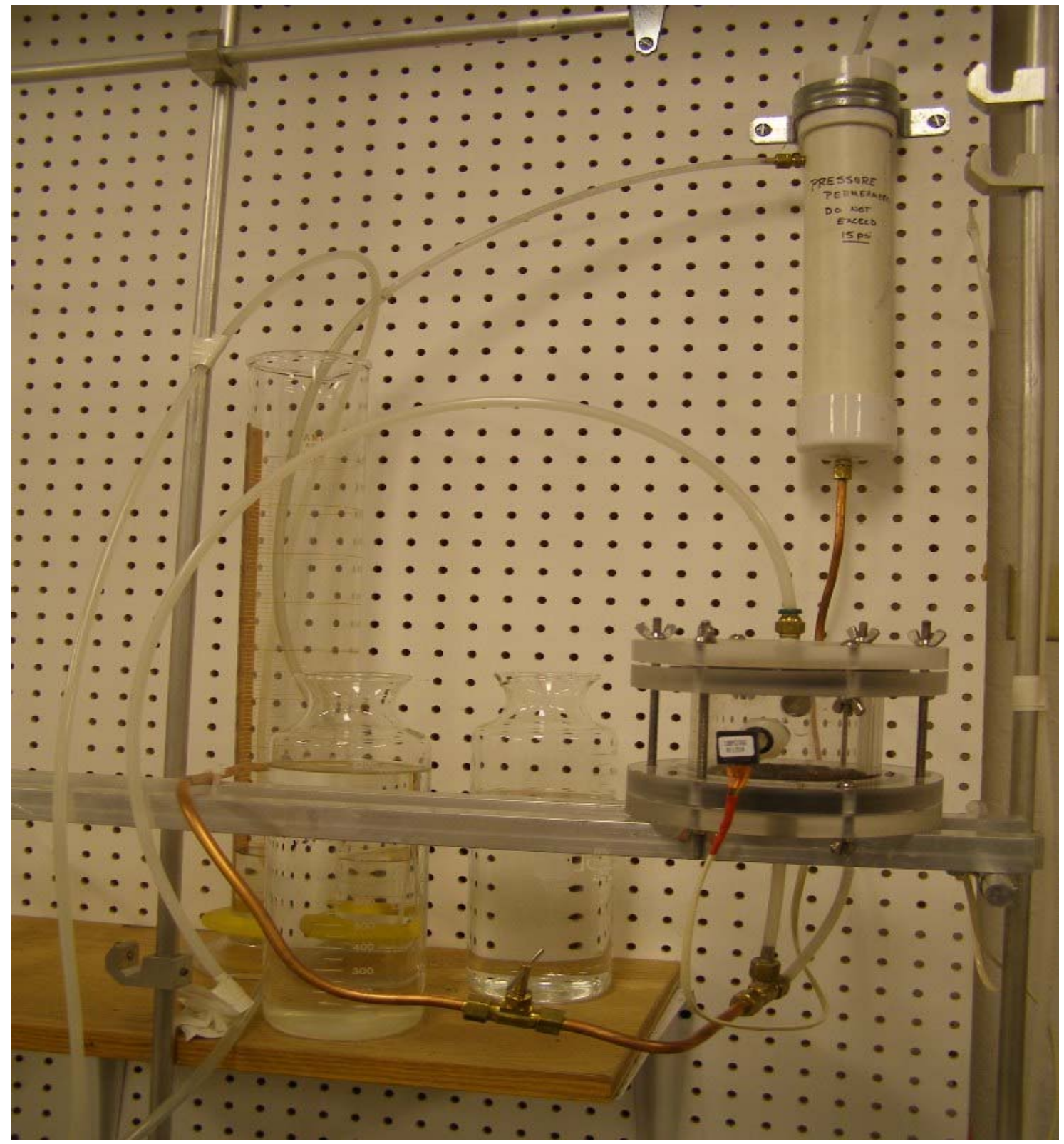

Figure: 6: Photograph of the column experimental setup 


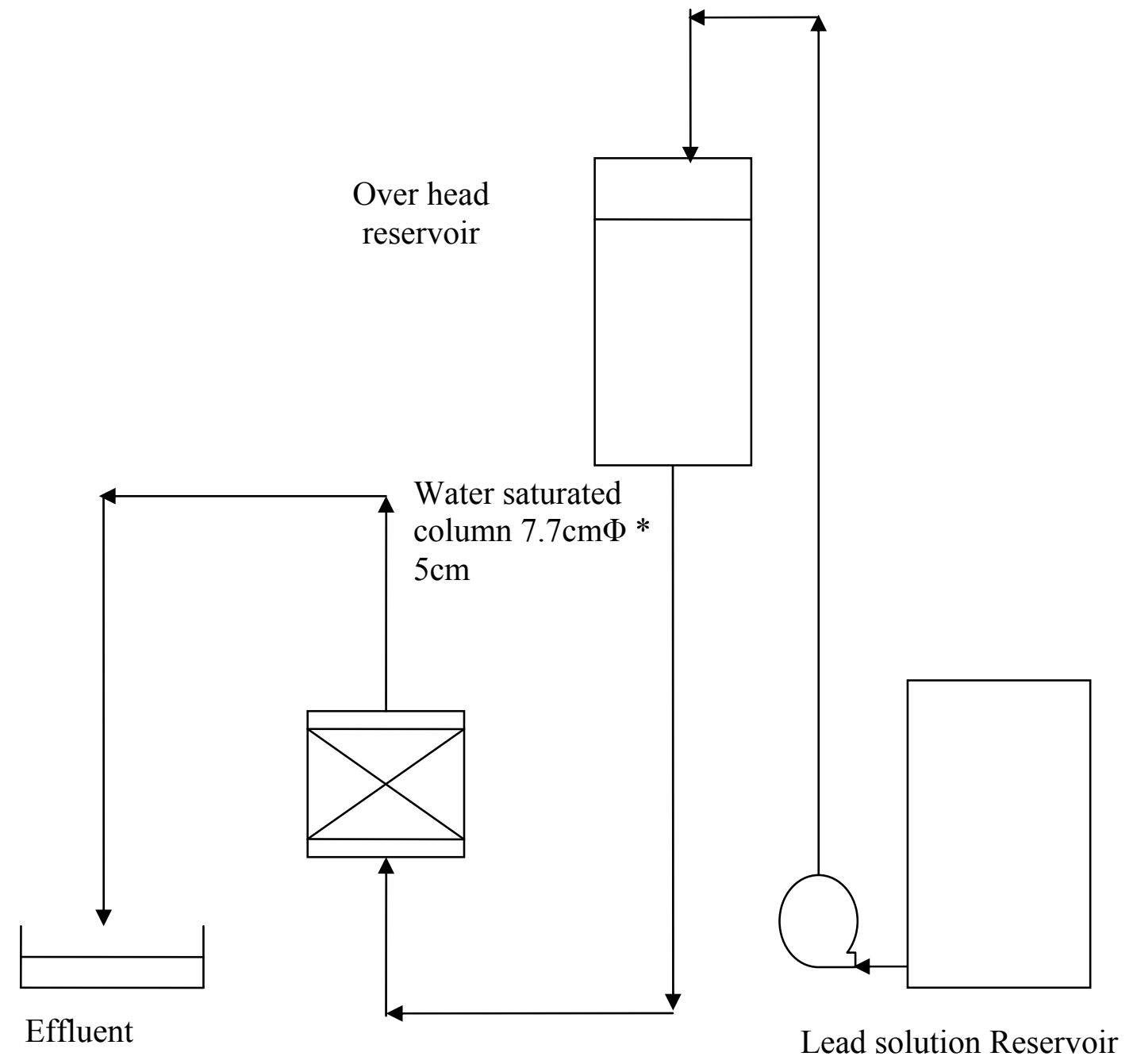

Figure-7: Schematic representation of the column experimental set up 
The apparatus for the $\mathrm{m}$ igration experiments is schem atically shown in Figure - 7. A glass column $7.0 \mathrm{~cm}$ in diam eter and $8 \mathrm{~cm}$ tall was used to support the soil samples obtained from Yucca Mountain. Filters of $10 \mu \mathrm{m}$ were fitted on both the top and the bottom of the column. The diameter of the column was chosen to avoid wall effects and to maintain a constant $\mathrm{f}$ low rate velocity ac ross the entire cross section of the column. The column was charged with Nev ada desert soil and the density and porosity of the medium was determined to be $1.5 \mathrm{gm} / \mathrm{cm}^{3}$ and $45 \%$, respectively [10][29][30].

The lead ion stock solution to be fed to the column was prepared by dissolving $103.99 \mathrm{mg}$ of lead nitrite in $1 \mathrm{~L}$ of de-i onized water to get $0.314 \mathrm{~m} \mathrm{ol} / \mathrm{m}^{3}$ of initial concentration and the $\mathrm{pH}$ was adjusted to 4.5 using nitric acid. All the required solution for the experiments was prepared and stored in the reservoir as shown in the Figure - 7. Fresh solution was added to maintain a constant level in the reservoir. A pinch valve was used to control the rate at which solution was fed from the reservoir to the soil column. The solution was fed through the soil column from the bottom at a volumetric flow rate of $6 \mathrm{~m} \mathrm{1/min} \mathrm{which} \mathrm{the}$ maximum volumetric flow rate is obtained when reservoir is maintained at constant head. Throughout the duration of the experim ent, the lead concentration of the solution was maintained constant at the inle t. The effluent samples that passed through the soil la yer were collected at reg ular interval in sa mple bottles and analyze $d$ for lead ion concentration using IC P-MS. Experiments were conducted for three different bed thicknesses $3 \mathrm{~cm}, 4.5 \mathrm{~cm}$, and $7 \mathrm{~cm}$. The experi ments were also conducted for different input solution concentrations. 


\subsection{Determination of porosity of the soil medium:}

The column was packed with the prepared Nevada test soil. The solution was introduced from the bottom until the entire be $d$ was sa turated. Then the water $w$ as drained and collected in the measuring flask and the volum e was noted this volum e is called as pore volume. The total volume of the soil packed bed was calculated by measuring the height and the diameter of the column. The ratio of pore volume and the total volume gives the porosity of the medium. The same procedure was repeated for different bed thickness and the average value found to be 0.45 [38].

\subsection{Determination of soil bed density:}

The column was filled with soil a nd height of the bed was record ed. The soil was removed from the column and wei ghed. The volume of the bed was calculated from the height and diam eter of the colum $\mathrm{n}$. The ra tio of the weight and the volum e gives the

density of the column. The procedure was repeated for several tim es and average density was evaluated. It was found to be $1500 \mathrm{~kg} / \mathrm{m}^{3}$ [38]. 


\section{CHAPTER 3}

\section{MODELING}

\section{MODELING}

The present work was focused on two major aspects

- Bulk phase contaminate modeling

- Pore diffusion modeling

\subsection{Bulk phase contaminate transport modeling:}

Darcy's law was employed to evaluate the velocity and the pressure drop in the porous medium which is explained in the first section of this chapter. In the second section more detail about Advective Dispersion Reaction Equation (ADR) and the implem entation for the contaminate transport in the po rous media. The associated, adsorp tion equilibrium terms can be evaluated by using adsorption isotherms and are discussed in the third section. All three equations such as Da rcy's motion equation, ADR and Adsorption isotherm are coupled to solve for the conc entration distribution in the colum $\mathrm{n}$ was explained in the fourth section 3.4 .

\subsection{Pore Diffusion Modeling:}

Pore diffusion m odeling was e mployed to observe the diffusion and contam inant adsorption on a single soil pa rticle. The sha pe of the $\mathrm{p}$ articles was assumed to be spherical. The mass balance on the spherical particle and the $\mathrm{m}$ ass balance in the bulk phase (liquid phase) are coupled at the inte r-phase. The pore diffu sion model equation is 
also associated with the ad sorption equilibrium term which was expla ined by laboratory equilibrium isotherm experiments. The $\mathrm{m}$ ass balance equation on soil particle, $\mathrm{m}$ ass balance equation in the bulk pha se and the equilibrium isotherms were coup led and solved for bulk phase concentration change w ith time to verify with the batch adsorption kinetic experiments.

\subsection{Darcy's Law:}

Darcy's Law describes the flow through a porous m edium [31][32]. Darcy's equation is the modified version of the Navier-Stokes e quation and is also ca lled the equation of motion. Darcy's is based on the homogenization principle that is microscopic momentum balance on the fluid element in the pore space was averaged and extended to macroscopic porous media. The shear stress in the fluid is neglected but the friction between solid and the fluid in the pore space was acco unted in the Darcy's equation. Darcy's law is more applicable to one dimensional and saturated flow of homogenous fluid in a hom ogenous and an isotropic porous $m$ edium [33] [36 ][37].Darcy's law is applicable where the hydraulic gradient is the driving force for the flow of fluids. The Darcy's velocity or the specific discharge vector is given by [32] [34][35].

$$
u=-\frac{k}{\mu}(\Delta p)
$$

Where $k$ is the permeability. $\mu$ is the viscosity of the fluid. $p$ is the fluid pressure. The permeability represents the res istance to the flow over a co nsidered volume consisting solid grains pores.

Incorporating Darcy's law to the continui ty equation gives the generalized governing equations. 


$$
\begin{aligned}
& \frac{\partial\left(\rho_{f} \varepsilon\right)}{\partial t}+\nabla \cdot \rho_{f} u=0 \\
& \frac{\partial\left(\rho_{f} \varepsilon\right)}{\partial t}+\nabla \cdot \rho_{f}\left(-\frac{k}{\mu}(\Delta p)\right)=0
\end{aligned}
$$

Equation (3) can be used to solve pressure di stribution and Darcy's velocity which is the Adjectives dispersion reaction equation [36] [37].

\subsection{Advective Dispersion Reaction Equation:}

In the present work an attempt was made to derive the ad vective dispersion reaction equation. It involves three steps.

1. Obtain equation for solute transport called advective transport equation

2. Addition of dispersion term to the advective transport equation.

3. Addition of reaction term (sorption term) to the advec tive dispersion transport equation.

\subsubsection{Advective Transport equation:}

Even though contaminates are fully miscible in the water they are considered to be tagged with water. Movement of such tagged particles is called the solute transport or advective transport. It is assumed that all particles move with an average seepage velocity [39].

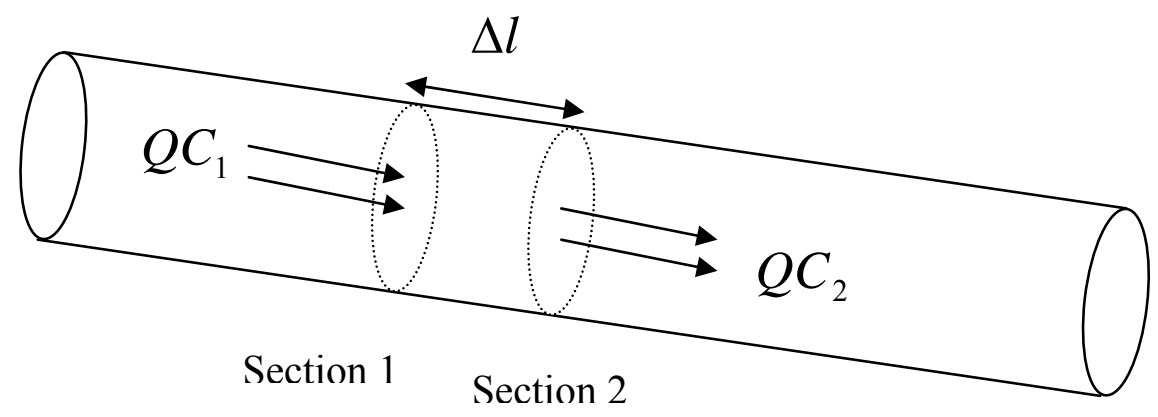

Figure $-8:$ Solute mass transport in the porous medium 
As shown in the Figure- $8 \Delta l$ is the distance between two cross section s. A is the cross sectional area of the conduit. $\mathrm{C}_{1}, \mathrm{C}_{2}$ represents the concentration at the upstream and downstream cross sections respectively. $\mathrm{Q}_{\mathrm{m} 1}, \mathrm{Q}_{\mathrm{m} 2}$ are the volum etric flow rate entering and leaving the system respectively. The rate of change of mass in the volume is given by [39],

$$
\frac{\partial M}{\partial t}=Q_{1} C_{1}-Q_{2} C_{2}=q A\left(C_{1}-C_{2}\right)
$$

Where, $q$ is the Darcy's velocity v ector, under these conditions the v olume of water containing solute in the bulk volume is given by $A \Delta l \theta$, where $\theta$ is the effective porosity. Let $C$ be the average concentration in the vo lume, then the $m$ ass of the solute be tween two planes is given by $(A \Delta l \theta) C$ and Equation-4 becomes,

$$
\begin{aligned}
& \frac{\partial M}{\partial t}=A \theta(\Delta l) \frac{\partial C}{\partial t} \\
& q A\left(C_{1}-C_{2}\right)=A \theta(\Delta l) \frac{\partial C}{\partial t} \\
& \left(C_{1}-C_{2}\right)=-(\Delta l) \frac{\partial C}{\partial t}
\end{aligned}
$$

Combining Equations-6 and 7 we get the following equation.

$$
-\frac{\partial(C q)}{\partial l}=\theta \frac{\partial C}{\partial t}
$$

Extending the same to the three dimensions and replacing $q$ by $v$ we get the following equation.

$$
-\frac{\partial\left(v_{x} C\right)}{\partial x}-\frac{\partial\left(v_{y} C\right)}{\partial y}-\frac{\partial\left(v_{z} C\right)}{\partial z}+q_{s} \frac{C_{s}}{\theta}=\theta \frac{\partial C}{\partial t}
$$

Equation (6) can also be written as 


$$
-\nabla \cdot(v C)+\frac{q_{s}}{\theta} C_{s}=\frac{\partial C}{\partial t}
$$

$q_{s} C_{s}$ Represents the net ra te at which solute $m$ ass is added to or rem oved from the volume element by source and the sink.

\subsubsection{Dispersive transport:}

It is assumed that all fluid particles move $w$ ith the average seepage velocity of the water in the advective transport. But dis persion theory addresses the deviation of particle velocity from the average seepage velocity [37] [40]. Diffusion of solute particles is common in the porous structured solid phase a nd high concentration gradient. This is not an issue at the higher ve locities. But it is significant at the extremely low velocities. The primary reason for this kind of behavior is the macroscopic heterogeneity.

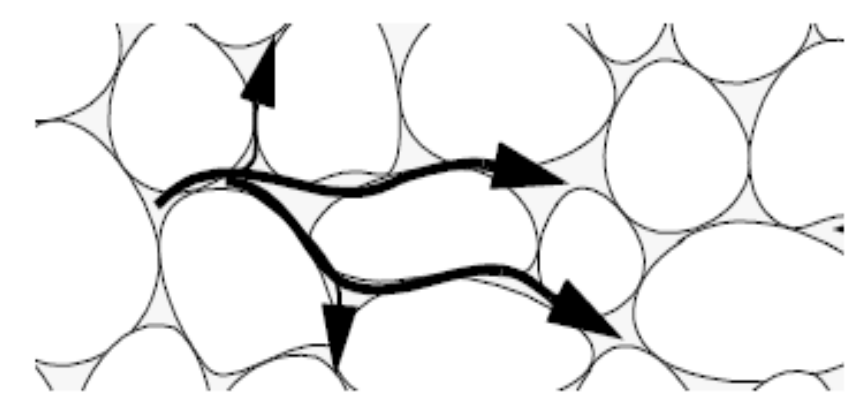

Figure - 9: Dispersion of fluid around solid particles in the porous medium [41] Hydrodynamic dispersion also describes the spr eading of contaminates. It accounts for the local velocity variati on in the pore volum e and $\mathrm{m}$ olecular diffusion. The solute particles travel around the solids which cause s dispersion. The dispersion norm al to the direction of flow is called longitudinal dispersion which is 3 to 10 tim es more than the 
transverse dispersion which is along the direction of the flow as shown in the Figure - 9. Molecular diffusion which is being driven by the concentr ation gradient is u sually neglected because of the mixing effect. It only predominates during low velocity flows.

The dispersive flux was added to the advective transport equation to get the combined equation called as advective dispersive transport equation [43].

To obtain the equation for advective dispersion transport the the system shown in Figure10 was considered.

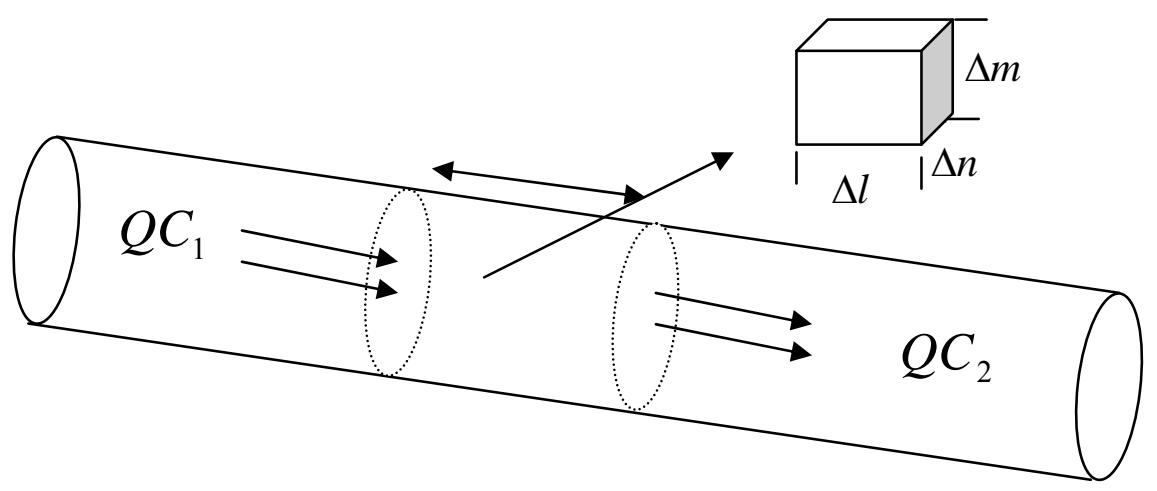

Figure-10: Representation of the element in the porous medium

Let $\Delta l, \Delta m, \Delta n$ represent the dimension of the element considered in the porous medium.

Let $q, C$ be the Darcy's velocity and concentr ation of the solute. The net difference between advective inflow and out flow is gi ven at the upstream and downstream face of the element is therefore.

$$
-\frac{\partial(C q)}{\partial l} \Delta l \Delta m \Delta n
$$

The dispersive transport term for unidirectional flow is given by the following equation.

$$
-D_{l} \frac{\partial(C)}{\partial l} \theta \Delta m \Delta n
$$

The expression for the difference between mass inflow and $\mathrm{m}$ ass out flow due to longitudinal dispersion is given by 


$$
-\frac{\partial}{\partial l}\left(\theta D_{l} \frac{\partial C}{\partial l}\right) \Delta m \Delta n \Delta l
$$

Dispersion occurs normal to the flow occurs in both $\mathrm{n}$ and $\mathrm{m}$ directions. There fore the net difference between dispersive mass inflow and outflow in the $\mathrm{m}$ and $\mathrm{n}$ directions are given by respectively [43].

$$
-\frac{\partial}{\partial n}\left(\theta D_{l} \frac{\partial C}{\partial n}\right) \Delta m \Delta n \Delta l,-\frac{\partial}{\partial m}\left(\theta D_{l} \frac{\partial C}{\partial m}\right) \Delta m \Delta n \Delta l
$$

The general mass accumulation in the element is given by,

$$
\frac{\partial(\theta C)}{\partial t} \Delta m \Delta n \Delta l
$$

Combining Equations-9, 10, 11, and 12, the follo wing expression is obtained and $\mathrm{q}$ is replaced by $\mathrm{v}$.

$$
\frac{\partial(C \theta)}{\partial t}=-\frac{\partial(v C)}{\partial l}+\frac{\partial}{\partial l}\left(\theta D_{l} \frac{\partial C}{\partial l}\right)+\frac{\partial}{\partial n}\left(\theta D_{n} \frac{\partial C}{\partial n}\right)+\frac{\partial}{\partial m}\left(\theta D_{m} \frac{\partial C}{\partial m}\right)
$$

The equation in the three dimensional flow is represented by the following equation [43]

$$
\frac{\partial(C \theta)}{\partial t}=\nabla \cdot(\theta D \cdot \nabla C)-\nabla \cdot(q C)+q_{s} C_{s}
$$

\subsubsection{Sorption term in the advective dispersion transport equation:}

The sorption and ion-exchange are class ified under heterogeneous class of reactions or surface reactions. Some chemicals and dissolved ions such heavy metal, actinides have a greater tendency to sorb on the soil surface. Hence, $m$ any researchers have aim ed to develop models incorporating the sorption term in the conta minate transport model. The 
effect of sorption on the advective dispersion transport is represented by the source/sink terms $\frac{\partial q}{\partial t}\left(\frac{1-\varepsilon}{\varepsilon}\right) \rho$ which are represented in the following Equation-17.

$$
\frac{\partial(C \theta)}{\partial t}=\nabla \cdot(\theta D \cdot \nabla C)-\nabla \cdot(q C)+q_{s} C_{s}+\frac{\partial q}{\partial t}\left(\frac{1-\varepsilon}{\varepsilon}\right) \rho
$$

This sorption mechanism slows the contam inate transport through porous m edium. It is assumed that the concen tration of the solute in the liqu id phase is in equilibrium with solid phase. Let $C$ be the concentration of th e chemical in the liquid and $q$ be the concentration in the so lid phase. If the solute concentration is chan ged to ano ther concentration it is exp ected that the solid phase concentration also changes. It is reasonable to imagine, that the wa ter concentration on the soil is changed continuously due to the flow. After sufficient time it is observed both the phases will be in equilibrium. The plot between equilibrium concentrations in both the phases at constant temperature is termed as the adsorption isotherm.

The following are the commonly found adsorption isotherms that most of the researchers have associated with the soil con taminate systems. The slope of the isotherm is of particular interest in the solute transport analysis. The Langmuir adsorption is given by the following equation [43].

$$
q=\frac{q_{\max } b C}{1+b C}
$$

The slope of Equation-18 is given by [44],

$$
\frac{\partial q}{\partial C}=\frac{q_{\max } b}{(1+b C)^{2}}
$$


Equation-19 is referred to as Langmuir adsorption isotherm it consists of $q_{\max }$, maximum sorption capacity and $b$, Langmuir constant, expressed as maximum mass that can be sorbed per unit mass of the porous medium. At lower solute concentrations the isotherm appears to be similar to linear adsorption isotherm and at higher solute concentrations the $q$ approaches maximum limiting value.

$$
q=K_{d} C^{a}
$$

Equation (20) is referred as the Freundlich isotherm [45]. The Freundlich isotherm is based on the concept that the solid matrix has infinite sorption capacity. $q$ is expressed as milligram/kilogram and $K_{d}$ is expressed as $\mathrm{m}^{3} /$ kilogram. Similar to the Langmuir, at low concentrations ' $a$ ' becomes unity and result in a linear relationship between $q$ and $C$. Slope of the equation is given by [45],

$$
\frac{\partial q}{\partial C}=K_{d} a C^{a-1}
$$

In the present work we intended to determine the contaminate transport in one dimension and to validate using colum $\mathrm{n}$ experimental results. The three dim ensional form of advective dispersive adsorption transport is deduced to be as follows [10].

$$
\frac{\partial C}{\partial t}=-v \frac{\partial C}{\partial x}+D_{L} \frac{\partial^{2} C}{\partial^{2} x}-\frac{\rho(1-\varepsilon)}{\varepsilon} \frac{\partial q}{\partial t}
$$

Where $\mathrm{C}$ is the bulk phase concentration, $v$ is the Darcy velocity evaluated by coupling with the transport equation. $D_{L}$, is the longitudinal di spersion coefficient. $\rho$, is the density of the par ticles. $\varepsilon$, is the porosity of the porous $\mathrm{m}$ edium. Initial batch 
experiments revealed that the system follows Langmuir adsorption isotherm. Equilibrium between the solid and the liquid phase is given by

$$
\frac{\partial q}{\partial t}=\frac{\partial q}{\partial C}\left[\frac{\partial C}{\partial t}\right]
$$

Replacing $\frac{\partial q}{\partial C}$ by the slope of the Langm uir isotherm and in the equation - 19 the following final expression is obtained [10][26][27][30].

$$
\frac{\partial C}{\partial t}\left[1+\frac{\rho(1-\varepsilon)}{\varepsilon} \frac{q_{0} K}{(1+K C)^{2}}\right]=-v \frac{\partial C}{\partial x}+D_{L} \frac{\partial^{2} C}{\partial^{2} x}
$$

\subsubsection{Adsorption dynamic modeling using pore diffusion model:}

The dynamic behavior of the batch adsorpti on process is explaine $d$ by the following steps [46]:

- Mass transfer from bulk fluid phase to adsorbent surface.

- Liquid diffusion within the adsorbent pores

- adsorption on to the surface

- Diffusion on the adsorbent surface

The film diffusion explains the mass transfer of solute from the bulk phase to the exterior surface of the adsorben $t$. The flux is proportion al to a m ass transfer coefficient and the concentration difference between the bulk phase and the surface.

$$
N_{A}=K_{m}\left(C_{A b}-C_{A s}\right)
$$

Where $N_{A}$ is the $m$ ass flux, $K_{m}$ is the mass transfer coefficient, $C_{A b}$, is the bulk phase concentration. $C_{A s}$, is the concentration on the adsorbent surface. Usually, mass transfer resistance is neglected for well stirred solutions. Fick's second law describes the 
diffusion of liquid due to concentration gradient between the exterior surfaces to the inner surface in the porous structure of the soil particle [46].

$$
N_{A}=-D_{e, p} \frac{\partial C_{A}}{\partial r}
$$

Where $D_{e, p}$ is the effective diffusion coefficient, $\frac{\partial C_{A}}{\partial r}$ is the concentration gradient. The effective diffusivity is the liquid - phase molecular diffusivity $D_{A B}$, adjusted for porosity and tortuosity of the adsorbent.

$$
D_{e p}=\frac{\varepsilon_{p} D_{A B}}{\tau}
$$

The adsorption on the s urface is given by the adsorption equilibrium isotherms. It was concluded from batch adsorption experim ents that th e system follows Langmuir adsorption isotherm. Some time it is observed that in some cases where the adsorbent has high adsorption capacity and weak bond, the so lute is adsorbed on to the surface and migrates along the surface under the concentr ation gradient in the adsorbed phase. The flux due to the surface diffusion is given by [47],

$$
N_{A}=-D_{e, s} \rho_{p} \frac{\partial q}{\partial r}
$$

Where, $D_{e, s}$ is the surface diffusion coefficient. The surface diffusion is a function of absorption bond and physical prop erties. In the present work the effect of surface diffusion is neglected.

The following partial differential equation represents the shell mass balance on the soil spherical particle which was perform ed to investigate the unsteady state adsorption process [46] [48]. 


$$
\varepsilon_{p} \frac{\partial C_{A}}{\partial t}=D_{e, p}\left(\frac{\partial^{2} C_{A}}{\partial r^{2}}+\frac{2}{r} \frac{\partial C_{A}}{\partial r}\right)-\rho_{p} \frac{\partial q}{\partial t}
$$

Where, the first term represents the accumulation term, $\frac{\partial C_{A}}{\partial r}$ represents the flux term , $\frac{\partial q}{\partial t}$ and represents the adsorption term. In corporating the slope of the Langm uir adsorption isotherm the equation-19 reduced as follows.

$$
\frac{\partial C_{A}}{\partial t}\left(\varepsilon_{p}+\frac{\rho_{p} b q_{\max }}{\left(1+C_{A} b\right)^{2}}\right)=D_{e, p}\left(\frac{\partial^{2} C_{A}}{\partial r^{2}}+\frac{2}{r} \frac{\partial C_{A}}{\partial r}\right)
$$

The macroscopic mass balance in the bulk liq uid is coupled with the above Equation-30 as a boundary cond ition. It is assumed that the concentration change in the bulk phase with time is same with that of the exterior surface due to well stirring [46][48].

$$
-V \frac{d C_{A}}{d t}=m S D_{e, p}\left(\frac{\partial C_{A}}{\partial r}\right)
$$

Both the equations are solved simultaneously for the concentration $C_{A}$. 


\section{CHAPTER 4}

\section{MODELING USING COMSOL}

\subsection{Comsol Multiphysic and Finite Element Method:}

The transport phenomena due to m ass momentum and concentration gradients are well described mathematically using partial differential equations (PDE’s). Occas ionally, problems involve solving all transport equa tions simultaneously, merging with complex coupled equations. These kinds of problem s have no analytical solutions, but num erical approximations can be obtained. Most of the PDE's in transport phenomena are of second order. Finite elem ent methods are well suite $d$ to treat second order system $s$ that have wide applicability. The large dom ain is divided into small units called finite elements or sub-domains. The corners of the elem ents are called nodes at which the solutions to the dependent variables are computed. More elements mean more accuracy; however, more time is required to solve these equations using more powerful systems [49].

Comsol Multiphysic -3.2 is a graphical user interphase (GUI) and integrated m odeling application based on the finite elem ent method. Comsol Multiphysic follows sem i analytical techniques to so lve the defined problem $\mathrm{s}$ by assembling the FEM matrix. Basically, Comsol Multiphysics is a partia 1 differential equation engine like FLUENT, CFX or any other com mercially available PDE solver. It $\mathrm{h}$ as many advantages over the other packages. Prebuilt m odule designs provide a window to solve common and well know problems. It is highly compatible with MATLAB. Subroutines used during modeling which can be exported from MATL AB and post solution analysis can be 
performed in a MATLAB environm ent. It also provides links between different application modes (many modules can be coupled and solved simultaneously) [49].

Comsol Multiphysics involve six steps to solve any given problem.

- Selection of proper "application mode" based on the physics of the problem.

- Geometry construction using environment of the Comsol multiphysic representing the actually system.

- Setting up the equation in the sub-dom ain region (internal geometry) with specified the boundary conditions.

- Meshing the generated geometry. It is complete with default mesh generating feature. There are options to refine the mesh size and shape.

- Solving the defined problem. Comsol is provided with th e default solver selection base on the application mode.

- Post - processing: the results obtained can be interpreted in $m$ any different ways and a variety of plots can be generated to represent the results in a better way.

- In the present case two problem s are solved using the above steps and are discussed in the following section.

\subsection{Solution to Advective Dispersion Reaction Equation:}

The ADRE Equation derived in Chapter 3 was solved using convective diffusion application mode in the chemical engineering module. Since it is an unsteady state partial differential equation, the tran sient analysis type was se lected. Default Lagrange - 
quadratic element type was adopted. 'C' (b ulk phase concentration) is the default dependent variable in this application mode.

\subsubsection{Geometry of the system:}

A 2 - dim ensional space geometry was created representing the actual dim ension of the column. Figure-11 shows the geometry generated using Comsol Multiphysics-3.2 in the CAD environment. Width and length of th e column was taken as $7.5 \mathrm{~cm}$ and $4.5 \mathrm{~cm}$ respectively.

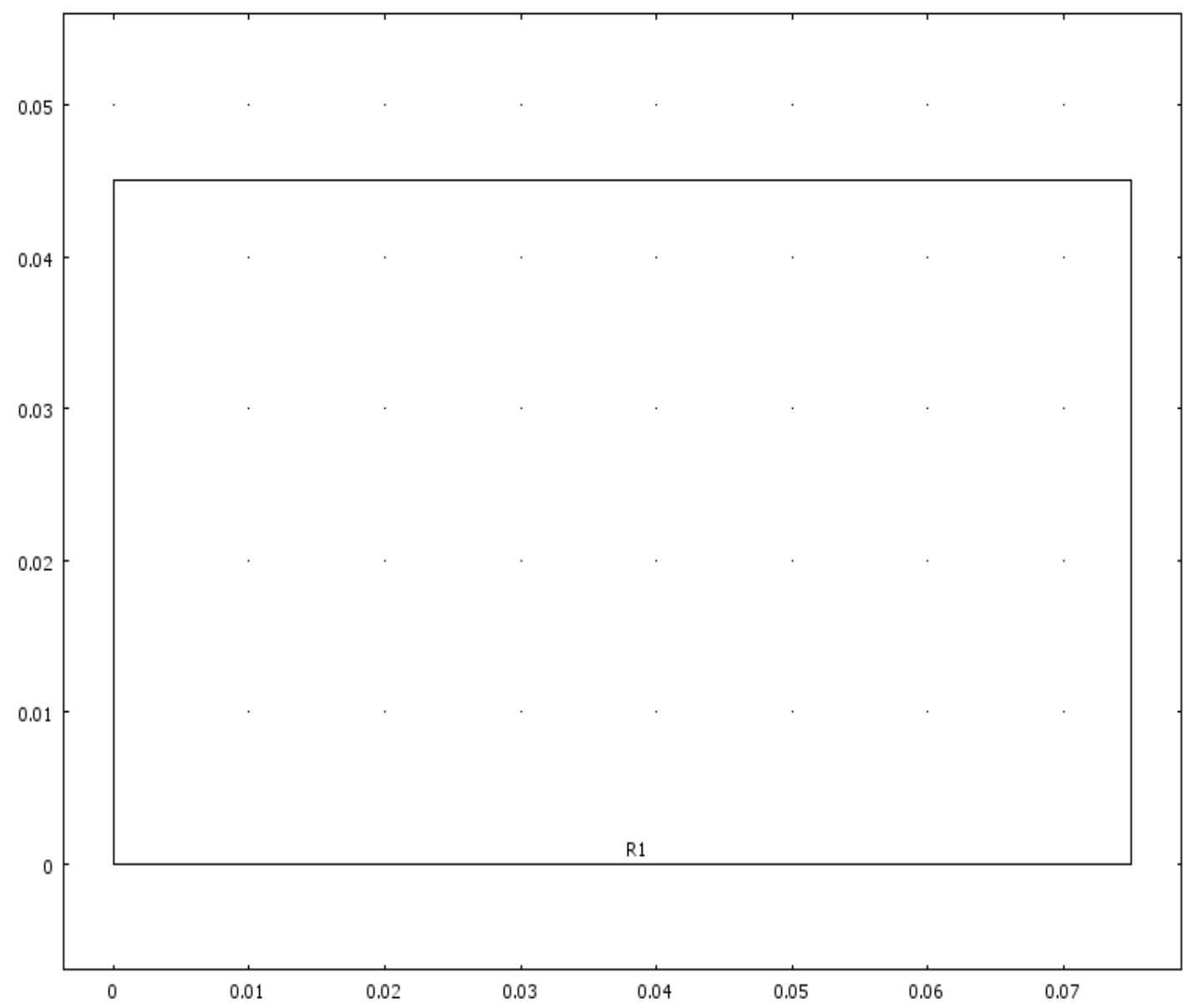

Figure-11: Geometry of the column

The region enclosed in the rectang le is called the sub-domain region where the mode 1 equation (ADRE) is so lved for the concentration distribution insi de the column. It 
represents the soil pack ing and the porosity of the $\mathrm{m}$ edium as specified which accounts for the pore structure of the soil packed column.

\subsubsection{Meshing:}

The mesh is a partition of geom etry model into small units of simple shape. The default meshing type can be either tria ngular or quadrilateral elem ents. Free mesh can also be generated using a m esh generator which can be employed to any geom etry. It creates unstructured mesh which has no restrictions in terms of e lement distribution. In the present study a triangular mesh was employed for $2-\mathrm{d}$ representation of the column and is shown in the Figure -12 .

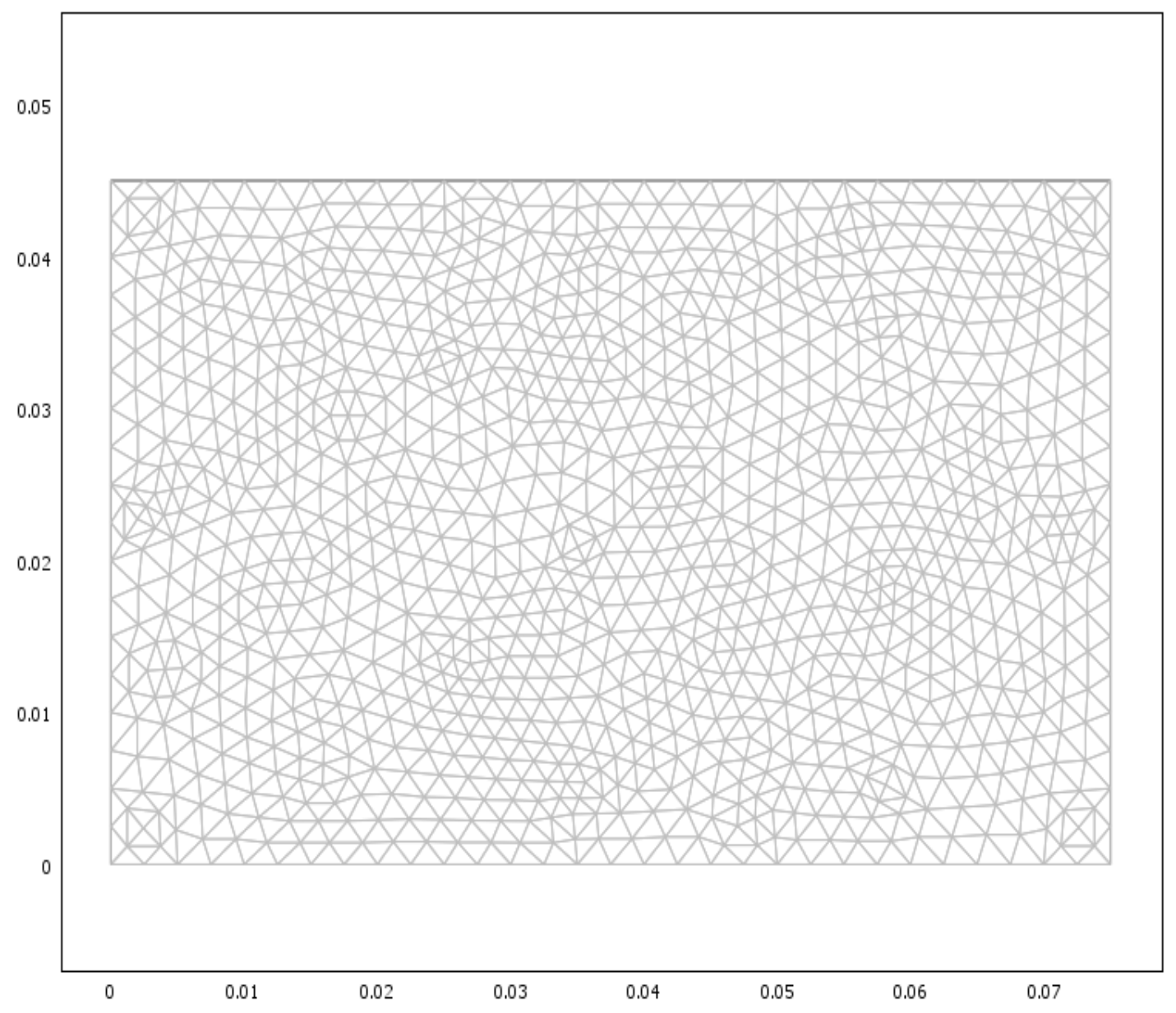

Figure- 12: Triangular meshing of the geometry 
The sides of the triangle are called mesh edges and the corners are called mesh vertices.

Table-IV describes the mesh statistics employed to solve ADRE in a column.

\begin{tabular}{|l|c|}
\hline Number of degrees of freedom & 4449 \\
\hline Number of mesh points & 1137 \\
\hline Number of elements & 2176 \\
\hline Triangular & 2176 \\
\hline Quadrilateral & 0 \\
\hline Number of boundary elements & 96 \\
\hline Number of vertex elements & 4 \\
\hline Minimum element quality & 0.757 \\
\hline Element area ratio & 0.252 \\
\hline
\end{tabular}

Table-IV: Meshing statistics for ADRE model

\subsubsection{Solver settings:}

A linear sy stem solver, time dependent tran sient analysis type was used. The tim e parameter was set as $0-15,000$ seconds with an increm ent of $10 \mathrm{sec}$. The relative and absolute tolerance was set to 0.01 and 0.001 , respectively.

\subsubsection{Post processing:}

The model equation was solved for the bulk phase concentration and the top boundary was integrated to get the average concentration. The av erage concentration was plotted with time to observe the break through point and to com pare with the column experimental results. The results are explai ned in detail in the results and discussion chapter. 


\subsection{Solution to pore diffusion model:}

The six steps in Section-4.1 were followed to solve the model equations. Detailed model equations are described in the Chapter -3 . The PDE's coefficient tran sient analysis application mode was employed. Both the mass balance equations in the liquid phase and solid phase are solved by incorporating two PDE modules and are coupled at the interphase.

\subsubsection{Geometry and meshing:}

The particle shape is consid ered to be spherical and show $n$ in the Figure - 13. In the present case the one dimensional geometry represents the radius of the particle in the subdomain region. Only solid phase $\mathrm{m}$ ass balance equations were solved in the sub-dom ain region. The length of the radius is considered as 100 microns.

Table $-\mathrm{V}$ describ es the mesh statistics employed to solve the pore diffusion model equations.

\begin{tabular}{|l|c|}
\hline $\begin{array}{l}\text { Number of degrees of } \\
\text { freedom }\end{array}$ & 242 \\
\hline Number of mesh points & 61 \\
\hline Number of elements & 60 \\
\hline $\begin{array}{l}\text { Number of boundary } \\
\text { elements }\end{array}$ & 2 \\
\hline Element length ratio & 1 \\
\hline
\end{tabular}

Table-V: Meshing statistics for pore diffusion model 


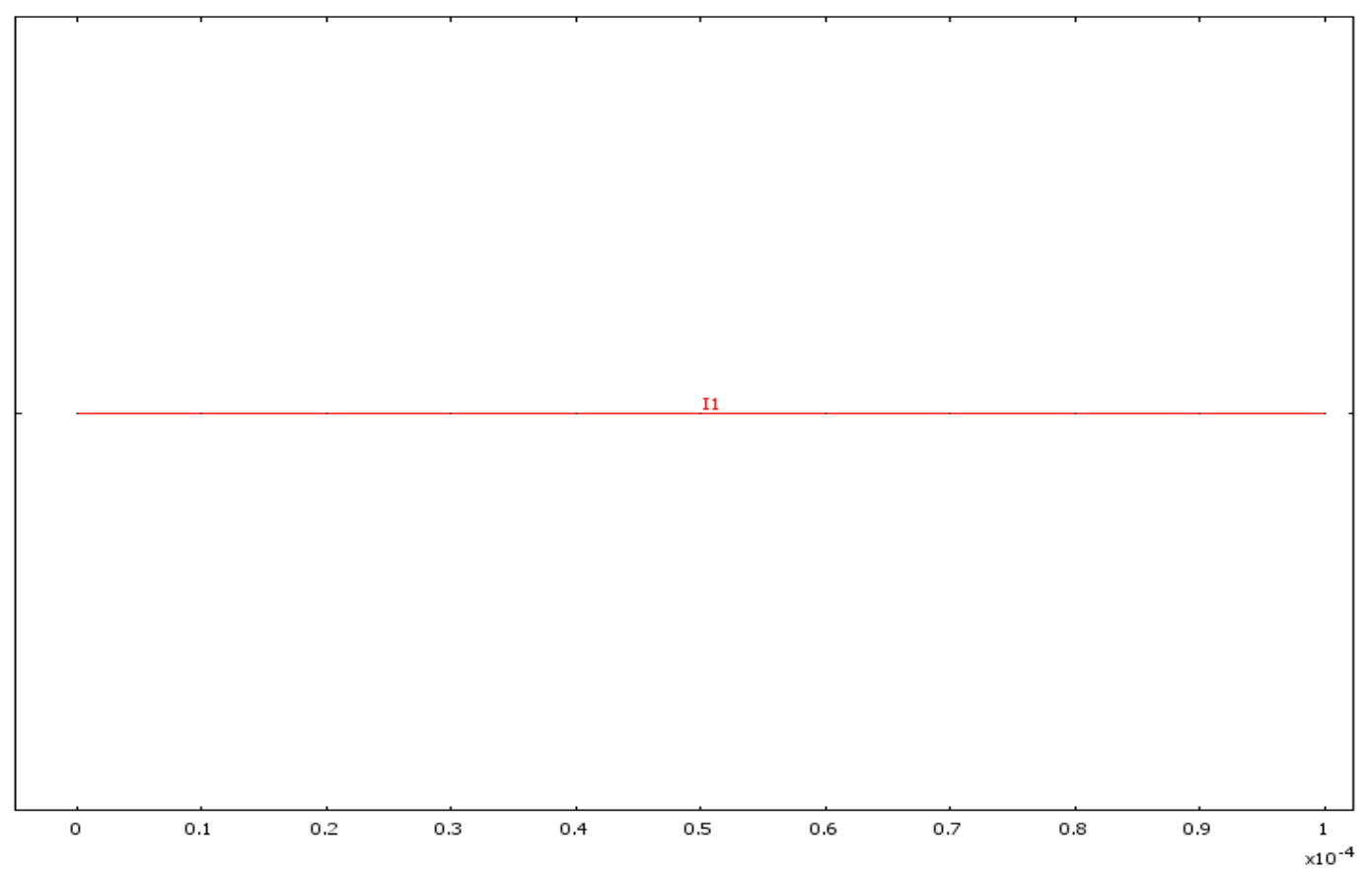

Figure-13: Geometry represents the radius of the particle.

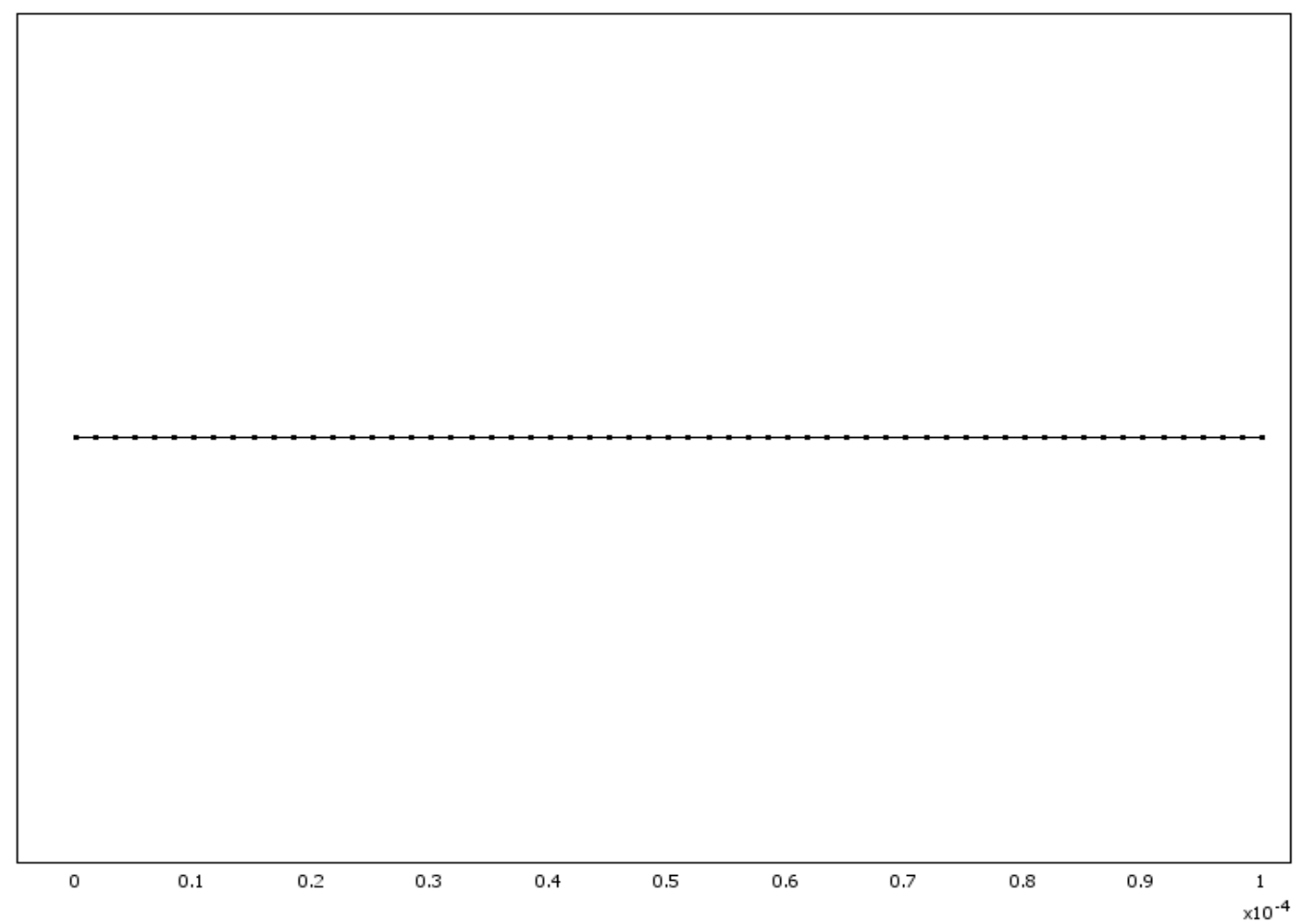

Figure-14: Meshing the geometry of the pore diffusion model 


\subsubsection{Solver settings:}

The linear system solver, tim e dependent tr ansient analysis type was used. The time parameter was set as 0-86400 s econds with an increm ent of $100 \mathrm{sec}$. The relative and absolute tolerance was set to 0.01 and 0.001 respectively.

\subsubsection{Post processing:}

The model equation was solved for the bulk ph ase liquid concentration with time at the particle surface. The co ncentration was plotte $d$ with tim e to observ e the kin etics of adsorption and was compare with the batch adsorption kinetics experimental results. The results are explained in detail in Chapter 5. 


\section{CHAPTER 5}

\section{RESULTS AND DISCUSIONS}

\subsection{Effect of Temperature on the Adsorption Equilibrium:}

Figure-15 shows the batch absorption experim ental results fitted to Langmuir adsorption isotherms at different temperatures $\left(25{ }^{0} \mathrm{C}, 35^{0} \mathrm{C}, 45^{\circ} \mathrm{C}\right)$. As observed from the plot the adsorption behavior of the test soil decreases with increase in temperature, as would be excepted Various research groups, working wi th different clay and soil sam ples have reported similar trends [12] [17] [16]. As can be seen from Figure-15 Langmuir adsorption isotherm model is in agreement with the experimental results and is given by,

$$
q=\frac{q_{0} C K}{1+C K}
$$

The equation param eters $q_{0}$, and $K$ are evaluated and by perform ing nonlinear regression on the experimental data points at different temperature. The root mean square error (RMSE) is given by $R M S E=\sqrt{\left(q_{\exp }-q_{\text {langmuir }}\right) \frac{1}{n}}$ where $\mathrm{n}$ is the number of data points. From Table VI it can be concluded that the equilibrium adsorption coefficient $K$ is a strong function of temperature, $44.5 \%, 77.5 \%$ decrease in $K$ value is observed 


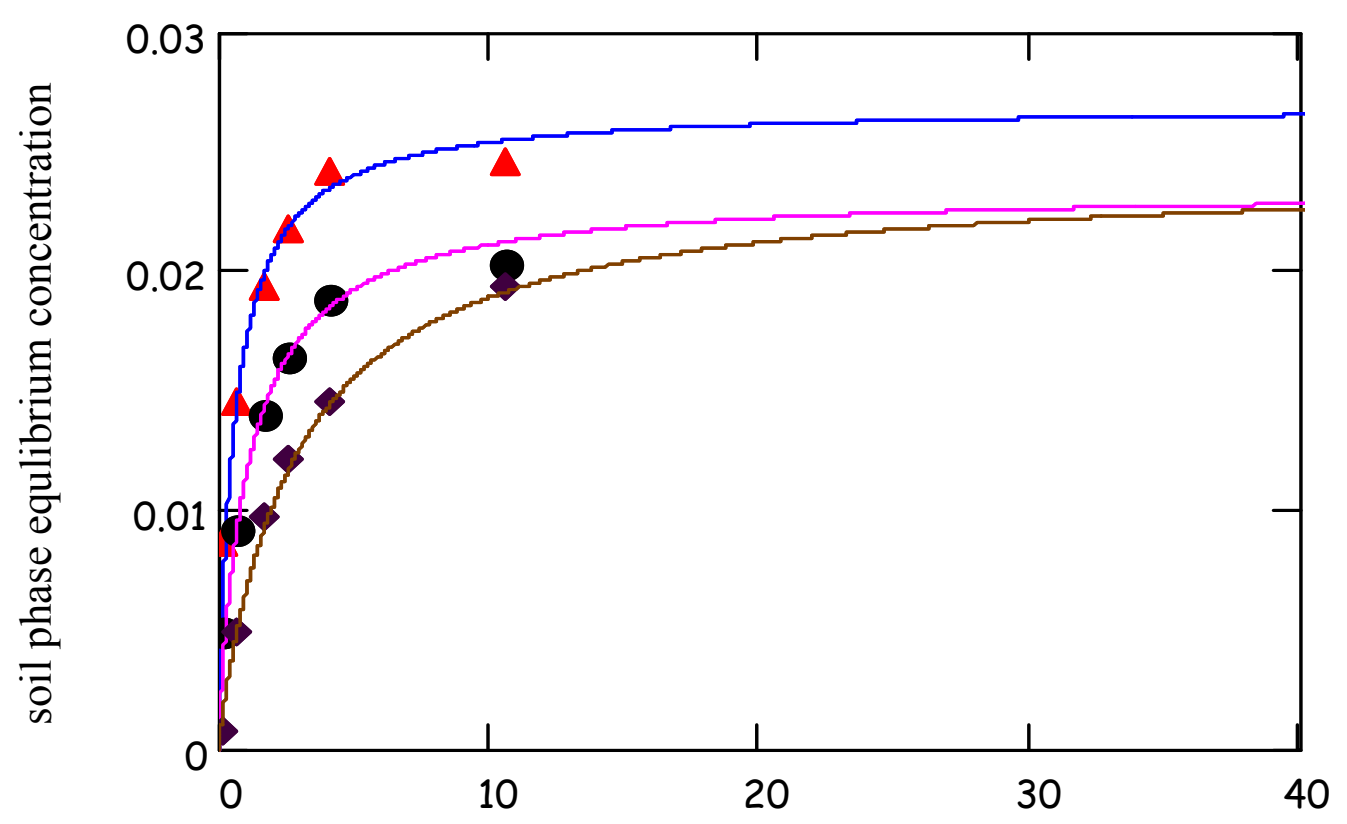

Liquid phase equlibrium concentration

$\Delta \Delta \Delta$ Exp at $25 \mathrm{C}$

- Langmuir fit

000 Exp at $35 \mathrm{C}$

Langmuir fit

$\leftrightarrow \bullet$ Exp at $45 \mathrm{C}$

Langmuir fit

Figure 15: Equilibrium Isotherms for the batch adsorption experiments solid lines:

Langmuir Curve fit, points: experimental data

when temperature increases from $25{ }^{0} \mathrm{C}-35^{\circ} \mathrm{C}$ and $25{ }^{0} \mathrm{C}-45^{\circ} \mathrm{C}$ re spectively. Little variation in case of monolayer adsorption capacity, $q_{0}$ with temperature was observed.

\begin{tabular}{|l|l|l|l|}
\hline Temperature & $q_{0}, \mathrm{~mol} / \mathrm{kg}$ & $K, \mathrm{~m}^{3} / \mathrm{mol}$ & RMSE \\
\hline
\end{tabular}




\begin{tabular}{|c|c|c|c|}
\hline $25^{\circ} \mathrm{C}$ & 0.027 & 1.633 & 0.00060 \\
\hline $35^{0} \mathrm{C}$ & 0.023 & 0.906 & 0.00069 \\
\hline $45^{\circ} \mathrm{C}$ & 0.022 & 0.357 & 0.00069 \\
\hline
\end{tabular}

Table VI: Langmuir isotherm parameters evaluated at different temperatures

\subsubsection{Effect of pH on the adsorption equilibrium:}

The batch experimental results for different $\mathrm{pH}$ conditions are provided in the Figure- 16. The results were fitted to a Langm uir model and the param eters were evaluated and are provided in Table- VII. It can be observed that at higher $\mathrm{pH}(6)$ the lead ion uptake is lower because the lead exists in hydroxide or oxide states depending on Eh (shown in the Eh-pH diagram of the lead water sys tem from Figure-4 ). As a result the availab ility of lead ions was reduced in the solutio ns which reduce the concentration gradient which is the driving force for the adsorption $\mathrm{p}$ rocess. It is also observed that at very low $\mathrm{pH}$, the uptake of lead ions was significantly reduced because of the competition between $\mathrm{H}^{+}$and $\mathrm{Pb}^{+2}$ for available adsorption $\mathrm{s}$ ites. According to the mechanism proposed by other researchers the $\mathrm{H}^{+}$ions are capable of replacing $\mathrm{Cs}^{+}$that are adsorbed to the soil surface. Along with this competition at a lower $\mathrm{pH}(0.2)$ there is the possibility of solubilizing of soil minerals resulting in the destruction of available sites which in turn lowers the $\mathrm{Pb}^{+2}$ adsorption. The adsorption coefficient is low for the very high $\mathrm{pH}$ at 6 a nd for very low $\mathrm{pH}$. It can be easily concluded from the results that under extreme $\mathrm{pH}$ levels, migration of the lead ions will be increased as they cannot readily be adsorbed on the soil surface [13]. 


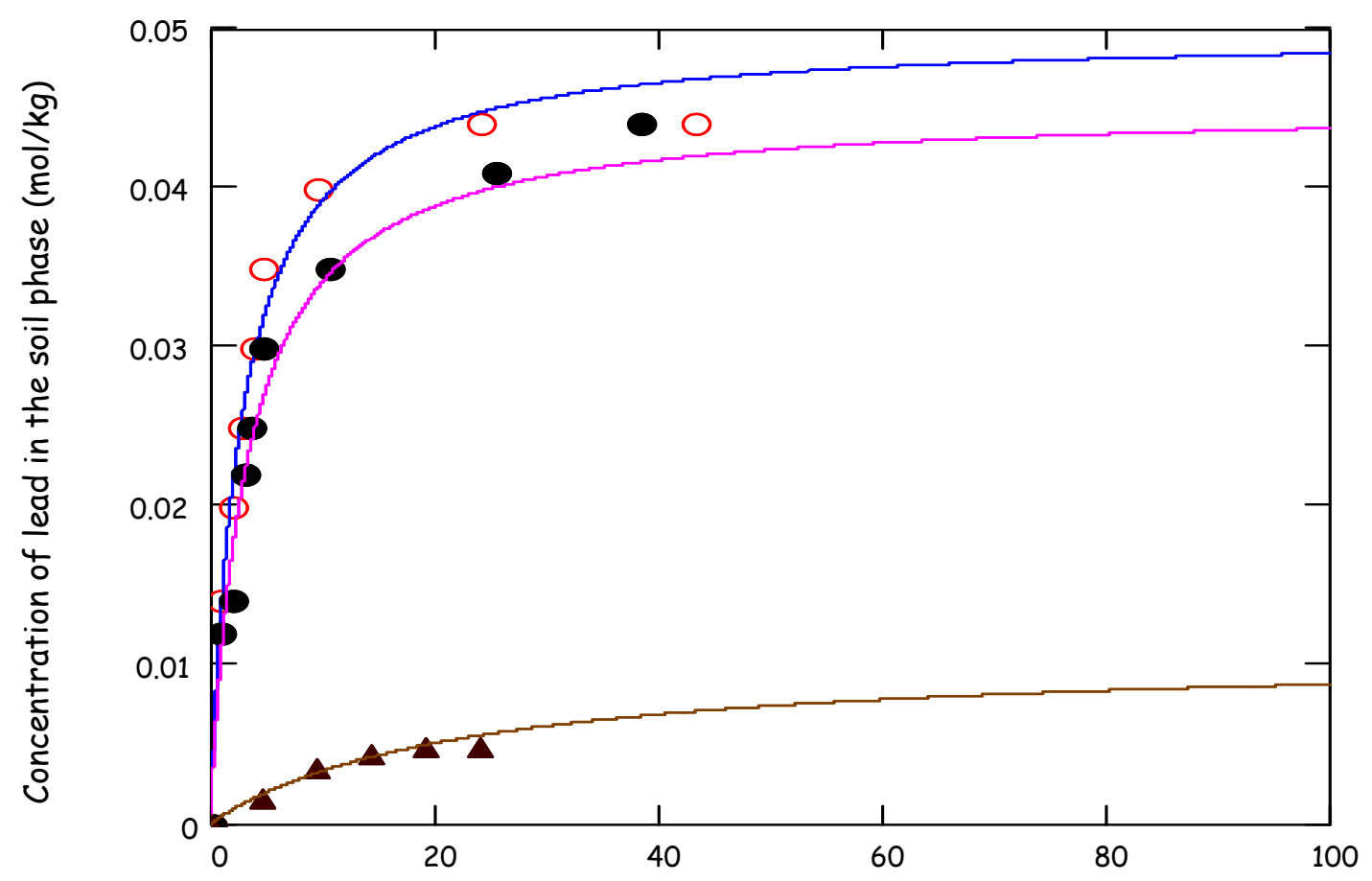

Concentration of lead in the liquid phase $\left(\mathrm{mol} / \mathrm{m}^{\wedge} 3\right.$

000 Exp pH-4.0

Langmuir fit -pH-4.0

00 Exp pH-6.0

langmuir fit $\mathrm{pH}-6.0$

$\Delta \Delta \Delta \operatorname{Exp} \mathrm{pH}-0.2$

Langmuir fit $\mathrm{pH}-0.2$

Figure-16: Langmuir fit to batch adsorption data for the different $\mathrm{pH}$ conditions

\begin{tabular}{|c|c|c|c|}
\hline $\mathrm{pH}$ & $q_{0}, \mathrm{~mol} / \mathrm{kg}$ & $K, \mathrm{~m}^{3} / \mathrm{mol}$ & RMSE \\
\hline 0.2 & 0.011 & 0.044 & 0.0002 \\
\hline 4.0 & 0.05 & 0.369 & 0.00021 \\
\hline 6.0 & & & 0.00045 \\
\hline
\end{tabular}

Table VII: Langmuir isotherm parameters evaluated at different $\mathrm{pH}$ conditions 


\subsubsection{Thermodynamics of adsorption:}

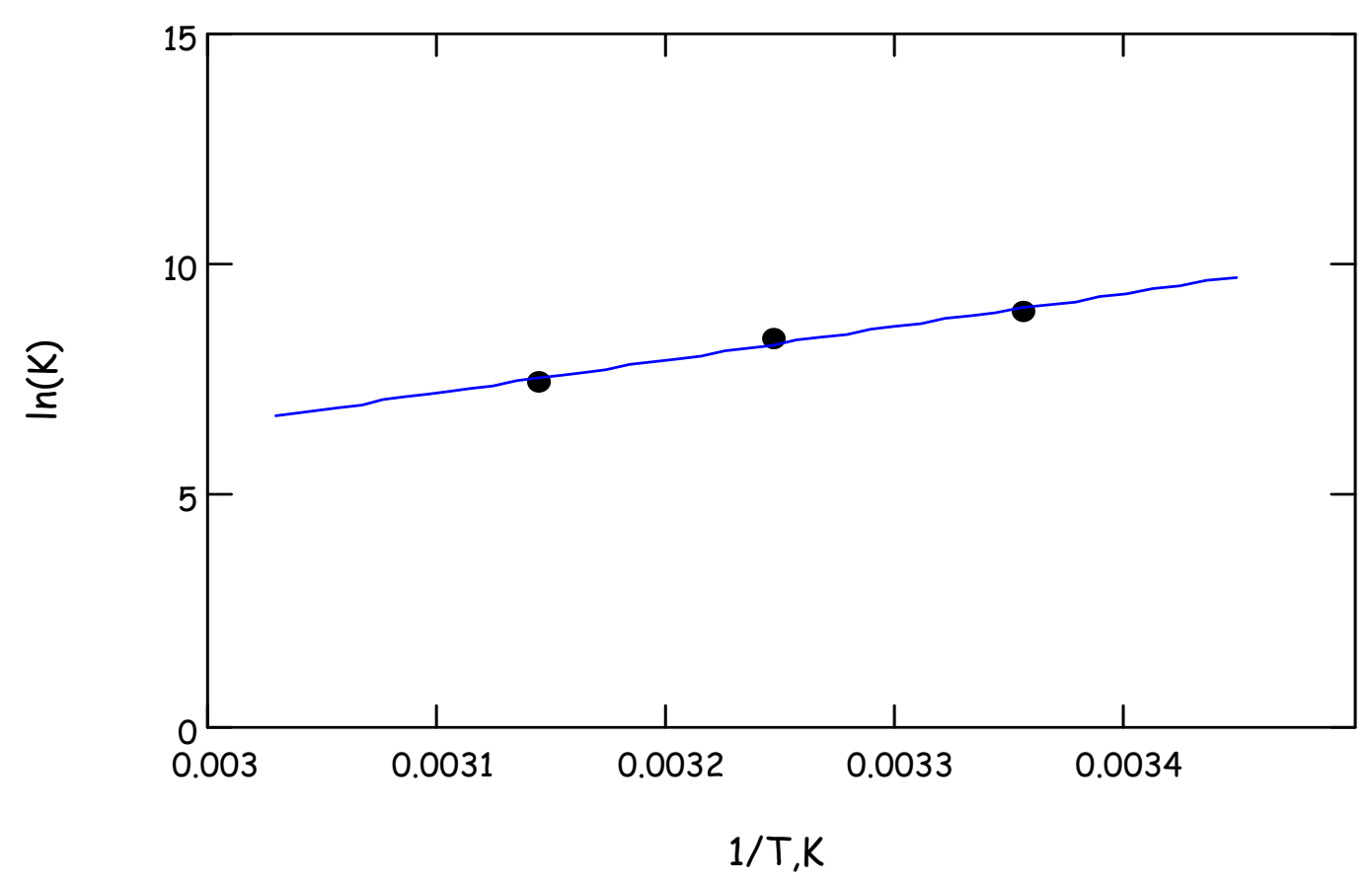

Figure-17: Van't Hoff plot for lead adsorption on Nevada test soil clay

It is evident from the experiments that the Langmuir parameter adsorption coefficient $\left(k_{d}\right)$ was a strong function of tem perature. In order to analyze the temperature dependency of the system a few therm odynamic parameters were evaluated. The Gibbs free energy $\left(\Delta G^{0}\right)$ change for different temperatur es was evaluated to check the criterion of spontaneity. The relation between free energy ch anges for sorption reaction and temperature was given by the following equation [13][50].

$$
\Delta G^{0}=-R T \ln \left(k_{d}\right)
$$

Where, $k_{d}$ is the sorption equilibrium constant, $R$ is the gas constant and $T$ is the temperature. The calculated values of the Gibbs free change in the Table-VIII confirm the spontaneity of the sorption reaction. The enthalpy changes $\left(\Delta H^{0}\right)$, entropy change $\Delta S^{0}$ 
are evaluated by the slope and the intercept of the straight line equation given below and are tabulated.

$$
\Delta G^{0}=\Delta H^{0}-T \Delta S^{0}
$$

Combining the equation $a$ and $b$, the following expression is obtained which is the Van't Hoff's Equation.

$$
\ln \left(k_{d}\right)=\frac{\Delta H^{0}}{R T}-\frac{\Delta S^{0}}{R}
$$

The linear regres sion of experimental results with Van't Hoff equation is shown in Figure-17. If $\Delta H^{0}$ is positiv e, the sorption reaction is considered to be endotherm ic. $\Delta H^{0}$ is found to be $59.7 \mathrm{~kJ} / \mathrm{mol}$ for the plot (Figure-17). It is reported that the value $\Delta H^{0}$ for chemisorptions is between $40-120 \mathrm{KJ} / \mathrm{mol}$. [51] [50] Hence, chemisorptions predominate. It can therefore be concluded that the adsorption of lead ions on Nevada test soil is dominated by chemisorption.

\begin{tabular}{|c|c|}
\hline Temperature $(K)$ & Gibbs free energy $(\mathrm{KJ} / \mathrm{mol})$ \\
\hline 298 & -22.22 \\
\hline 308 & -21.47 \\
\hline 318 & -19.7 \\
\hline
\end{tabular}

Table-VIII: Change in Gibbs free energy at different temperature 


\subsection{Kinetics of Adsorption process:}

Batch experiments were used to quantify the dynamics of sorptive uptake of contaminates on the soil and sedim ents. The results of the batch adsorption kinetics data are shown in the Figure -18 . The lead ion concentration in the bulk liquid phase decreases with tim e due to the adsorption of lead ions onto th e surface. During the first few $\mathrm{m}$ inutes the concentration drops steeply as shown in the Figure -18 due to the high concentration

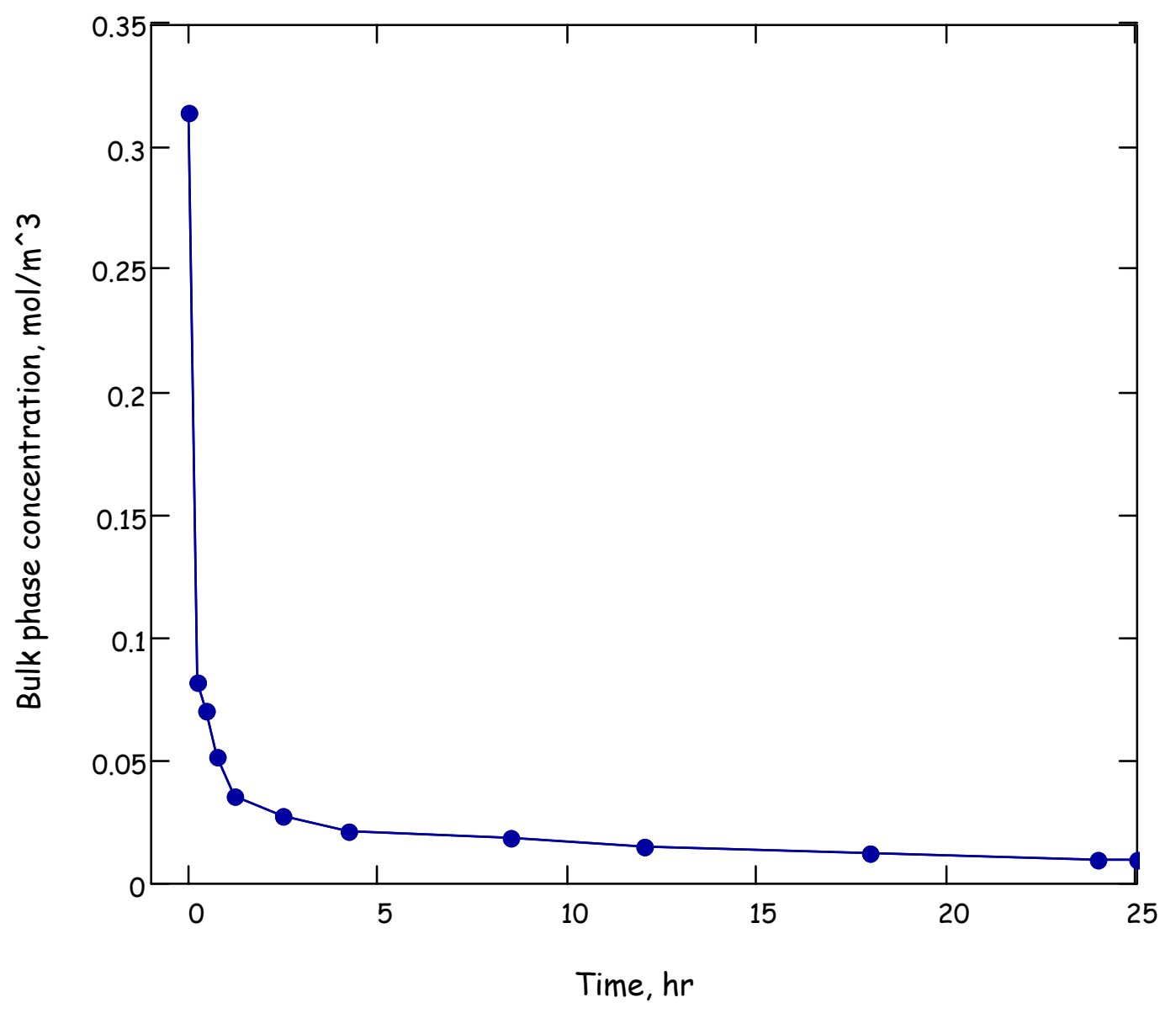

$\cdots$ Experimetal

-... model - 35C

Figure-18: Kinetic batch experimental results 
gradient. Since the lead solutions are properl y mixed with soil samples the mass transfer resistance at the inter-phase are negligible which results in fast uptake of the lead on the soil. It is observed that during the firs $t$ hour the con centration decreases $\mathrm{f}$ rom $0.314 \mathrm{~mol} / \mathrm{m}^{3}$ to $0.035 \mathrm{~mol} / \mathrm{m}^{3}$ dropping nearly $1 / 10^{\text {th }}$ the initial concen tration. Later it decreases gradually and drops to the equilibrium concentration of $0.012 \mathrm{~mol} / \mathrm{m}^{3} \mathrm{after}$ 24hr. It appears that the adsorption process is controlled by the diffusion phenom ena as time elapses in the present case also. The lead ions have to diffuse through the liquid phase, then through the soil particle and ad sorb on to the soil surface. As a result the system takes considerably longer time to reach equilibrium. The liquid phase diffusion is completely neglected as the system was under optimum mixing conditions at all tim e. The diffusion process is expl ained by Fick's Second Law. The entire system was modeled using the pore diffusion model explai ned in the Chapter 3 to evaluate the diffusion coefficient by the curve fitting routine procedure.

\subsubsection{Simulation using Comsol Multiphysics:}

The PDE coefficient module was employed to solve the unsteady state liquid phase and solid phase mass balance equations which are coupled with a Langmuir adsorption. The expression obtained by taking the derivative of the equilibrium isotherm with respect to liquid phase concentration is fitted with the time scaling coefficient expression in the subdomain setting in the option $\mathrm{m}$ enu. The dist ribution coefficient and the $\mathrm{m}$ onolayer capacity in the expression were evaluated from the equilibrium batch experiments.

The parameters and the constants used are listed in Table IX. The m odel equations were solved for the liqu id phase concentration with time and concentration distribution in a 
single spherical soil particle. In itially the so lution concentration $C_{A_{0}}(t=0)$ in the sub-domain region (inside the particle) is zero and the required parameters to be specified in the sub-domain setting option are taken for the Table IX. The system was simulated for the different initial concentrations and $K$ values to va lidate the model with the experimental results which in turn gives the effect of temperature.

\begin{tabular}{|c|c|}
\hline$C_{A 0}$ & $0.314 \mathrm{~mol} / \mathrm{m}^{3}$ \\
\hline$K$ & $1.633,0.906,0.357 \mathrm{~m}^{3} / \mathrm{mol}$ \\
\hline$\varepsilon$ & 0.7 \\
\hline$\rho$ & $1500 \mathrm{~kg} / \mathrm{m}^{3}$ \\
\hline$q_{0}$ & $0.027,0.023,0.022 \mathrm{~mol} / \mathrm{kg}$ \\
\hline$D_{e f}$ & $9 \times 10^{-12} \mathrm{~m}^{2} / \mathrm{s}$ \\
\hline$\delta t$ & $\varepsilon+\rho \frac{q_{0} K}{(1+K C)^{2}}$ \\
\hline
\end{tabular}

Table IX: Parameters and constants for the pore diffusion model

\subsubsection{Initial and boundary conditions:}

The geometry of the soil particle was assum ed to be spherical. Figure - 19 represents the one dimensional geometry of the soil particle. The average particle radius is considered to be around 100microns and is shown in Figure-19 and discretized into 60 elements. Initial and boundary conditions are given in the Table $-\mathrm{X}$. 


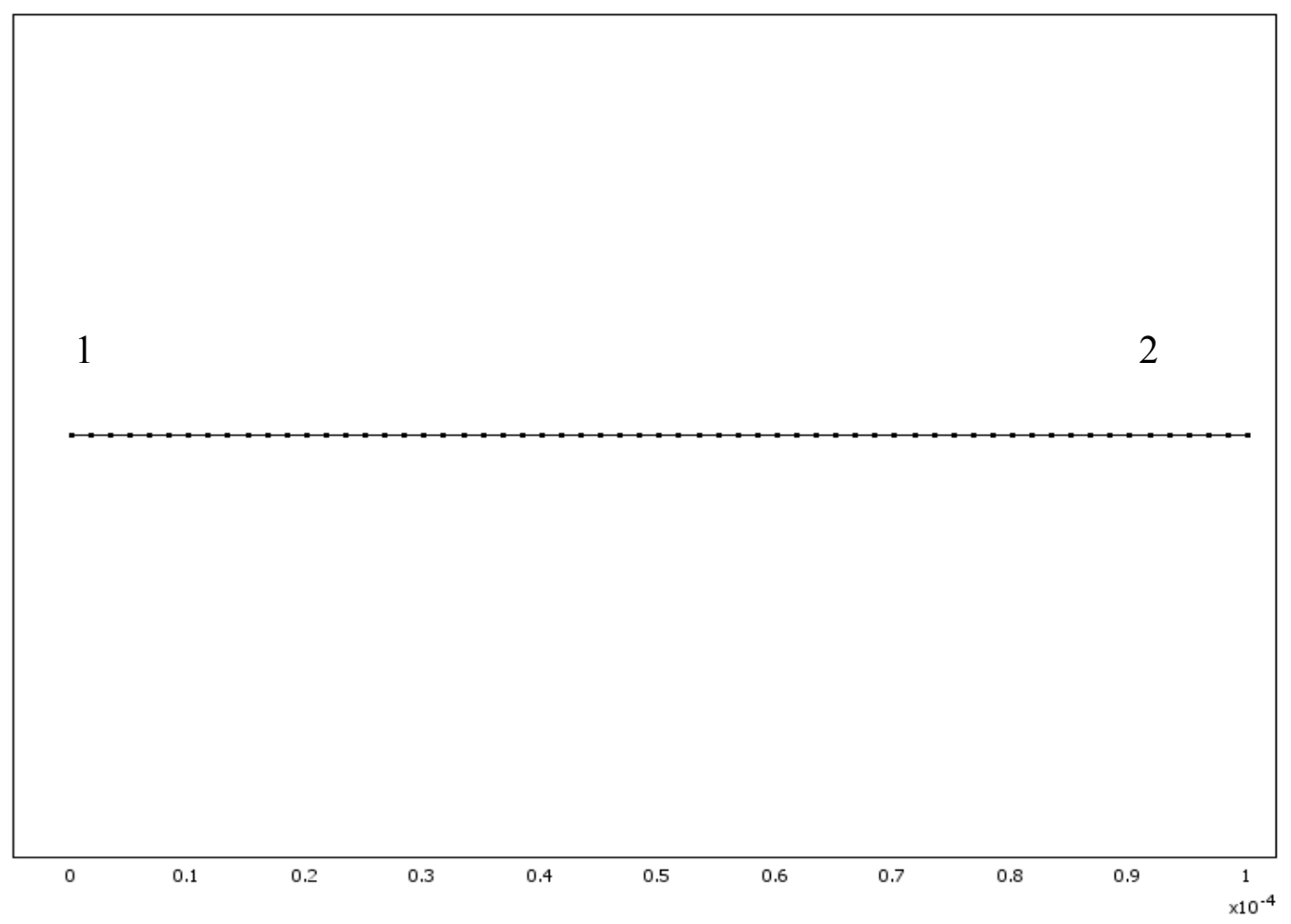

Figure-19: Representation of particle radius in one dimension

\begin{tabular}{|c|c|}
\hline Boundaries & Boundary conditions \\
\hline 1 & Insulation (Flux $\left.=0, \frac{\partial C}{\partial t}=0\right) t \geq 0$ \\
\hline 2 & $\frac{\partial C}{\partial r}=-\frac{d C_{A}}{d t}\left(\frac{V}{m S}\right) D_{e f} t \geq 0$ \\
\hline $\begin{array}{c}\text { Initial bulk phase } \\
\text { concentration }\end{array}$ & $C_{A}=0.314 \frac{m o l}{m^{3}}$ at $t=0$ \\
\hline
\end{tabular}

Table X: Initial and Boundary conditions 


\subsubsection{Simulation results:}

The partial differential equations obtained from the mass balance on the spherical soil particle represented by the sub-dom ain region in the Com sol- Multiphysics-3.2 coupled with liquid phase $\mathrm{m}$ ass balance equation are solved for the $\mathrm{c}$ oncentration distribution in the soil particle.

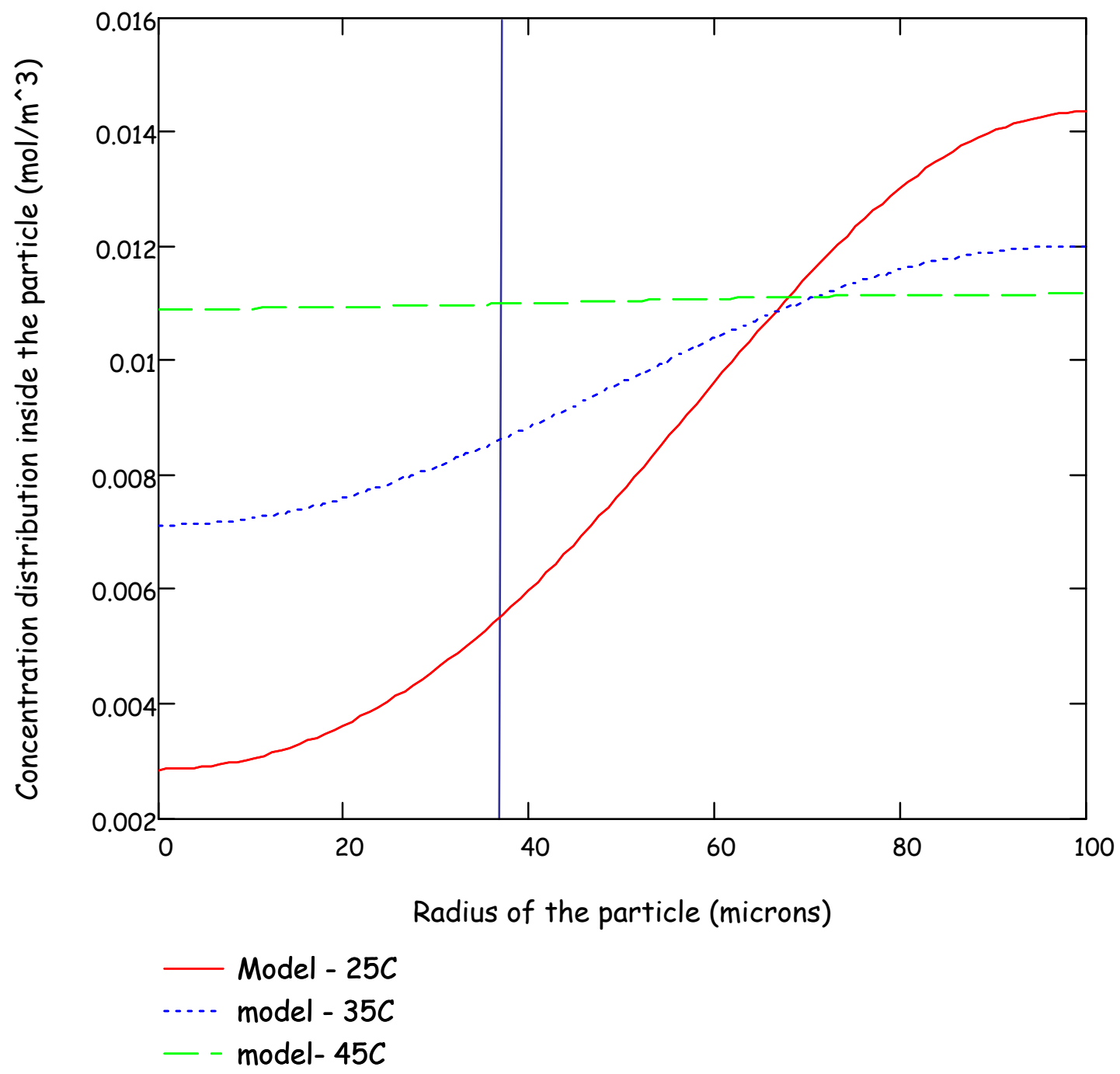

Figure - 20: Concentration distribution inside a particle at different temperature 
Figure - 20 represents the sim ulated liquid phase concentration profile in a spherical soil particle after $10 \mathrm{hr}$ of adsorp tion dynamics for different valu es of adsorption coefficient $K_{d}$ of $1.633,0.906$, and $0.357 \mathrm{~m}^{3} / \mathrm{mol}$ obtained from equilibrium adsorption batch experiments at different tem peratures such as $25^{\circ} \mathrm{C}, 35^{\circ} \mathrm{C}$, and $45^{\circ} \mathrm{C}$, respectively. All other parameters such as density, porosity and particle size, are kept constant as given in Table - X. It was observed from the results in Figure-14 that the ou ter surface of the particle (at 100microns) the concen tration is maximum as far as first case is con cern $\left(25^{\circ} \mathrm{C}\right)$. From the surface towards th e center of the particle, the concentration decreases. In the second case $\left(35^{\circ} \mathrm{C}\right)$ the trend is similar but the curve is approaching the uniform concentration along the length of the radius. In the third case $\left(45^{\circ} \mathrm{C}\right)$ the profile is almost horizontal to the $\mathrm{x}$-axis, indicating that the co ncentration is the same at all points in side the particle. It shows that as the temperature increases the concentration profile inside the particle flattens. At 100 microns radius ins ide the $\mathrm{p}$ article the $\mathrm{c}$ oncentrations at temperatures $25^{\circ} \mathrm{C}, 35^{\circ} \mathrm{C}, 45^{\circ} \mathrm{C}$ are $5.983 \times 10^{-3} \mathrm{~mol} / \mathrm{m}^{3}, 8.84 \times 10^{-3} \mathrm{~mol} / \mathrm{m}^{3}, 0.011 \mathrm{~mol} / \mathrm{m}^{3}$ respectively after the sam e simulation time of $10 \mathrm{hr}$. Lead ions diffus e more quickly at higher temperature because of high $\mathrm{m}$ ass transfer rate and increasing behavior of diffusion coefficient $\left(D_{e f}\right)$ with temperature. Hence the diffusion coefficient is an important parameter that needs to be determined. 


\subsubsection{Parametric study of adsorption dynamic:}

The mass balance equations in the liquid pha se and the solid phase coupled with a Langmuir isotherm were solved simultaneous ly for bulk phase concentration and are shown in the Figure - 21. Effective diffusion coefficient was varied as the fitting parameter in the model equations.

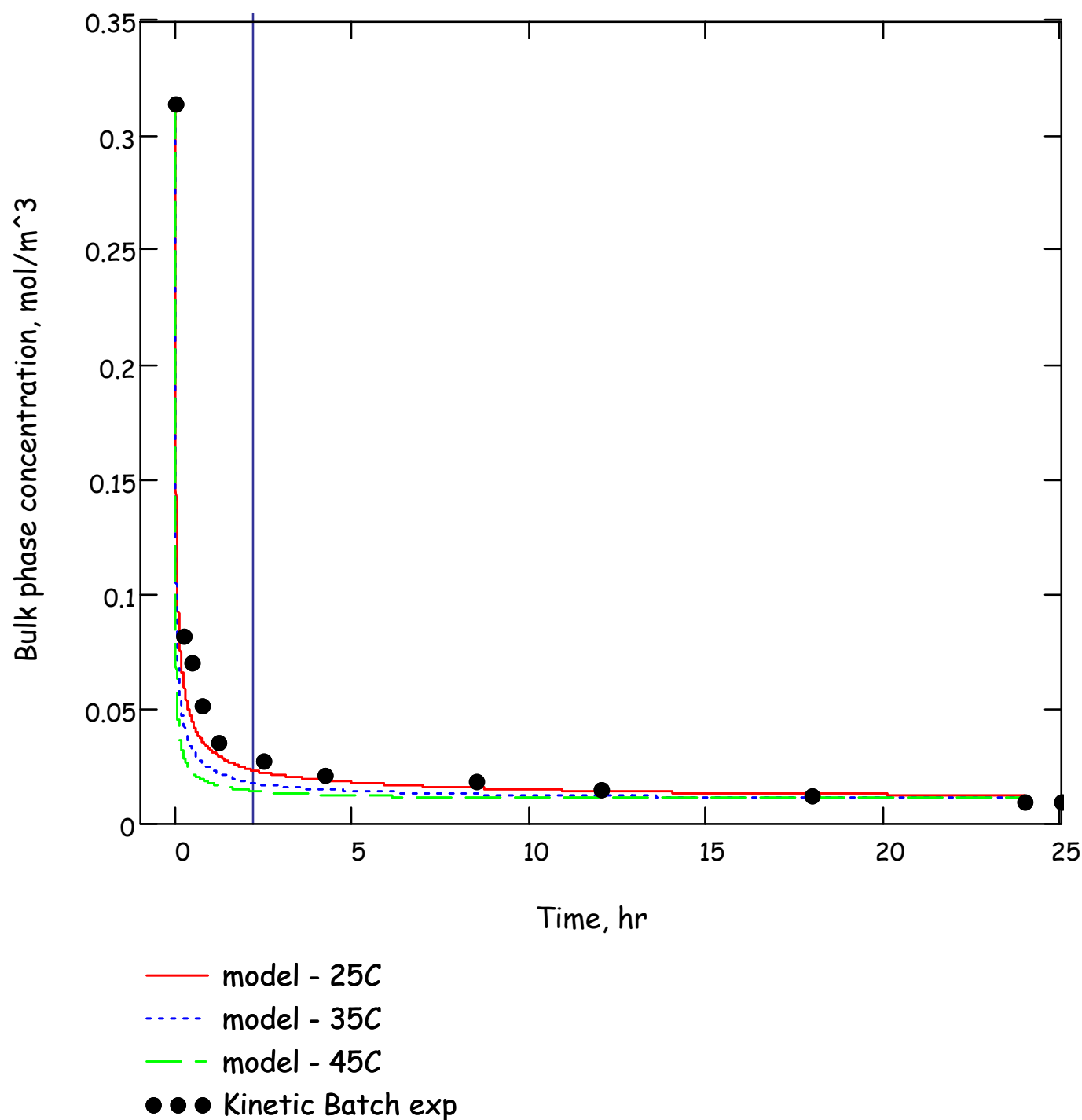

Figure-21: Adsorption dynamic data fitted to pore diffusion model equations and modeling results for different $K_{d}$ values 
Using non-linear regression analys is on the kinetic batch expe rimental data the diffusion coefficient was found to be $9 \times 10^{-12} \mathrm{~m}^{2} / \mathrm{s}$. The experimental data agrees with the model predictions based on diffusion limited intra-particle sorption. The simulation was carried out for different $K_{d}$ values such as $1.633,0.906$, and $0.357 \mathrm{~m}^{3} / \mathrm{mol}$ evaluated from the batch equilibrium experiments at different te mperatures. All other param eters, such as porosity and density, were kept constant. Since $K_{d}$ is a function of temperature, the simulation at different $K_{d}$ values can be considered as

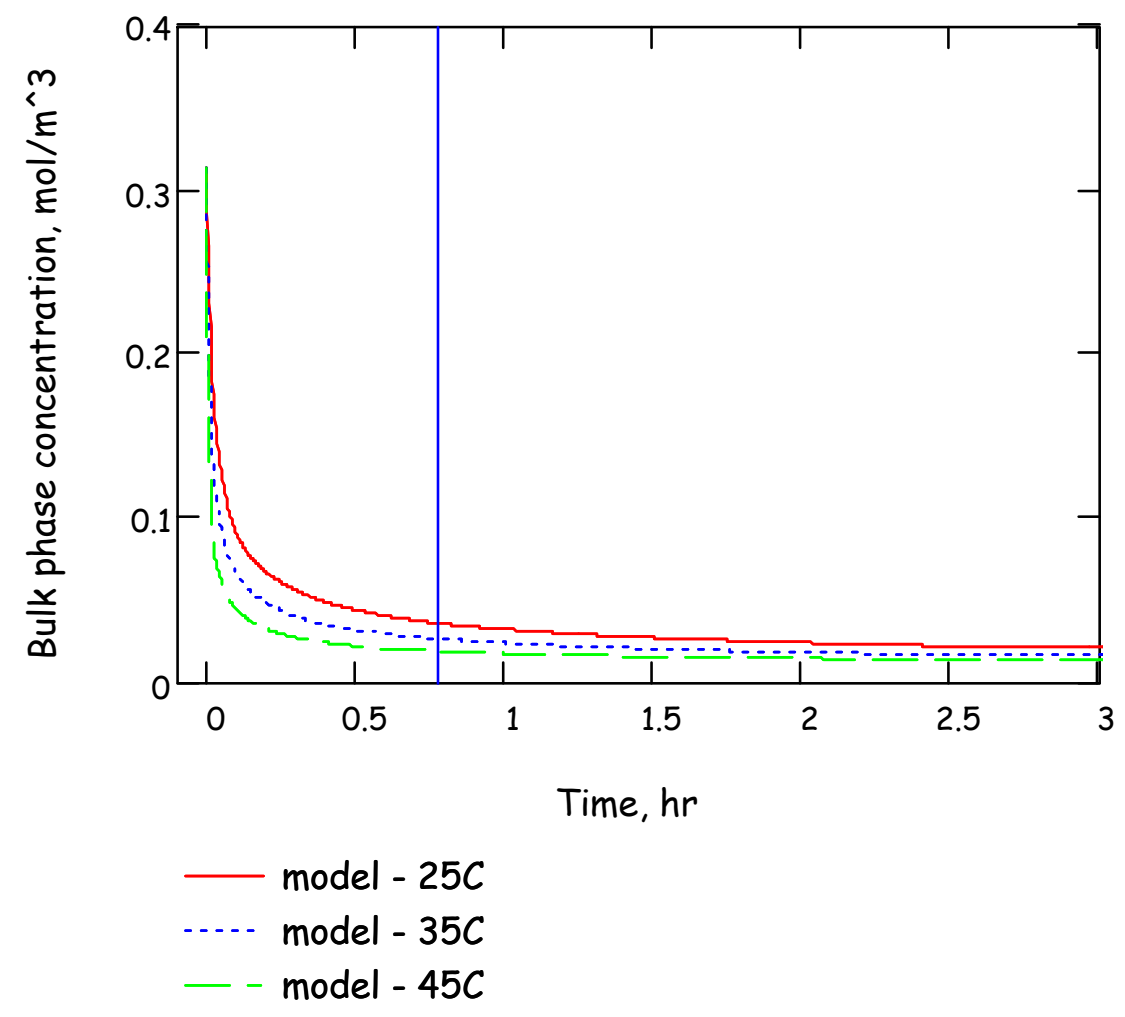

Figure -22: simulation results after $3 \mathrm{hr}$ for different $K_{d}$ values 
the temperature dependency of the s ystem. Figure -22 represents the model predicted results after $3 \mathrm{hr}$. It is observed from Figure -14 that the concentration drops from $0.314 \mathrm{~mol} / \mathrm{m}^{3}$ to $0.032 \mathrm{~mol} / \mathrm{m}^{3}, 0.024 \mathrm{~mol} / \mathrm{m}^{3}$ and to $0.017 \mathrm{~mol} / \mathrm{m}^{3}$ in case of $25^{\circ} \mathrm{C}, 35^{\circ} \mathrm{C}, 45^{\circ} \mathrm{C}$ respectively. This indicates that the diffusion is high at higher temperatures. The only parameter in the model equation that depends on temperatures is the diffusion coefficient and it increases with the increase in temperature.

\subsubsection{Effect of initial concentration on adsorption dynamics:}

Simulations were repeated for changes in the initial concentration of the bulk phase. The batch kinetics experim ents conducted at $0.314 \mathrm{~mol} / \mathrm{m}^{3}$ agreed well with the model predicted results. The initial co ncentration of the solution was changed to $0.514 \mathrm{~mol} / \mathrm{m}^{3}, 0.714 \mathrm{~mol} / \mathrm{m}^{3}$ and $1 \mathrm{~mol} / \mathrm{m}^{3}$. The trends in all the cases were the same as an upward shift with a measured initial concentration. At higher concentrations the gradient is greater but the diffusion co efficient is low since the sim ulation was performed at $25^{\circ} \mathrm{C}$. The final equilibrium concentration is also depend ent on the initial concentration. Hence, it can be concluded that at higher temperatures the adsorptio $n$ is limited by the diffusion rate. 


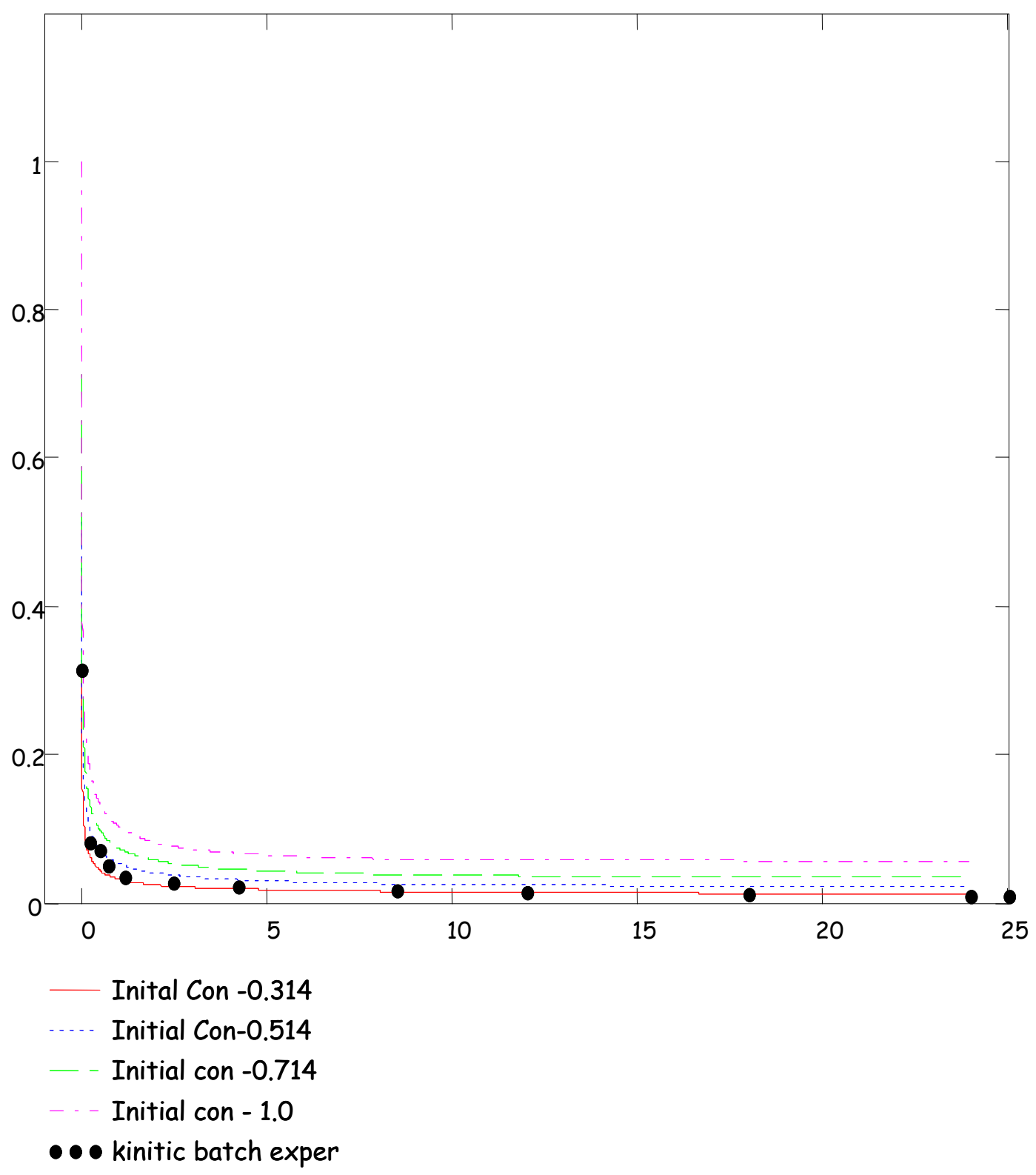

Figure-23: Bulk phase concentration profile at different initial conditions 


\subsection{Experimental and Simulation Results of Column Experiments}

The convection diffusion $\mathrm{m}$ odel in the chem ical engineering module was em ployed to solve the unsteady state liquid phase $\mathrm{m}$ ass balance which is coupled with Langm uir adsorption. The expression obtained by taking the derivativ e of the equilibrium isotherm with respect to liquid $p$ hase concentration is $\mathrm{f}$ itted with the time scaling coef ficient expression in the sub-domain setting in the option menu. The distribution coefficient and the monolayer capacity in the expression we re evaluated from the batch experim ents. Inlet velocity of the solution was evaluated by coupling ADRE with Darcy's law.

The parameters and the constan ts are list ed in Table XII. Initia lly the solu tion concentration $C_{0}(t=0)$ in the sub-dom ain region (5 in Figure 24) is zero and the required parameters to be specified in the sub-domain setting option are taken from Table XII. The system simulated the different bed thicknesses and $K$ values to validate the model from the experimental results. The simulation time is 30 minutes performed using $1.8 \mathrm{MHz}$ - Pentium 4 processor.

\subsubsection{Initial and boundary conditions:}

Schematic 2-dimension geometry of the co lumn packed with so il was crea ted. The dimensions were selected to exactly match the column used in the migration experiments. The boundaries of the geometry are shown in Figure-24. The boundary conditions for the geometry are provided in Table XII. 


\begin{tabular}{|c|c|}
\hline$C_{0}$ & $0.314 \mathrm{~mol} / \mathrm{m}^{3}$ \\
\hline$K$ & $1.633,0.906,0.357 \mathrm{~m}^{3} / \mathrm{mol}$ \\
\hline$\varepsilon$ & 0.45 \\
\hline$\rho$ & $1500 \mathrm{~kg} / \mathrm{m}^{3}$ \\
\hline$q_{0}$ & $0.027,0.023,0.022 \mathrm{~mol} / \mathrm{kg}$ \\
\hline$v$ & $1.5 * 10^{-5} \mathrm{~m} / \mathrm{s}$ \\
\hline$D_{L}$ & $8.7 * 10^{-7} \mathrm{~m}^{2} / \mathrm{s}$ \\
\hline$\delta t$ & $1+\frac{(1-\varepsilon)}{\varepsilon} \frac{q_{0} K}{(1+K C)^{2}}$ \\
\hline
\end{tabular}

Table XII: values for parameters and constants

4

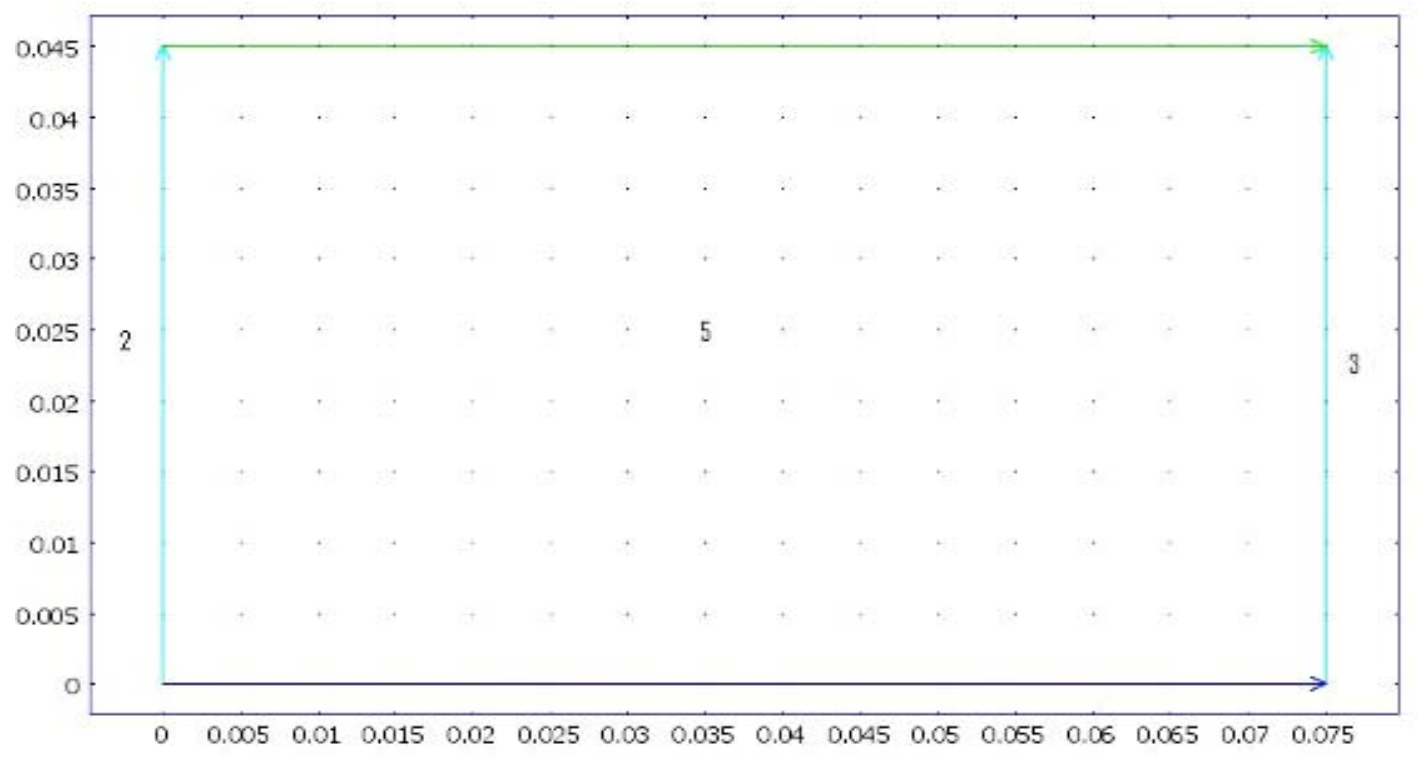

Figure-24: Boundaries of the geometry representing the column 


\begin{tabular}{|c|c|}
\hline Boundaries & Boundary conditions \\
\hline 1 & $\mathrm{C}=\mathrm{C}_{0} \quad t \geq 0$ \\
\hline 2 & Insulation (Flux $\left.=0, \frac{\partial C}{\partial t}=0\right) t \geq 0$ \\
\hline 3 & Insulation (Flux $\left.=0, \frac{\partial C}{\partial t}=0\right) t \geq 0$ \\
\hline 4 & Convective Flux $t \geq 0$ \\
\hline
\end{tabular}

Table XII: Initial and Boundary conditions 


\subsubsection{Quantitative evaluation of migration behavior:}

The model predicts the outlet concentration as a function of tim e and the concentration distribution of lead in the column as shown in Figure 25. The bed thickness and inlet lead concentrations were varied and th e results were compared with ex perimental data. Simulations were performed for different values of $K$ obtained from batch experiments and used to validate the model. The uniqueness of this model is that it readily couples a nonlinear adsorption isotherm with the "advective dispersion transport equation" which is an improvement over the lim itation constrained to line ar adsorption [12][10][17]. Comsol Multiphysics gives $\mathrm{m}$ uch better visualization of results to better understand the phenomena of contaminant transport in soil medium.

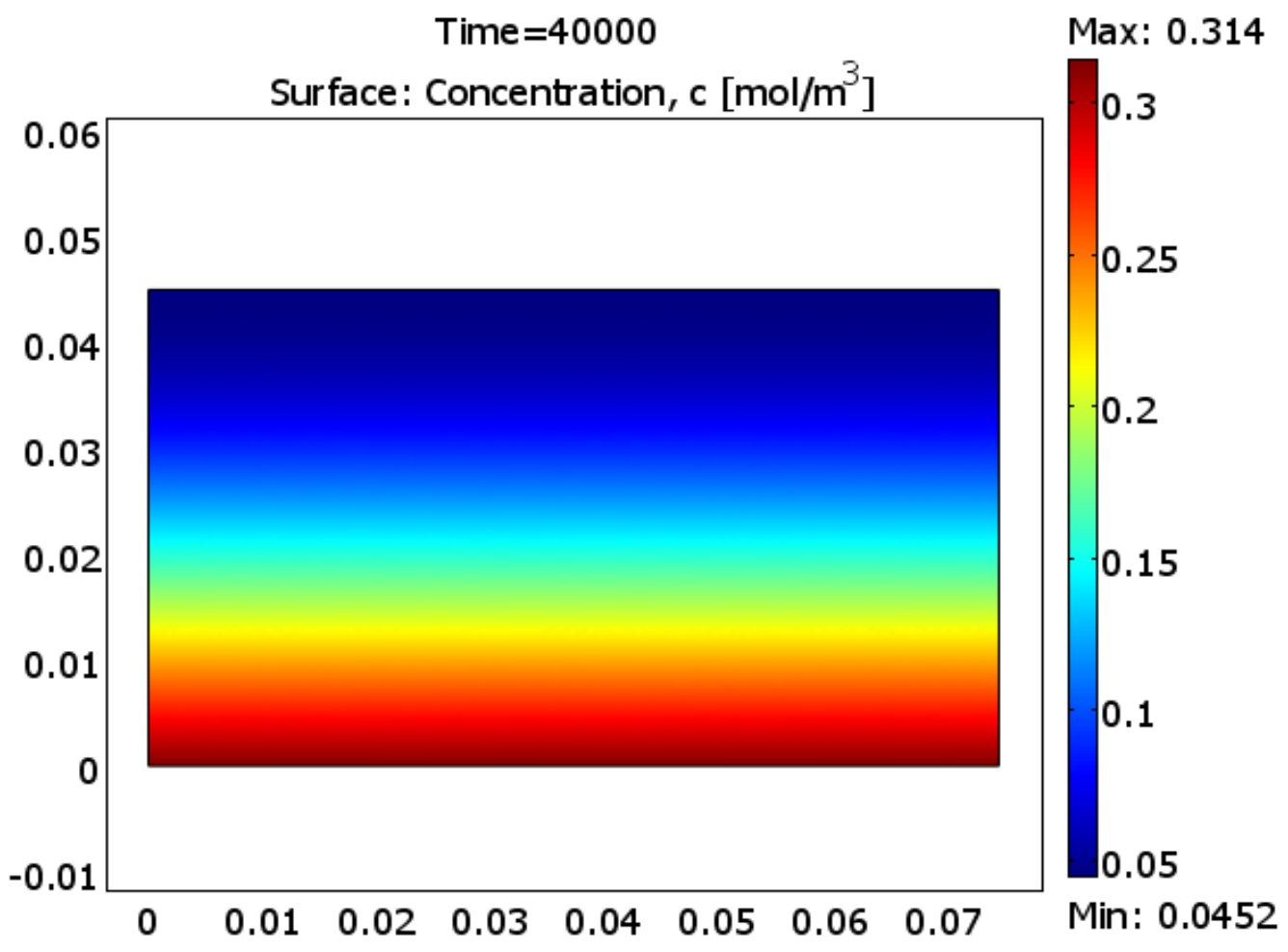

Figure-25: Simulated Lead Concentration Distribution in the column 


\subsubsection{Effect of bed thickness:}

The model equation was solved for different soil bed thicknesses. The effect on effluent concentration was reported for a flow rate of $6 \mathrm{ml} / \mathrm{min}$ at an inlet solution concentration of $0.314 \mathrm{~mol} / \mathrm{m}^{3}$. Figure-25 shows the simulation of the considered bed thickness. Break through curves from the column experiments for different thicknesses are shown in


Figure - 26: Break through curve at various bed thicknesses 
Figure-26. It was observed that as the bed thickness increased from $3 \mathrm{~cm}$ to $4.5 \mathrm{~cm}$, and from 4.5 to $7 \mathrm{~cm}$, the break through saturation point time increases from $1.5^{*} 10^{5} \mathrm{sec}$ to $2 * 10^{5} \mathrm{sec}$ and from $2 * 10^{5} \mathrm{sec}$ to $4.0^{*} 10^{5} \mathrm{sec}$, respectively. This shows that in smaller bed thicknesses the effluent concentration increases faster than deeper ones. In turn, the bed gets saturated in less tim e for smaller bed th ickness. Logically, it follows that for a smaller bed thickness, less soil (ad sorbent) is available w hich means smaller capacity, and the uptake will be $\mathrm{f}$ aster. The simulated results are in agreement with the migration experimental data, as shown in Figure.26.

\subsubsection{Effect of inlet concentration:}

The resulting change in break-through curves by varying effluent concentration is provided in Figure-27. The inlet adsorbate concentration considered $\mathrm{w}$ as $0.314 \mathrm{~mol} / \mathrm{m}^{3}$, $0.414 \mathrm{~mol} / \mathrm{m}^{3}$ and $0.514 \mathrm{~mol} / \mathrm{m}^{3}$. The simulation was performed with a constant bed height $(4.5 \mathrm{~cm})$ and flow rate $(6 \mathrm{~m} \mathrm{l} / \mathrm{min})$. From Figure -27 , we can see that as the inlet solution concentration increases the time of break through decreases and the break through curve becomes steeper for higher values of feed concentration, because the $\mathrm{m}$ ass transfer rate reduces from bulk solution to the particle surfac e due to the driving force. In addition, at higher concentration, the concentration gradient increases while the isotherm gradient is less, resulting in a higher driving force along the pores. Thus, the equilibrium is attained faster for values of higher adsorbent concentration as represented in the Figure 27. 


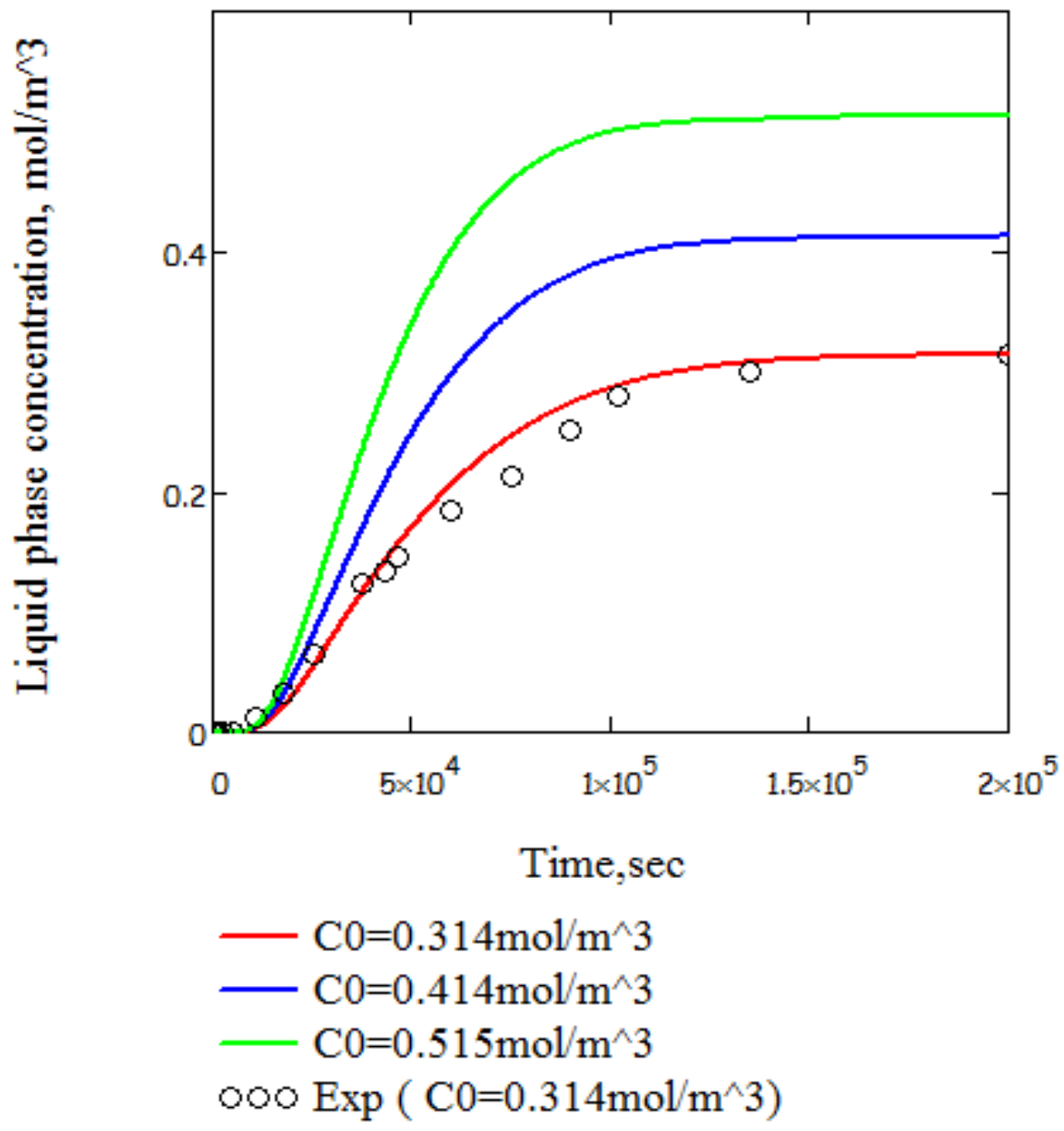

Figure - 27: Effect of inlet adsorbate concentration on break through curve 


\subsubsection{Effect of adsorption Coefficient:}

Batch experiments revealed that the adso rption coefficient is a strong function of temperature. It can be concluded that the simulation for different values of $K$ represents the behavior of the system at different temperature. The values obtained for $K$ at different temperatures from curve fitting to batch experimental data are incorporated in the

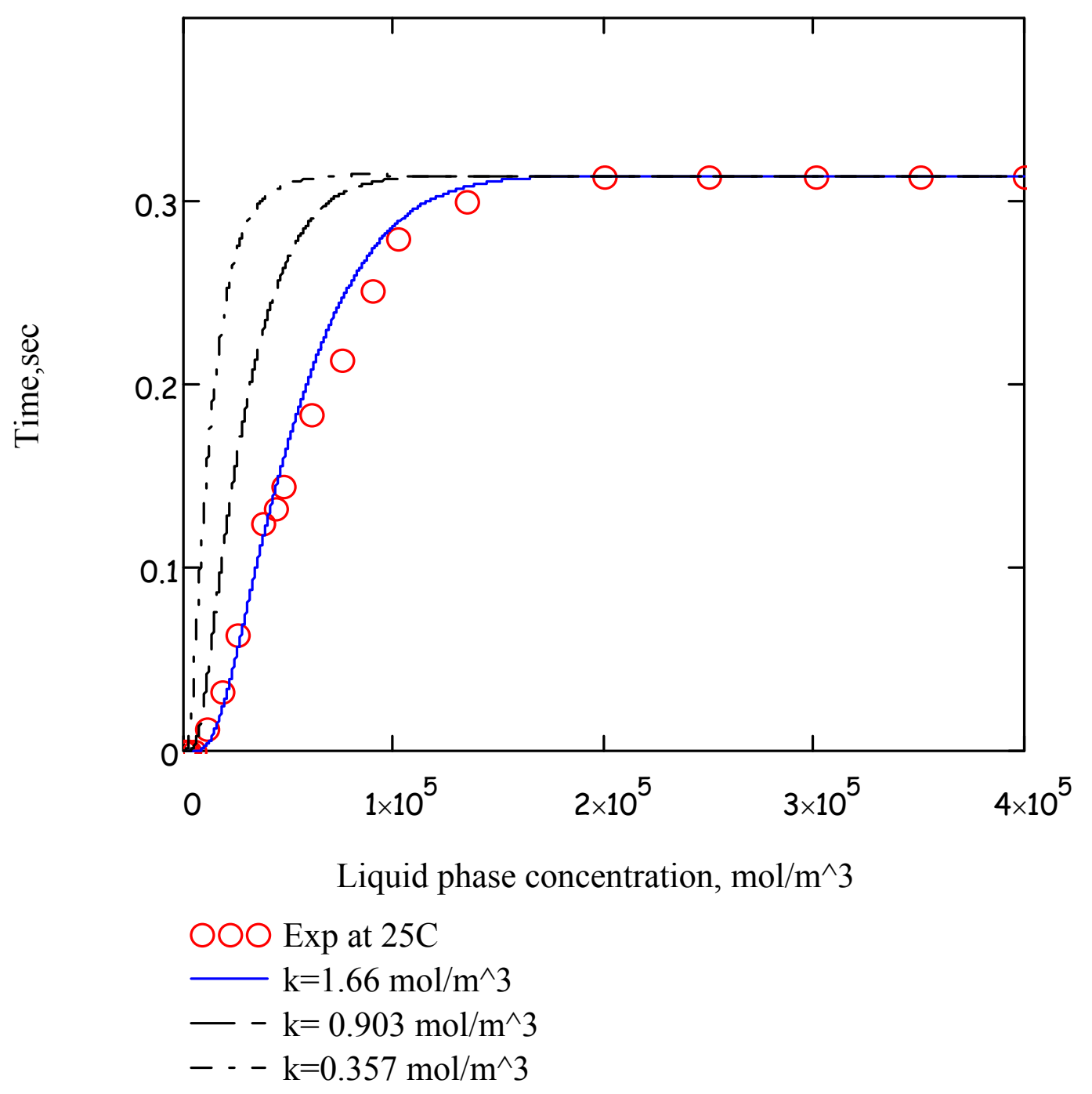

Figure - 28: Break through curves for different values of adsorption Coefficient 
migration model. The effect of adsorption coefficient on effluent concen tration at different values of $K$ is presented in Figure 28. Other para meters, such as flow rate, inlet concentration and bed thickness, were held constant at $6 \mathrm{ml} / \mathrm{min}, 0.314 \mathrm{~mol} / \mathrm{m}^{3}$, and $4.5 \mathrm{~cm}$ respectively. The specific $K$ values considered are given in Table III. Figure 28 shows the variation of break through cu rves for the various con ditions. The soil $\mathrm{b}$ ed attains saturation in less time as the $K$ decreases. When $K$ value was less, the quantity of solute adsorbed on the solid $\mathrm{p}$ hase to the quantity present in the liquid phase was s maller at equilibrium. In other words, the effluent concentration of the adsorbate reaches the inlet concentration in a short peri od of time. It is seen in Figure 28 that satur ation time decreases from $2 * 10^{5}$ to $0.7 * 10^{5} \mathrm{sec}$ when $K$ decreases from 1.66 to $0.35 \mathrm{~m}^{3} / \mathrm{mol}$ Simulation results with respect to $k=1.66 \mathrm{~m}^{3} / \mathrm{mol}$ were in clos e agreement with the migration experimental results. 


\section{Conclusions:}

The adsorption and migration behavior of cont aminates in the Nevada Test Site so il were investigated. It was conc luded from this work that the interaction between lead and soil follows Langmuir adsorption isot herm. Batch experim ents at different $\mathrm{pH}$ revealed that the adso rption of lead (which is u sed as a surrogate con taminate) was maximum in the range 4-5. Kinetic batch expe rimental results were used to validate the pore diffusion $\mathrm{m}$ odel with considerab le assumptions. Non linear regression analysis was performed on the results to ev aluate the diffusion coefficient which was determined to be $9 \times 10^{-12} \mathrm{~m}^{2} / \mathrm{s}$. Parameters such as initial bulk phase liquid concentrations, temperature were varied and concluded that th e adsorption kinetics increases with increase in temperature.

The migration behavior of contam inates in the Nevada tes $t$ soil we re investigated using column experiments and the results were used to validate the $\mathrm{m}$ odel proposed “Advective Dispersion Reaction” model coupled with Langmuir isotherm. The model equation was solved by employing finite element numerical method procedure using Comsol Multiphysics - 3.2. Disp ersion coefficient which was considered as the model parameter was evaluated by the re gression analysis routine procedure and found to be $8 \times 10^{-7} \mathrm{~m}^{2} / \mathrm{s}$. The model was verified by varying the parameters, such as temperature and inlet concentration, and bed thicknesses. This model can be used to predict the behavior of the system under various conditions without conducting the experiments if the adsorption parameters are known. 


\section{Reference:}

1. www.nv.doe.gov/nts

2. www.nv.doe.gov/library/publications/ , "Nevada Environmental Report-2007".

3. www.sord.nv.doe.gov/climate

4. Regional Groundwater Flow and Tritiu m Transport Modeling and Risk Assessment of the Underground Test Area, Nevada Test Site, Nevada

5. Geochemical Interaction of actinides in the environm ent, Wolfgang Runde Los Alamos National Laboratory, Los Alam os, New-Mexico, Geochemistry in soil radionuclides, "SSSA special publication number - 59”.

6. Choppin, G.R 1983. Sol ution chemistry of actinides. Radiochimica Acta 32:3453.

7. Choppin, G.R., and BE. Stout. 1989. Actinide behavior in natural water. Sci. Total Environ 83:203-216.

8. Langmuir, D. 1997. Aqueous environm ental geochemistry. Prentice Hall, Upper saddle river, $\mathrm{NJ}$.

9. Triay, I.R., A.Meijer, J.L Conca, K.S Kung, R.S.Rundberg, B.A Strietelm eier, C.D. Tait, D.L Clark, M.P Neu, a nd D.E Hobart. 1997. Summ ary and synthesis report of radionuclide retardation for th e yucca m ountain site characterization project LA-13262-MS. Los Alamos National Laboratory, Los Alamos, NM.

10. T. Tanaka, ${ }^{1 *}$ M. Mukai, ${ }^{1}$ T.Maeda, ${ }^{1}$ J.Matsumoto, ${ }^{1}$ H. Ogawa, ${ }^{1}$ Zhentang Li, ${ }^{2}$, Xudong Wang, ${ }^{2}$ Zhiwen Fan, ${ }^{2}$ Liangtian Guo, ${ }^{2}$ Cunli Liu ${ }^{2}$, “ Migration mechanisms of ${ }^{237} \mathrm{~Np}$ and ${ }^{241}$ Am through loess media". 
11. Cesium adsorption on soil clay macroscopic and spectroscopic measurements L Bergaoui, J F Lambert, R Prost, Applied Clay Science, Vol- 29 (2005).

12. F.Giannakopoulou", C.Haidouti, A.Chronopoulou, D.Gasparatos "Sorption behavior of cesium on vari ous soils under different $\mathrm{pH}$ levels", Journal of Hazardous Materials Vol 149 553- 556 (2007).

13. R.Naseem* and S.S Tahir "Rem oval of $\mathrm{Pb}$ (II) from aqueous/acid solutions by using bentonite as an adsorbent” Water Resource. Vol 35, 3982-3986 (2001).

14. M. Cruz-Guzma' n, R. Celis, M. C. Herm osi'n, P. Leo ne, M. Neg re, and J. Cornejo*, "Sorption-Desorption of Lead (II) and Mercury (II) by Model Associations of Soil Colloids", Soil Science S ociety of Am erica, Vol 67, pp 1378-1387 (2003).

15. Shih- Chin Tsai, ${ }^{1 *}$ Kai Wei Juang, ${ }^{2}$ Yi-Lin Jan ${ }^{3}$, "Sorption of cesium on rocks using heterogeneity - based isotherm models", Journal of Radioanytical and nuclear chemistry, Vol.266, 101-105 (2005).

16. Min Zhang ", Wenqing Li, Yuechao Yang, Baocheng Chen, Fupeng song, "Effect of readily dispersible colloid on adsorption and transport of $\mathrm{Zn}, \mathrm{Cu}, \mathrm{Pb}$ in soils". Environment International, Vol 31, 840-844 (2005).

17. L.Krasu, Z.Klika "Modeling of Ce sium Transport Through Sand - Bentonite Mixture", Czechoslovak Journal of Physics, Vol.56 (2006).

18. Modeling the adsorption of $\mathrm{Cr}(\mathrm{III})$ from aqueous solution onto Agave lechuguilla biomass: Study of the advective and dispersive transport J. Romero-González ${ }^{\mathrm{a}, \text {, }}$, J.C. Walton ${ }^{\mathrm{b}, \mathrm{d}}$, J.R. Peralta-Videa ${ }^{\mathrm{c}}$, E. Rodríguez ${ }^{\mathrm{a}}$, J. Romero ${ }^{\mathrm{d}}$ and J.L. GardeaTorresdey ${ }^{\mathrm{b}}$. 
19. B.V Babu * and Suresh Gupta, "Modeling and simulation of fixed bed adsorption column: Effect of velocity variation'.

20. Suresh A. Kartha a and Rajesh Srivastava ${ }^{b}$, "Effect of immobile water co ntent on contaminant transport in unsaturated zone", Journal of Hydro-environm ent Research Volume 1, Issues 3-4, 20 April 2008, Pages 206-215.

21. Ian C. Bourg ${ }^{\mathrm{a}, \mathrm{b}, \mathrm{c}, \mathrm{d}}$, Garrison Sposito ${ }^{\mathrm{a}, \mathrm{c}}$ and Alain C.M. Bourg, "Modeling the diffusion of $\mathrm{Na}^{+}$in compacted water-saturated Na-bentonite as a function of pore water ionic strength", Applied Geochemistry Vol 23, Issue 12, December 2008, Pages 3635-3641

22. Buning Chen, Chi W ai Hui and Gordon McKay, "Film-pore diffusion modeling and contact time optimization for the adsorption of dyestuffs on pith", $\underline{\text { Volume }}$

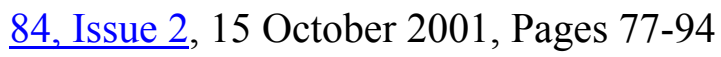

23. Hrissis K.Karapanagioti*, Chris M. gossard, Keith A.Strrevett, Randall L.Kolar, David A.Sabtini "Mod el coupling intra-particle diffusion /sorption nonlinear sorption, and biodegradation processes". Journal of Contam inate Hydrology 48(2001) 1-21.

24. Chunmiao zheng, Gordon D.Bennett, "A pplied Contaminate Transport modeling", second edition, Chapter -4

25. Chunmiao zheng, Gordon D.Bennett, "A pplied Contaminate Transport modeling", second edition, Chapter -7

26. Ramanathan Sundaraman, "Adsorptive Desulfurization of the Liquid hydrocarbon: Langmuir Adsorption modeling using Comsol" This paper was not from the COMSOL Conference. 
27. Agnes Joly ${ }^{1}$,Vitaly Volpert ${ }^{1}$, Alain Perrard ${ }^{2}$, "Dyna mic Adsorption with FEM LAB, Modeling breakthrough curves of gaseous pollutants through activated carbon beds", COMSOL Multiphysics users conference 2005 Paris.

28. Eh-pH diagrams for lead water and uranium water system from HSC-Chemistry software -5.1

29. Carl I.steefel*, Susan Carroll, Pihong Zhao, Sarah Roberts, "Cesium migration in Hanford sediment: a multisite ca tion exchange model based on laborato ry transport experiments", Journal of Contamiante Hydrology 67(2003) 219-246

30. Toshihiko Ohnuki and Tadao Tanaka "Migration of Radionuclides controlled by the several different $\mathrm{m}$ igration mechanism through a sandy soil layer". Health physics vol.56 No.1 (January) pp 47-53, 1989.

31. Hong-Yuan Lee ${ }^{\mathrm{a}, *}$ Shang-Shu Shih ${ }^{\mathrm{b}, 1}$,"Impacts of vegetation changes on the hydraulic and sedim ent transport charac teristics in Guandu m angrove wetland" Ecological Engineering 23 (2004) 85-94.

32. Minh Nguyen Ngoc ${ }^{a}$, Stefan Dultz ${ }^{b}$ and Jörn Kasbohm a , "Simulation of retention and transport of copper, lead and zinc in a paddy soil of the Red River Delta, Vietnam", Agriculture, Ecosystems \& Environm ent Volume 129, Is sues 1-3, January 2009, Pages 8-16.

33. J. Bear, Hydraulics of Groundwater, McGraw-Hill, 1979.

34. S.E. Ingebritsen and W.E. Sanford, Groundwater in Geologic Processes, Cambridge University Press, 1998.

35. N.H. Sleep and K. Fujita, Principles of Geophysics, Blackwell Science Inc., 1997.

36. D.L. Turcotte and G. Schubert, Geodynamics, Cambridge University Press, 2002.

37. J. Bear, Dynamics of Fluids in Porous Media, Elsevier Scientific Publishing Co, 1972. 
38. Editor Arnold Klute "Methods of Soil analysis", Part-1 physical and Mineralogical Methods Second Edition, American society of Agronomy, Icc. Soil Scien ce Society of America, I cc. Publisher Madison, Wisconsin USA 1986.

39. Chunmiao zheng, Gordon D.Bennett, “Applied Contaminate Transport modeling", second edition, Chapter -2.

40. J. Bear, Hydraulics of Groundwater, McGraw-Hill, 1979.

41. Comsol Multiphysics -3.4 user manual Earth science Module.

42. Chunmiao zheng, Gordon D.Bennett, "Applied Contaminate Transport modeling", second edition, Chapter -3.

43. J. Bear and A. Verruijt, Modeling Groundwater Flow and Pollution, D. Reidel Publishing Co., 1994.

44. Langmuir, "Chemical reactions at low temperatures," J. Amer. Chem. Soc., vol. 37, 1915.

45. C.G.L. Freundlich, Colloid and Capillary Chemistry, Methuen, 1926

46. David Jayne, Ying Zhang, Shaker Haji, Can Erkey, "Dynamic of Removal of org an sulfur compounds from diesel by adsorption on carbon aero g els for fuel cell application". International Journal of H ydrogen of Energy 30 (2005) 1287-1293.

47. Komiyama H, Smith JM. Surface diffusion in liquid-filled pores. AICHE J 1974; 20:1100.

48. Duong D. Do "Adsorption Analysis: Equilibrium and Kinetics" Series on chemical Engineering and kinetics volume-2, Imperial College Press. Chapter-9.

49. William B J Zimmerman, "Multiphysics Modeling with Finite Element Methods", series-A, Volume-18.

50. E.Metwally, R.O Adbel Rahman a nd R.R. Ay oub, "Modeling batch Kine tics of Cesiu m, Cobalt, and Strontium ions adsorption from aqueous using hydrous titanium oxide", R adiochim. Acta 95, 409-416 (2007).

51. Alkan, M.,Demirbas,O., Alikcapa, S., Dogan,M.: Sorption of Acid red $57 \mathrm{fr}$ om aqueous solution on to sepiotite. J.Hazard. Mater.B116,135 (2004).

\section{Reference}

1. Venkateswaran, K., D.P. Moser, M.E. Dollhopf, D.P. Lies, D.A. Saffarini, B.J. MacGregor, D.B. Ringelberg, D.C. White, M. Nishijima, H. Sano, J. Burghardt, E. Stackebrandt, and K.H. Nealson. 1999. Polyphasic taxonomy of the genus 
Shewanella and description of Shewanella oneidensis sp. Intern. J. Syst. Bact. 49:705-724.

2. Fredrickson JK, Zachara JM, Balkwill DL, Kennedy D, Li SM, Kostandarithes HM, Daly MJ, Romine MF, Brockman FJ. Geomicrobiology of high-level nuclear waste-contaminated vadose sediments at the hanford site, washington state. Appl Environ Microbiol. 70:4230-4241 (2004).

3. J.I. Kim and K.R. Czerwinski: Complexation of Metal Ions with Humic Acid: Charge Neutralization Model. Radiochimica Acta 73, 5 (1996).

4. J. van der Lee (1998) Thermodynamic and mathematical concepts of CHESS. Technical Report Nr. LHM/RD/98/39. CIG-Ecole des Mines de Paris, Fontainebleau, France.

5 Dzombak, D.A. and FM.M. Morel (1990). Surface Complexation Modeling: Hydrous Ferric Oxide. Wiley-Interscience (New York).

6. Delany, J.M., and Lundeen, S.R.: The LLNL Thermodynamic Database. Technical Report UCRL-21658, Lawrence Livermore National Laboratory (1990).

7. G. Curran, W. Rattray, and K.R. Czerwinski, Solubility of Thorium from $\mathrm{Th}_{3} \mathrm{UO}_{8}$ and $\mathrm{ZrTh}_{3} \mathrm{UO}_{10}$ Ceramics, Radiochimica Acta 91(4), 203-209, (2003).

8. J. Plaue and K.R. Czerwinski, Actinide Speciation in Environmental Remediation, J. Nucl. Sci. Supp 3, 461-465 (2002).

9 Appl. Radiat. Isot. 49, 1289 (1998).

10 The Plutonium Challenge: Stockpile Stewardship. Los Alamos Science 26, 2000 